\title{
DDE/ET/27125-T2-VOI.3
}

DOE/ET/27125--T2-Vol.3

DE84 008042

\section{SYSTEMS DESCRIPTION}

Hugh B. Matthews

Sperry Research. Center, Sudbury, MA 01776

\author{
SPERRY LOW TEMPERATURE GEOTHERMAL \\ CONVERSION SYSTEM - PHASE 1 \\ Contract No. DE-ACO3=78ET27125 \\ (Former ly ET-78-C-02-4633) \\ and PHASE II \\ Contract No. DE-AC03-79-ET27131
}

\section{Einal Report - Volume III}

SRC-CR-83-40

Edited by: Warren McBee

\section{HOTIGE}

PORTIONS OF THIS REPORT ARE ILLEEIELE.

It has been reproduced from the best available copy to permit the broadest possible availability.

Prepared for

U.S. Department of Energy

San Francisco Operations Office

133 Broadway

Oakland, CA 94612

\section{DISCLAIMER}

This report was prepared as an account of work sponsored by an agency of the United States Government. Neither the United States Government nor any agency thereof, nor any of their employees, makes any warranty, express or implied, or assumes any legal liability or responsiility for the accuracy, completeness, or usefulness of any information, apparatus, product, or frocess disclosed, or represents that its use would not infringe privately owned rights. Reference herein to any specific commercial product, process, or service by trade name, trademark, manufacturer, or otherwise does not necessarily constitute or imply its endorsement, recommendation, or favoring by the United States Government or any agency thereof. The views and opinions of authors expressed herein do not necessarily state or reflect those of the United States Goveramentarangaseng thereof. 


\section{DISCLAIMER}

This report was prepared as an account of work sponsored by an agency of the United States Government. Neither the United States Government nor any agency Thereof, nor any of their employees, makes any warranty, express or implied, or assumes any legal liability or responsibility for the accuracy, completeness, or usefulness of any information, apparatus, product, or process disclosed, or represents that its use would not infringe privately owned rights. Reference herein to any specific commercial product, process, or service by trade name, trademark, manufacturer, or otherwise does not necessarily constitute or imply its endorsement, recommendation, or favoring by the United States Government or any agency thereof. The views and opinions of authors expressed herein do not necessarily state or reflect those of the United States Government or any agency thereof. 


\section{DISCLAIMER}

Portions of this document may be illegible in electronic image products. Images are produced from the best available original document. 


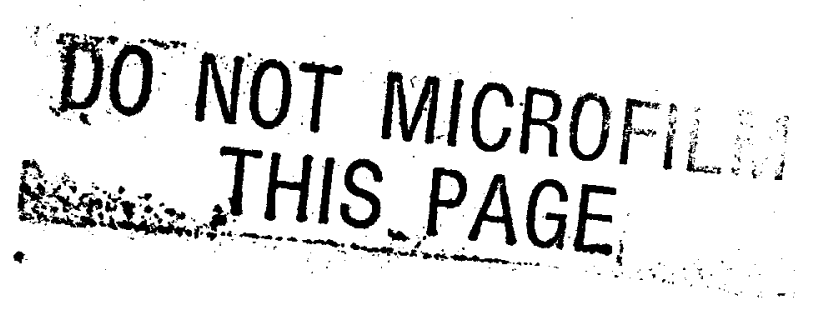

DISCLAIMER

This report was prepared as an account of work sponsored by an agency of the United States Government. Neither the United States Government nor any of their emp loyees, makes any warranty, express or implied, or assumes any legal liability or responsibility for the accuracy, completeness, or usefulness of any information, apparatus, product, or process disclosed, or represents that its use would not infringe privately owned rights. Reference herein to any specific commercial product, process, or service by trade name, trademark, manufacturer, or otherwise, does not necessarily constitute or imply its endorsement, recommendation, or favoring by the United States Government or any agency thereof. The views and opinions of authors expressed herein do not necessarily state or reflect those of the United States Government or any agency thereof. 


\section{FOREWORD}

This final report covers the work performed under the "Sperry Low Temperature Geothermal Conversion System" project, both Phase I under Contract No. DE-AC03-78-ET27125 (formerIY ET-78-C-02-4633) and Phase II under Contract No. DE-AC03-79-ET27131.

Vols. I and II, submitted in 1982 covered a portion of the work accomplished under Phase I. Vols. III, IV, V, and VI submitted at this time cover the balance of work performed under Phase I and work performed under Phase II. 
VOLUME TABLE OF CONTENTS

I ORGANIC WORKING FLUID PROPERTIES

II SYSTEM COMPONENT COMPATIBILITY \& R-114 STABILITY

III SYSTEMS DESCRIPTION

IV FIELD ACTIVITIES

V COMPONENT DEVELOPMENT

VI ECONOMIC STUDIES

iii 
VOLUME III

TABLE OF CONTENTS

3.1

PROGRAM DETAILS

3.1 .1

Program Backgound

Problem Statement

Solutions - Achieved \& Proposed

Listing of Related Contracts

Performed by Sperry Research

Center

3.1 .5

Inventions and Petents

2

3

5

THERMODYNAMIC COMPARISONS

3.2 .1

Conventional Binery Plant versus the Gravity Head Plant

3.2 .2

Conventional Geothermal Binary

$$
\text { Plant - The Strawman }
$$

The Gravity Head Plant

Heat Exchanger Parameters 13

Fouling of Heat Exchanger $\quad 14$ Surfaces

Cleaning of Heat Brchanger $\quad 15$

$3 \cdot 2 \cdot 3 \cdot 7$

$3.2 \cdot 3.8$

$$
\text { Surfaces }
$$

Working Fluid

Heat Transfer Diagram

Comparison of Binary \& Gravity

Efficiency Comparisons

Plant \& Operating Cost

Comparisons

3.2 .4 .3

3.2 .4 .4

3.2 .4 .5

Effect of Higher Efficiency

Plent Cost in Absolute Terms

Optimum Well Flow Comparison

R \& D Programs Completed

21

The Pump Test

22

$3 \cdot 3 \cdot 3$

$3 \cdot 3 \cdot 4$

Power Generating Turbine

23

Integral Packer.

24

3.3 .5

Down-Hole Pump 
3.3 .6

$3 \cdot 3 \cdot 7$

3.3 .8

3.3 .9

3.3 .10

3.3 .11

$3 \cdot 3.12$

3.3 .13

$3 \cdot 3.14$

3.3 .15

3.3 .16

APPENDIX A

APPENDIX B
Heat Rejection Unit

Heat Exchanger Design

Inthalpy Recovery Unit

Welded Connections

R-114 Scrubbing

Instrumentation \& Controls

27

Control Method

Operating Modes - Float, Constant

Output, or Spinning Reserve

Wellhead Versus Gathering Plants

Field Assembled Plant

28

Factory Module Plant

On-Site Photographs, low-temperature Geothermel Conversion System.

Feasibility Demonstration of the Sperry Down-Well Pumping System, Executive Summary of the Final

Report, May, 1977. 


\section{LIST OF ILLUSTRATIONS}

Eigure

$1 \quad$ Conventional binary power plant.

2 Cycle diagram for conventional Rankine cycle $-\mathrm{R}-114$ fluid.

3 Heat transfer diagram for conventional binary system supercritical Rankine cycle.

4 Thermodymamic diagrams.

5 Gravity-head system

6 Gravity-head cycle - R-114 fluid.

7 Thermodynamic diagrams.

Casing profile.

Fouling factor extrapolation.

10. Heat transfer diagram for gravity-head cycle with combined heat rejection unit - constant working fluid heat capacity vs temperature.

11 Radial inflow turbine.

Preliminary radial inflow turbine sizing.

13 Autonatic deploying cup-type packer for geothermal pump.

Sperry stand-alone pump.

Typical tubular heat exchanger section.

16 Enthalpy recovery unit.

Pressure-enthalpy diagram for enthalpy recovery unit. 


\subsection{Introduction of Volume III}

This Volume should be considered the introductory volume to the series of six volumes even though numbered out of sequence. Volumes $I$ and II were completed first and released in 1981 while a staff nember was available to do the work.

Volumes III through VI are being written and released some two years later as DOE funding became available for the purpose. They are as complete as possible considering that almost all the people involved in the program are now unavailable.

This Volume III is an overview of the entire program, and many of the Items presented herein briefly will be found in expanded form in one of the other five volumes. It will be noticed that assumptions and parameters such as well flow, well temperature, wet bulb temperatures, etc., involved in the several different performance calculations in the volume vary somewhat. These calculations were made at different times for different purposes and no attempt has been made to bring them into exact egreement. 


\subsection{PROGRAM DETAIIS}

\subsubsection{PROGRAM BACKGOUND}

The Sperry Research Center, the corporate research entity of the Sperry Corporation, has been engaged in geothermal research and development since 1972. At that time a new concept for a down-hole pump was conceived in which a portion of the heat energy in the hot brine is extracted down hole at the site of the pump and used to head a separate working fluid circulated from the surface. This working fluid powers a turbine which is coupled directly to the pump impeller. This system provided a practical and very efficient way of bringing the brine to the surface under pressure. Its feasibility was proven in a 1976 field test in a Heber, California, well. This test was supported by the National Science Foundation and ERDA, with Cherron Oil Company as the field operator. The Executive Summary of the Final Report on this pump test is included in this Volume as Appendix B.

In August, 1976, Sperry proposed to ERDA a program to develop an innovative geothermal electric generating plant using, in part, the results from the earlier tests and promising, in comparison with the next best proposed system of which we are aware, to pump more brine from a given well; to generate significantly more electricity per pound of brine; and to do this with less equipment. This program was funded in September, 1978 by the U.S. Department of Energy (DOE) and has been proceeding since that time toward the testing of a full-scale wellhead power plant ( 4 to $7.0 \mathrm{MW}$ depending on well productivity and other circumstances). 


\subsubsection{PROBLEM STATEMENT}

The major fraction of hydrothermal resources that have the prospect of being econamically useful for the generation of electricity are in the $3000^{\mathrm{F}}$ to 4250 temperature range. Cost-effective conversion of the geothermal energy to electricity requires the conception and reduction to practice of new ideas to improve conversion efficiency, enhance brine flow, reduce plant costs, increase plant availability, and shorten the time between investment and return. These points are amplified in later sections. The problems addressed during our past activities are those inherent in the geothermal environment, in the binary fluid cycle, in the difficulty of efficiently converting the energy of a low-temperature resource, and in geothermal economics. Explained in detail in the body of this document, some of these problems are:

- The energy expended by the down-hole pump;

- The difficulty in designing reliable down-hole equipment;

- Fouling of heat-exchanger surfaces by geothermal fluids;

- The unavailability of condenser cooling water at most geothemal sites;

- The large portion of the available energy used by the feed pump in a binary system;

- The "pinch effect" - a loss in available energy in transferring heat from water to an organic fluid;

- Flow losses in fluids that carry only a small amount of useful energy to begin with;

- High heat-exchanger costs - the lower the temperature interval of the cycle, the higher the heat exchanger costs in $\$ / \mathrm{kW}$ (actually, more than inversely proportional);

- The complexity and cost of the many auxiliary elements of proposed geothermal plants;

- The unfortunate cash flow vs. investment curve caused by the many years of investment required to bring a field into production before any income is realized. 


\subsubsection{SOLUTIONS-ACHIEVED OR PROPOSED}

The Sperry Research Center has conceived several significant new technical approaches to important aspects of the above problem.

(1) An efficient and reliable approach to down-well pumping.

(2) A novel thermodynamic cycle, called the "gravity-head cycle," for geothermal energy conversion, which takes advantage of the vertical configuration of a hydrothermal well to reduce plant cost and complexity, improve conversion efficiency, and maximize available energy.

(3) A combination condenser/cooling-tower heat rejection unit, which uses the geothermal brine itself (or similar highly saline water) as a coolant and with some automatic means to periodically remove fouling.

(4) An enthalpy recovery unit that desuperheats the turbine exhaust and restores thermodynamic losses caused by pressure losses and subcooling in the condenser.

(5) An automatic welding system to weld together the down-hole conduit as it is being lowered in the hole and remove the weld when the conduit is withdrawn.

(6) A scrubbing unit to periodically remove liquid and solid contaminents of sub-micron size from the organic working fluid.

(7) A method of decomposing chloro-fluorocarbons compounds into biodegradable compounds before disposal.

A detailed discussion of the above is given in later sections. 


\subsubsection{LISTING OF RELATED GEOTHERMAL CONTRACTS PERFOMRED BY SPERRY RESEARCH CENTER}

NSF Grant \#AER 74-08874 Geothermal Down-Well Pumping System July 1974

The objective was to design, fabricate, and experimentally test the Sperry Geothermal pump. No field testing was done. For administrative convenience of the goverment, Phase II was subdivided into IIa and IIb. Phase IIa included laboratory tests. Phase IIb, the field test, was funded by ERDA.

ERDA Contract \#EY76-C-02-2750 Geothermal Down-Well Instrumentation June 1975

The objective of the program was to develop and demonstrate a wireless system for transmitting data to the surface from down-hole in a geothermal well during pumping. Our primary approach was to generate signal power from available down-hole energy sources, to modulate it with the commutated outputs of sensors of various down-hole parameters, and to transmit the data acoustically via the pipestring to the surface where receiver transducers converted the acoustic signals to electrical signals for transmission to signal processing, recording, and indicating instruments. Electromagnetic transmission from down hole to the surface was also considered. The proposed plan included field measurement of the acoustic noise spectral present in a representative sample of field situations; the analysis of existing energy sources and acoustic channels; and the development, lab testing, and field feasibility demonstration of the necessary signal generation, data transmission, and signal processing systems. The field demonstration was performed in conjunction with the field test of the Sperry geothermal pump.

ERDA Contract \#EY-76-C-02-2817 Geothermal Down-Well Instrumentation (During Drilling) December 1975

The objective of the program was to develop and demonstrate a wireless system for transmitting data to the surface from downhole in a geothermal well during drilling. The primary approach was to use acoustic transmission up piping strings that are present and to generate signaling power from energy sources normally present downhole. The planincludes field measurement of the acoustic noise spectra present in a representative sample of field situations; the analysis of existing energy sources and acoustic channels; and the development, lab testing, and field feasibility demonstrations of the necessary signal generation, data transmission, and signal processing systems. 
ERDA Contract \#EY76-C-02-2838 Feasibility Demonstration of Geothermal DownWell Pumping System (Also referred to as "Phase IIb") October 1975

This was the field test phase of a total approach to geothermal downwell pumping. Earlier phases were supported by the National science Foundation. The objective was to demonstrate the feasibility of the Sperry Geothermal Down-Well Pumping System by actual operation in a geothermal well for an accumulated total test time of 60 days at full output. The scope of work included final lab checkout of the previously developed turbine-pump unit and surface subsystem, spare parts for the unit and subsystem, transport to the test site and possible rework of the unit and subsystem during test operations, disassembly, overhaul, transport to test site, and interconnection of brine-handling equipment, procurement and installation of a 1500-foot brine spur pipeline, procurement and installation of a well and wellhead hardware, well preparation, test operations, and test analysis and technical reports.

\section{D.O.E. Contract: ET-78-C-02-4633 and DE-AC03-78ET27125 and DE-AC03-79ET27131 May 1978}

The objective of this program is to design, fabricate, and test an experimental geothermal power plant having a down-hole turbine-driven pump and gravity-head heat exchanger with $4 \mathrm{MN}$ e output from a surface-installed turbine generator.

The program entails drilling a well of sufficient cross section to accept the pump and heat exchanger; testing the turbine-driven pump in the well and finally installing and performance testing the pump, down-well gravity-head exchanger and turbine generator at a nominal power level of 4.2 $M N$ e. The geothermal fluid which is withdrawn will be reinjected. Both an organic-fluid powered Sperry pump and the Sperry gravity-head cycle system was to have been tested down well. Funding for this program was essentially withdrawn in late 1981.

LAST Contract \#4-IP9-6833K-1 Turbodrill RPM Instrumentation November 1979

\section{LASL Contract \#4-YPO-7841M-1 Turbodrill RPM Instrumentation (Durining Drilling)}

The objective of the above programs was to investigate means of determining and displaying RPM of turbodrill tests for the LASL Hot Dry Rock program. Our approach was to instrument various turbodrill tests in an attempt to characterize the arilling systen with the intent to extract RPM information. Data was collected during a number of tests and during actual operations. Pressure pulse techniques were demonstrated in actual practice to be a simple and reliable method of tracking turbodrill RPM. Further work is needed to develop actual tools for wellhead use; in particular, attenuation versus depth at different frequencies must be studied to determine if this technique is viable to the depths required. 


\subsubsection{INVENTIONS AND PATENTS}

As a result of its research, Sperry Corporation has made fifty inventions in the field of geothermal energy. Twenty-seven have been issued as U.S. patents and foreign coverage has been obtained in many cases. Eight patents have been applied for and seven applications are being prepared. The gravity-head power system is the subject of U.S. Patent No. 4,142,108 by Hugh B. Matthews. Title to the gravity-head system has been waived to Sperry Corporation by the U.S. Department of Energy. 


\subsection{THERMODYNAMIC COMPARISONS}

\subsubsection{CONVENTIONAL BINARY PLANT VERSUS THE GRAVITY-HEAD PLANT}

When complex mechanical systems are in their comceptual stage, it is difficult to establish hardware costs and almost futile to estimate operating costs. Therefore, in order to evaluate our plant we have previously followed the practice of designing the best competing system that we could conceive of and comparing our plant to it - the "strawman" procedure. This allowed a fairly comprehensive understanding of relative efficiencies and outputs, an idea of relative hardware costs, and some feeling for operating costs. We now, some years later, can make reliable hardware cost estimates and somewhat reasonable estimates of operating costs. Even so, in order to facilitate an understanding of the advantages of the proposed systems, we are presenting in Section 3.2.2 the strawman plant - the highest efficiency "conventional" plant of acceptable complexdity - and presenting for comparison the gravity-head concept operating under the same conditions in Section 3.2.3. Both plants are somewhat idealized in the process diagrams, but not to the extent of invalidating conclusions.

\subsubsection{CONVENTIONAL GEOTHERMAL BINARY PIANT - THE STRAWMAN}

There are several types of actual or proposed geothermal brine plants: direct flesh, double flash, total flow, and binary. of these plants, the binary system is the most efficient by a considerable mergin, but it has its problems, as do the others. For background and comparison with our proposed generating station, this section presents in Fig. I what might be termed conventionel binary plant, even though to our knowledge no such plent yet exists.

A brine pump will be inserted into the production well as a sufficient depth to provide inlet pressurization requirements for the pump, a depth of possibly 1000 to 2000 feet. This pump might be hydraulically, electrically, or shaft-driven or in the case of the Sperry pump, a down-hole turbine driven by the heat of the brine itself by virtue of a separate working fluid. This pump will in all cases have some amount of support equipment on the surface. The purpose of the pump is to add pressure to the brine to prevent its flashing into steam as it loses its pressure in approaching the surface. Flashing is undesirable, since it precipitates much of the solids in solution in the brine, which then scale the well casing and the heat exchanger surfaces. Also, because the precipitious drop in fluid temperature caused by the fleshing occurs without work being performed, there is corresponding loss in efficiency. A further use for the pump (if it is quite efficient) is to enhance the flow of the well. 
The brine is then routed through the primary heat exchanger, where its heat is removed and injected into another fluid, and the cooled brine is then reinjected into the ground in another well, probably with a boost from a surface reinjection pump.

The principal components of the organic fluid cycle are, as shown in Fig. 1, the feed pump, one side of the primary heat exchanger, the turbine, and the condenser.

The feed pump must take the condensed organic at perhaps 30 psi and boost it to perhaps $900 \mathrm{psi}$ into the heat exchanger. It typically can absorb $20 \%$ to $25 \%$ of the total energy of the system. A reduction of this pressure would, of course, lessen feed pump work, but would cause a greater loss due to a factor called "pinch effect", described later.

The primary heat exchanger is a standard shell and tube exchanger with the brine being inside the tubes. The outside structure of the exchanger (that is, the shell, the headers, the flanges, etc.) is very thick (and, therefore, expensive) because it must contain the organic fluid at 900 psi. The scaling of the inside of the tubes due to the brine will be cleaned periodically by chemical means in the same manner that most heat exchangers are now cleaned.

The turbine, because of the high energy density of the organic fluid, will be a fraction of the size of an equivalent steam turbine operating at the same low temperatures.

The condenser will be of conventional shell and tube design with the organic fluid condensing on the outside of the tubes and the cooling water inside the tubes.

A cooling tower is provided for the cooling water for conservation purposes, since plants will seldom be situated where the condenser can be cooled in a once-through manner from a flowing river or large body of water. Even so, the cooling tower water requirements for evaporation and blow-down will be about $250 \mathrm{GPM}$. This cooling tower feed is going to be very difficult to provide for at a typical geothermal site.

Figure 2 is a pressure-enthalpy diagram of $\mathrm{R}-114$ fluid $\left(\mathrm{C}_{2} \mathrm{Cl}_{2} \mathrm{~F}_{4}\right)$ with a supercritical Rankine cycle superimposed. R-114 is used here since it has qualities desirable for the Sperry systems to be described later in section 3.23 and we wish to be able to make direct comparisons. Isobutane was analyzed under the same circumstances and was somewhat less efficient. The operating parameters assumed are as follows:

Well Flow

$1000 \mathrm{GPM}$

Both plants are compared at this same well flow, even though the gravity-head pump would permit higher rates because of its higher efficiency. 
Wet Bulb Temperature

This is a reasonable design assumption for much of

the West. It is inappropriately low for the Imperial Valley. The subject of wet bulb variation is covered in Section 3.2.3.8.

The processes match those of Fig. 2 and are:

1-2 Feed pump work,

2-3 Heat added at constant pressure,

3-4 Expansion in turbine,

4-1 Heat rejected to atmosphere.

The turbine; of course, drives the alternator, which in turn furnishes the energy for the auxiliaries, including the brine pump, except in the case of the Sperry pump, which is a self-contained system.

Figure 3 is a heat transfer diagram of the Fig. I system. It has the rather nomal design goals of 200 mean effective termerature difference in the primary heat exchanger, 200 average temperature difference in the condenser, a 100 approach of the exit cooling tower water to the wet bulb temperature, and $200 \mathrm{~T}$ between the brine entering the heat exchanger and the working fluid leaving at the peak of its cycle. The 100 temperature increases which results from the feed pump work does not contribute to cycle output because at the low end of the exchanger $10^{\circ}$ less is removed fram the brine as a result of the increase.

The pinch between the two fluid temperature lines in the exchanger is caused by the mismatch between the heat capacity curves of the brine and the R-114 fluid; that is, the brine heat capacity has an almost constant value of $1 \mathrm{Btu} / \mathrm{lb}-\mathrm{O}_{\mathrm{F}}$ throughout the temperature range, while that of the R-114 varies from $0.25 \mathrm{Btu} / \mathrm{Ib}-\mathrm{O}_{\mathrm{F}}$ at the exchanger entrance to $0.75 \mathrm{Btu} / \mathrm{lb}-\mathrm{O}_{\mathrm{F}}$ at the 3300 exit. This heat capacity variation of the $R-114$ is at constant pressure conditions in the primary exchanger, as is normal in a Rankine cycle. Were the pressure not constant, the heat capacity curve would be different.

This mismatch simply means that there is no way to establish a correct ratio of organic fluid flow rate to brine flow rate. If the flow-rate ratios are correct at the low-temperature end so that the brine warms up the organic fluid one degree for each degree it cools off, then at the hightemperature end, where the organic fluid demands more heat to warm up one degree, the brine cannot furnish this added heat, and the R-114 temperature does not come up as high as it should. Conversely, if the flow rate ratio is correct at the high-temperature end, then at the low-temperature end the organic fluid cannot remove heat from the brine rapidly enough, resulting in 
a higher brine exit temperature. In either case, available energy is lost. This energy loss could be decreased by increasing the heat exchanger area, but the limit to this would be a pinch of $0 O_{\mathrm{F}}$, which would require infinite heat-exchanger area.

Figure 4 illustrates these relationships in the supercritical cycle and, for comparison, the subcritical cycles. Note that the pinch effect in the subcritical cycle is extreme, which is one of the reasons a supercritical cycle is favored.

\subsubsection{THE GRAVITY HEAD CYCLE}

Figure 5 is a simplified schematic of the gravity-head cycle. In this system, heat transfer between the brine and the R-114 takes place entirely in the well casing by virtue of the brine flowing upward in the outside annulus and organic fluid flowing dowrward in the second annulus, extracting the heat from the brine on its way down. Thus, the brine arrives at the surface cold, requiring no pressurization to prevent it from flashing, but merely suficient pressure to reinject' it into another well. The organic fluid arrives at the bottom of its downward path hot, within say 200 of the down-hole brine temperature. The organic fluid is then routed through a small Francis turbine, has a small portion of its thermal energy extracted therein, and returns to the surface in the central riser in a two-phase state with most of its energy intact. The shaft of the down-hole Francis turbine drives a pump impeller which adds whatever pressure is necessary to bring the brine to the surace. The liquid fraction of the feed - containing about $5 \%$ of the energy - is separated from the stream and used to power a variable-nozzle Pelton Wheel turbine which is coupled to a brine reinjection pump. The small unneeded portion of the liquid fraction will be sent to the main turbine nozzles. Because of the drying nature of the fluid, and if the liquid amount is below a certain threshold, the nozzle exit stream should be dry, a conclusion supported by some amount of experimentation and to be further verified in the laboratory.

On the surface, the vapor fraction - containing perhaps $95 \%$ of the energy - drives the variable-nozzle turbine which is mounted on the generator shaft. The two exhaust streams are joined, condensed, and returned down-hole for another cycle.

\subsubsection{Elimination of Feed Pump}

The brine pump, as indicated in the illustration, is set deeper in the well than would be the case with a normal surface cycle. This depth of 2100 feet, when coupled with the high density of the chosen R-114 fluid, is sufficient to pressurize the fluid to the required $900 \mathrm{psi}$ without the need for a feed pump. Circulation is maintained in the system by the fact that the density of the down-going organic fluid column is greater than that of the fluid in the riser due to the average temperatu5re difference. 


\subsubsection{Elimination of Brine Pump Support Equipment}

The down-hole turbine pump unit does not require any equipment or control means on the surface.

\subsubsection{Thermodynamic Cycle}

Figure 6 shows the gravity-head cycle superimposed on the same R-114 pressure-enthalpy diagram of Figure 2. An important difference between the two cycles is obvious. In the Rankine cycle the heat is added at constant pressure, whereas in the gravity-head cycle the heat is added at a constantly increasing pressure. In other words, heat is added to the fluid as it flows down the 2100-foot vertical heat exchanger with a constantly incresing pressure due to the gravity head.

The processes are as follows:

1-2 Heat extracted from the brine. Also there is an added enthalpy (heat energy) contribution due to the potential energy of the fluid (energy due to height) being transferred into heat energy as the fluid flows down. This is the $\mathrm{z} / \mathrm{J}$ term in the general energy equation.

2-3 Down-hole turbine work.

3-4 Lift work. This is the inverse of the proces of 1-2 in which enthalpy is being transferred back into potential energy. The process of potential energy going up is Carnot controlled and is a corollary to feed pump work, but is more efficient.

4-5 Expansion in surface turbine to drive generator.

5-1 Heat rejected to atmosphere.

The path of process $1-2$ is at our discretion because, by varying the amount of heat transfer surface per foot of depth as we go down the hole, we can cause the fluid to go through the various pressure zones at temperatures of our choosing, within limits. By selecting a path of our choice, we can, again within limits, select the heat capacity curve of the fluid. The one shown on the R-114 diagram has a slightly declining heat capacity with temperature instead of an increasing one. This means that we can eliminate the pinch effect with its attendant loss in available energy.

Figure 7 illustrates the relationship between the cycle diagram, the heat capacity curve, and the heat transfer diagram. Also shown in Fig. 7 is a variation of the gravity-head cycle in which the heat addition curve is structured so that it dips into the two-phase done, causing a sharply declining heat capacity curve. This is because at the bottom of the curve vaporization is occurring, which increases the heat absorbed by the fluid, and toward the top of the dome condensation is occurring, which restores heat to the system and decreases the apparent heat capacity of the fluid. This would cause the reverse pinch shown, the virtue of which would be to 
reduce the required amount of heat transfer surface. We have not analyzed this variation to a great extent, and such an analysis would not be of much value anyway without experimental data due to the difficulty in predicting two-phase behavior.

\subsubsection{Heat Exchanger Parameters}

The system parameters on which the heat exchanger design is based are:

Well Flow

Well Temperature

Wet Bulb Temperature

Working Fluid

(Dichlorotetrafluoroethane)

Working Fluid Flow

Flow Losses
1000 GPM

$350^{\circ} \mathrm{F}$

$50^{\circ} \mathrm{F}$
$479 \mathrm{lbs} / \mathrm{sec}$.

50 psi each in all three conduits

As mentioned previously, the desired curve on the thermodynamic diagram is obtained by varying the heat transfer surface per foot of depth. The design fouling factor was 0.0015 on the brine side and 0.0005 on the organic fluid side. Fluid velocities were chosen as a compromise between low flow losses, high heat transfer coefficients, low fouling rates, and small well casing size; they vary from $1.75 \mathrm{ft} / \mathrm{sec}$ at the top to $5 \mathrm{ft} / \mathrm{sec}$ at the bottam for the brine and are approximately $5 \mathrm{ft} / \mathrm{sec}$ in all sections for the organic fluid. Heat transfer coefficients are approximately $150 \mathrm{Btu} / \mathrm{hr}-\mathrm{ft}^{2} \mathrm{O}_{\mathrm{F}}$ in all sections when fouled.

Figure 8 is the desired well casing profile to accommodate our heatexchanger design. Down to the depth of the purm it is larger than required for the conventional system. Below the pump, the casing size would not be different from standard practice. The actual well profile at East Mesa is somewhat different and is explained in Volume IV.

The 30" well section will contain heat-exchanger sections composed of tubes disposed around a central riser as in section 33.7.1 40-foot section of this basic design will be tested during our upcoming pump test.

The 24" well portion will contain annular heat exchanger sections similar to Fig. 5. The turbine pump unit will hang from the lowest annular section, and there will be a seal between the pump and the well casing. 


\subsubsection{Fouling of Heat Exchanger Surfaces}

The actual scaling rates of our down-hole heat exchanger surfaces by the geothermal brine will have to be detemined through operations under actual field conditions. Scaling rates of carbonates and silica, which are the chief constituents of such deposits, can be predicted or determined in the laboratory given pure solutions and controlled conditions. The complex and variable chemistry of the brines, however, limits the usefulness of such an approach in predicting the behavior of a particular brine.

The situation, of course, is more benign with the moderate temperature brines where we intend to do our first work; in fact, the field experiments that have been made encourage quite an optimistic view conerning the permissible length of time between tube cleaning. Sperry is aware of several situations that have indicated low scale deposition rates in geothermal fluids if the liquid is kept suitably above saturation presure and free of outside contaminants. However, the most definitive research of which we are aware is described in a very useful report by G. L. Lombard of San Diego Gas and Electric Company, prepared for the Electric Power Research Institute (EPRI). This work was done with brine from the Nowlin \#I Well of the Heber Reservoir. The brine characteristics are typical of those that are desirable for the test, -3500 F and - 14,000 ppm solids. (East Mesa conditions are $355^{\circ} \mathrm{F}$ and $\left.3000 \mathrm{ppm}\right)$.

Figure 9 is a reprint of a graph appearing in the above-mentioned report. It shows data generated in three heat exchanger tests with the brine flowing inside the tubes at three different velocities. Charted is the fouling factor increase vs. operating hours. The brine inlet temperature was $3550 \mathrm{~F}$ and the outlet was $1500_{\mathrm{F}}$. Cooling water flowed at the outside of the tubes countercurrently, entering at 1200 and exiting at $2700_{\mathrm{F}}$. Thus, the temperature differential across the exchanger varied from $300_{\mathrm{F}}$ to $800_{\mathrm{F}}$. The higher fouling rates of the 10 and $20 \mathrm{ft} / \mathrm{sec}$ tests can reasonably be presumed to be caused by the higher heat transfer coefficients (Btu/hr-ft $\mathrm{C}_{\mathrm{F}}$ ) and therefore the increased heat flux (Btu/hr-ft $\mathrm{H}^{2}$ ) occasioned by the higher velocities. The $5 \mathrm{ft} / \mathrm{sec}$ trace is the one of interest, since it approximates our design brine velocity. We have added a line extrapolating this $5 \mathrm{ft} / \mathrm{sec}$ trace up to our design fouling factor of 0.0015 , which would indicate a time span of 7600 hours between required cleanings of the down-hole heat exchanger. Such a large extrapolation is, of course, dangerous. Nevertheless, in theory at least, it is conservative on two counts.

- The line was extrapolated linearly, whereas the actual fouling rate should decline as the heat transfer coefficient decreases from 240 Btu/hr-ft ${ }^{2}-O_{\mathrm{F}}$ with the 0.0015 fouling factor. Our lower clean heat transfer coefficient is due to the lower film heat transfer coefficient of organic fluid as compared to that of water.

- The average heat transfer coefficient in the report at $5 \mathrm{ft} / \mathrm{sec}$ brine velocity was $590 \mathrm{Btu} / \mathrm{hr}-\mathrm{ft}^{2}-\mathrm{O}_{\mathrm{F}}$, and the $\log$ mean temperature difference (LMTD) across the exchanger was $51 \mathrm{O}_{\mathrm{F}}$, giving an average heat flux of $591 \times 51$, or $30,141 \mathrm{Btu} / \mathrm{hr}-\mathrm{ft}^{2}-\mathrm{O}_{\mathrm{F}}$. The sperry system, 
with its clean tube coefficient of $240 \mathrm{Btu} / \mathrm{hr}-\mathrm{ft}^{2}-\mathrm{O}_{\mathrm{F}}$ and its approximately uniform temperature difference of $20{ }^{\circ}$, results in an average heat flux of $240 \times 20$ or $4,800 \mathrm{Btu} / \mathrm{hr}-\mathrm{ft}^{2}$. This considerably lower heat flux will without doubt favorably affect the time interval between cleaning.

The estimation of 7600 hours is not conservative in one respect - that our exchanger will pull the brine temperature down lower than in the EPRI research program. Fouling should be somewhat more rapid at the lower temperature. Taking the pros and cons of the above into account, a case can be made for an estimate of well over a year between required cleanings. These estimated fouling rates cannot be held in high regard in a quantitative sense, but they do give good reason to belive that the time interval between cleaning will be quite acceptable.

During the pump test at Heber, CA, we ran for 1000 hours with no detectable fouling.

\subsubsection{Cleaning of Heat Exchanger Surfaces}

The chemical cleaning of scale from boiler tubes is a well-developed art and is used wherever possible in preference to mechanical means, which are more costly, reguire more downtime, and may damage surfaces. In our case, it would be the ideal method because it can be done with the heater in place down-hole. The well would be shut off at the wellhead and the cleaning solutions pumped down-well to the bottam level of the heater, displacing the brine downward. A buffer liquid could be provided between the brine and the cleaning solution if necessary. After a probably soak time of 10 hours, well flow could begin and the cleaning solution could either be flowed into the reinjection well or deposited into a surface tank for disposal.

The constituents of geothermal scale are chemically generally the same as those found in boilers: corrosion products of iron, carbonates, silica and silicates, phosphates, and sulphates. The physical characteristics of geothermal scale, however, could well be different.

Cleaning solutions are sometimes alkaline, but most often a dilute acid solution (perhaps 58) with an inhibitor to prevent or reduce attack on the base metal is used. An effective industry exists to specify and supply the chemical compounds, and there is a service industry to perform the cleaning function if that is desired. The cost of the chemicals for cleaning the heater surfaces in one well would appear to be in the range of a few hundred dollars when bought in bulk.

\subsubsection{Working Fluid}

The correct choice of the working fluid is important in the gravity-head cycle. For most temperature ranges, satisfactory fluids for our purpose can be found among the halogenated light hydrocarbon refrigerants (cormonly referred to as Freons $R$ ). These fluids are made by substituting bromine, chlorine, or fluorine atoms for some or all of the hydrogen atoms in hydro- 
carbon molecules such as ethane, methane, or propane. This substitution tends to make the fluids less flanmable and toxic, more dense, and lowers their mass heat capacity.

The fluid qualities most desirable for the Sperry system are as follows:

- High density. This determines the required depth of the heat exchanger to obtain the necessary fluid pressure.

- High heat capacity. This, together with high density, limits the cross-sectional flow area required for the fluid in the heat exchanger tubes and the riser.

- It should be a "drying" fluid, which means that its vapor saturation line should trace a path of decreasing entropy as it drops in pressure.

- Referring to Fig. 6, the vapor saturation line is the right-hand boundary of the liquid-vapor dame, and the fact that it tucks back under at a steeper angle than the entropy line is the quality we seek. This quality makes it easier to eliminate the pinch effect.

- The always desirable qualities of: high film heat transfer coefficient, low viscosity, low decomposition rates, low cost, low flammability and toxicity, and inertness.

R-114 $\left(\mathrm{C}_{2} \mathrm{Cl}_{2} \mathrm{~F}_{4}\right.$ - dichlorotetrafluoroethane) is the best choice for our chosen well temperature of $3500_{\mathrm{F}}$, particularly for our early experiments, since it is essentially nontoxic and nonflammable. Tests at Allied Chemical and at the Sperry Research Center indicate that under the worst projected conditions the R-114 decomposition rates will be less than $1 \%$ per year.

Even though the refrigerants make the closest available match to our requirements, a better fluid for our purpose can probably be found or developed eventually. The thermodynamic properties we seek are different to same extent from those valuable to refrigeration technology, and matters of flamability and toxicity are not nearly so critical to our systems as in a home or comercial refrigeration installation.

\subsubsection{Heat Transfer Diagram}

Figure 10 is the heat transfer diagram of the complete gravity-head system, showing the elimination of the pinch effect and a total $30^{\circ} \mathrm{T}$ between wet bulb and condensing temperature rather than the $40^{\circ} \mathrm{T}$, which is the reasonable minimum of a heat rejection system composed of a separate cooling tower and condenser. We are using the same $500 \mathrm{~F}$ wet bulb temperature used in the strawman analysis for an economic comparison, but it is far from the worst that will be encountered. It is, however, what can be expected as a reasonable average over the entire West. In the Imperial Valley the wet bulb temperature averages $58 \mathrm{O}_{\mathrm{F}}$ year round, $64 \mathrm{O}_{\mathrm{F}}$ during the four sumer months, and for 18 of the summer months it exceeds $80^{\circ} \mathrm{F}$. 
Geothermal energy cycles, in common with other low-temperature conversions, are unuaualiy sensitive to variations in heat sink temperatures, since availiable energy is approximately a function of the square of the temperature interval over which the sjstem operates. In a $3500 \mathrm{~F}$ well, an increase in wet bulb temperature from $64 \mathrm{~F}^{\circ}$ to $800 \mathrm{~F}$ will diminish electrical output by approximately 11\%, a problem which will have to be faced by the geothermal industry. 


\subsubsection{COMPARISON OE BINARY AND GRAVITY-HEAD PLANTS}

\subsubsection{Efficiency Comparisons}

Both the binary and gravity-head plants have been analyzed as operating under the following conditions:

$\begin{array}{ll}\text { Brine Flow } & 1000 \mathrm{GPM}(124 \mathrm{lb} / \mathrm{sec}) \\ \text { Wet Bulb Temperature } & 500_{\mathrm{F}} \\ \text { Working Fluid } & \mathrm{R}-114 \\ \begin{array}{l}\text { Mean Effective Temp. } \\ \text { Difference LMEID }\end{array} & 200_{\mathrm{F}} \\ \text { Brine Temperature } & 3500_{\mathrm{F}} \\ \text { Total Pressure Added to Brine } & 500 \mathrm{psi} \\ \begin{array}{l}\text { Surface Turbine Efficiency } \\ \text { Generator Efficiency }\end{array} & 858 \\ \text { Binary Plant Net Output } & 96.28 \\ \text { Binar Plant Specific } & 3.08 \mathrm{MW} \\ \text { Brine Consumption } & 145 \mathrm{lb} / \mathrm{kWh} \\ \text { Gravity-Head Net Output } & \\ \text { Gravity-Head Specific } & 4.21 \mathrm{MW} \\ \text { Brine Consumption } & 106 \mathrm{lb} / \mathrm{kWh}\end{array}$

The approximate $37 \%$ efficiency increase by the use of the sperry system is principally due to the following items:

- Elimination of the feed pump;

- Elimination of the pinch effect;

- A more efficient brine pump;

- A reduction in the interval between wet bulb and condensing temperatures by the use of evaporative cooling technology.

\subsubsection{Plant And Operating Cost Comparisons}

Only approximate cost comparisons of the two plants can be made, since detailed design and cost studies of the strawman plant have not been made. 
Operating costs cannot yet be predicted with complete confidence, particularly for down-hole operations. Sperry's designs have been continuously influenced by operating cost considerations as we understood them, but firm numbers must await more experience. Useful relative comparisons based on major factors and equipment can be made, however, and are described in Sections 3.2.4.3 and 3.2.4.4.

\subsubsection{Effect of Higher Efficiency}

If both plants, including wells, cost the same for the same amount of brine flow, then plant capacity in $\$ / \mathrm{kW}$ depends only on efficiency. If the Sperry plant is $37 \%$ more efficient, then plant capacity will cost correspondingly less. If absolute operating costs in $\$ /$ year, including brine costs, are the same for both plants, then the Sperry system would have lower operating costs per $\mathrm{kWh}$ corresponding to its higher efficiency. In fact, all our studies support the contention that in geothermal power generation the first and best step to reduce operating and plant capacity costs is to increase efficiency.

\subsubsection{Plant Cost in Absolute Terms}

When compared in absolute terms (including wells) in $\$ / 1 \mathrm{~b}$ of brine flow rather than in $\$ / \mathrm{kW}$, where efficience is a major factor, the sperry plant also costs less:

- The gravity-head well costs more because it is larger for the upper 2200 feet, and the wellhead is more expensive. On the other hand, the heat exchanger does not require a shell, and a shell to withstand 900 psi would cost nearly as much as the rest of the exchanger. The exchanger would cost more to put in the'hole, but would not require the piping and installation needed for surface units. At a suitable distance down the learning curve, both extra well costs and lower exchanger costs appear to be in the $\$ 400 \mathrm{~K}$ to $\$ 500 \mathrm{~K}$ region and to approximately cancel each other.

- Elimination of the feed pump, a I MW machine, should save Sperry system $\$ 400 \mathrm{~K}$ when installation and controls are included. In addition, the feed pump in the binary plant preempts at least $20 \%$ of the entire plant for its power supply - 20\% of the cost of the wells, heat exchangers, turbine generator set, and heat rejection system must be assigned to the cost of the feed pump. The gravity-head working fluid circulating method uses its share of everything but the turbine generator set, but it's a smaller share.

- The gravity-head down-hole pump has no surface support or controls, whereas the surface support equipment for the strawmen down-hole pump, of whatever nature, when installation and controls are included, is not less than $\$ 200 \mathrm{~K}$ for any pump of which we are aware. And, as in the item above, the strawman pump requires a greater portion of the entire plant as its power supply. 


\subsubsection{Optimum Well Flow Camparison}

In Section 3.2.4, both plants have been rated at a well flow of $1000 \mathrm{GPM}$, which is a reasonable econanic optimum for low-efficiency purming systems. With the low energy consumption of the gravity-head turbine pump (approximately 1.28 of themmal energy is consumed for each $100 \mathrm{psi}$ added to the brine) and with the deep setting of the pump to provide inlet pressurization, the economic optimum for well flow appears to be $1300 \mathrm{GPM}$ (160.5 pounds per second). The well size of Fig. 8 is probably optimum for the 1300 GPM flow, although our cost analysis for production systems has assumed a slightly larger well. 


\subsection{GRAVITY-HEAD PLANT DETAILS}

This section will present the research and development programs completed to date as reguired precursors to the design and operation of the field tests, a description of the pump test (a precursor to the gravity-head test), details of gravity-head plant equipment and design, and a general discussion of the first-to-be-commercialized field-assembled plants and the later factory-manufactured module plants.

\subsubsection{R\&D Programs Completed}

Some of the items below are further described in the following sections:

- An experimental down-hole turbine-pump unit was operated for 1000 hours in Heber, $C A$ in 1976. This test demonstrated the feasibility of the concept. An Executive Sumary Report of this program is attached in Appendix B.

- A down-hole shaft-seal development program was completed by SperryVickers to evaluate the endurance of various seal materials and configurations for the turbine-pump unit.

- A bearing development program was completed by Barber-Nichols Engineering Company to evaluate various bearings and lubricants for the turbine-pump unit.

- An elastomeric cup was developed by Regal Tool \& Rubber Co. (Regal International, Inc.) and tested by Barber-Nichols to provide the seal element of a packer for the down-well pump. This work was preceded by laboratory development of an EPDM rubber compound to withstand abrasion and high temperatures while in the brine.

- Welding and weld-removal techniques and fixtures were developed at the Sperry Research Center for the efficient and reliable field installation down-hole heaters, pump, and conduits.

- Sliding seals (stabbing fixtures) were developed by Regal and tested by Barber-Nichols to provide leakproof connection for the R-114 riser conduit.

- Condenser fouling experiments are being performed with a small, portable R-114 test loop using various brines to evaluate candidate condenser-tube materials and tube-cleaning techniques.

- Barber-Nichols developed and built laboratory test fixtures to drive the down-hole turbine-pump unit at simulated down-well temperature and pressure conditions. With the aid of this fixture, the down-well turbine-pump unit was tested for endurance and performance.

- A heat-exchanger tube-sheet development program was completed at Mustang Engineering Company and a configuration consisting of double tube sheet with an elastaner filler seal in between was developed under temperature and pressure. 
- A smaller-diameter stabbing fixture for lubricating oll and instrument wire line was designed by SRC and tested at Mustang Engineering for reliability. In another experiment the tubing was shown to be capable of repeated installation and removal (onto $a \mathrm{durm}$ ) of the lube line.

- An instrumentation and control system development program was completed at SRC to measure down-well and surface variables and to provide scientific data acquisition hardware and software.

- R-114 thermodynamic properties were measured by Allied Chemical co. under a subcontract in the hitherto uncharted compressed liquid, supercritical dense gas and vapor regions. Several points were also established by Barber-Nichols (throttling experiment). The data were used to develop state-equation models for digital computer representation of R-114 simulation studies at the Sperry Research center.

- System component compatibility studies were made by Allied Chemical Company and included stability of R-114 in the presence of elastomers, metals, and ceramics - dry, wet and in the presence of iron oxides and at various temperature levels - and the stability of various elastomers in the presence of R-114 at high temperatures. Subsequent additional compatibility tests were made at the Sperry Research Center. These included evaluation of system component compatibility with brines, lubricating oils, and R-114.

- Thermodynamic analysis program were developed by both Barber-Nichols and at the Sperry Research Center to model the standalone purmp system and the gravity-head system.

- A laboratory device to dynamically measure thermodynamic and transport properties of candidate working fluids has been built at SRC.

- Professor Ernest Rabinowitz of Massachusetts Institute of Technology analyzed the possibility of tube abrasion in the heat exchanger.

- Hugh Davis of Davis Associates analyzed heat transfer and baffling design in the heat exchanger.

- Dean A. E. Dukler of the University of Houston made an analysis of upward two-phase flow in the down-hole riser, and Barber-Nichols conducted a laboratory experiment to verify his findings.

\subsubsection{The Pump Test}

As a precursor to the power plant, and using the same production and reinjection wells, a pump test will be started in May or June 1981. It is designed to expose problems before the construction of the power plant, which it mimics with the exception of power generation. 
are:

Same of the power plant concepts to be incorporated in the pump test

- Down-hole R-114 ariven turbine pump;

- Integral packer;

- Welded connections;

- Tubular heat exchanger;

- Emergency controls;

- Evaporative condenser operation and fouling suppression by chemical and magnetic (actually magnetohydrodynamic) means when spent brines are used;

- R-114 scrubbing;

- Instrumentation and controls;

- Enthalpy recovery unit;

- A separate evaporative condenser fouling and corrosion experiment.

\subsubsection{POWER GENERATING TURBINE}

Because of the characteristics of the working fluid and the low power level of the wellhead plant (say, $5 \mathrm{MW}$ ), a machine type known as the radial inflow turbine is ideally suited. Its optimm efficiency is not significantly different from the optimum of an axial flow turbine - both are perhaps $85 \%$ at our power level. A radial inflow turbine is small and inexpensive compared to an axial flow turbine at our projected power level. Figure 11 is a photograph of a very small turbine of this type.

of major importance from the standpoint of durability and cost is the fact that the blades are thick and do not have knife edges and the fact that the rotor runs in the ascast condition except for machining of the edges and belancing. The turbine will be directly connected to a 3600 RPM generator.

Listed below are turbine parameters for the chosen well conditions of $1300 \mathrm{GPM}$ and $355^{\circ} \mathrm{F}$ :

Fluid

Output (Gross

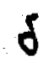

ve
$\mathrm{R}-114$

$6.0 \mathrm{MW}$

10.7 (turbine enthalpy drop)

$1.0 \mathrm{ft}^{3} / \mathrm{Ib}$ (specific volume at turbine exit) 


$$
\ddot{\boldsymbol{w}}
$$

Q

NS

RPM

\section{$596 \mathrm{lb} / \mathrm{sec}$ (working fluid flow)}

$623 \mathrm{ft}^{3} / \mathrm{sec}$ (volume flow at turbine exit)

90.5 (specific speed - with 60 to 120 being acceptable for radial inflow turbines).

Figure 12 is a preliminary sizing of this turbine.

\subsubsection{INTEGRAL PACKER}

Referral to Fig. 5 will show that it is necessary to have a seal of some sort between the pump and the well casing. A problem arises in that the turbine-pump unit will move up and down in the well bore by as much as two feet due to thermal expansion and contraction of the piping string, although during normal operation the movement will be perhaps \pm 3 inches per day.

We avoided this problem in the first test by using oil-field technology: a fixed packing element (it must be drilled out to remove) is set in the well casing just below where the TPU will be located. This packer has at its center a smooth through bore, and a tube attached to the TPU moves up and down inside this bore to provide a sliding seal between the TPU and the casing. This is an effective seal method, proven in the oil fields, if not in geothermal wells, but it has qualities we do not require: it will seal against very high differential pressures and is effectively leakproof, whereas same leakage can be permitted in our case. Also, it was selected a the only state-of-the-art possibility for the high temperatures originally considered. The fixed packer is relatively expensive to buy, to insert, and to remove. Its use increases by as much as a day the time required for deployment of equipment in the well.

Regal International, Inc. of Corsicana, Texas has developed a packer cup for Sperry (See photograph, page of the Appendix) patterned after swab cups as used in the oil fields, but of a size to fit in a 13-3/8" casing and with EPDM rubber to withstand temperatures of up to $400 \%$. It required a long development program with problems arising in compounding, bonding, and structural failure before the cups met specifications, but they are now performing well in the laboratory. Figure 13 shows a method of retracting the lip of the cup to prevent damage to the cup while sliding down the casing. The tieback cord would be released by a timed release or itself be dissolved in water in a given period of time. This will not be necessary in the pump test or the proposed power plant, as the cup will descend in a large casing until the last few feet of its journey downward. As a backup, the Baker oil Tool Company has developed an improved fixed packer that can be inserted and withdrawn with the pump. This is a more expensive expedient, but in many cases may be the correct one to use rather than the cups. 


\subsubsection{DOWN-HOLE PUMP}

The down-hole turbine-pump unit is similar in concept to the Sperry stand-alone pump, Fig. 14. There are, however, important differences. The turbine will be driven by the full R-114 fluid stream, fron which it will extract only a small portion of the energy. It will be an adaptation of the Francis turbine and rotate at 10,500 RPM. The unit should extract approximately 1.28 of the available themal energy for each $100 \mathrm{psi}$ it adds to the brine.

\subsubsection{HEAT REJECTION UNIT}

At most geothermal sites that we are aware of, cooling water for the condenser will be difficult to provide and may even be unobtainable. cooling water in an amount equal to $25 \%$ of brine flow will be required in most circumstances. Sperry has been experimenting for same time with the idea of using a portion of the spend well brine or other highly contaminated waters for this function. Our approach in the manner of air-conditioning evaporative condensers is to combine the functions of the cooling tower and condenser into a single "heat rejection" unit and to expose the outside of the condenser tubes over which the cooling water cascades. However, these tubes will be arranged in a geometrical pattern so that they can be periodically cleaned by a cavitating or high-pressure spray.

In the primary heat exchanger, as previously discussed, the holding of the brine under pressure and free from outside contaminants (chiefly oxygen) should keep fouling and corrosion under effective control. In the heatrejection unit, however, carbonates, silica, and other scale will in many cases build up at a rate too rapid for economical cleaning by chemical methods. The combining of the cooling tower and the condenser (evaporative condensing) permits a smaller $-T$ between the wet bulb temperature and the condensing temperature because the cooling water is continuously cooled as it pours over the condenser tubes, a situation similar to that found in evaporative coolers in the comercial air-conditioning industry.

Sperry has experimented with the removal of scale from metal coupons fouled by different waters by accelerated methods. These experiments were crude but did support the expectation that the scale can be readily removed by a variety of methods as long as it is not allowed to dehydrate or build up too thickly. We now have a more sophisticated experiment which is in essence a portable evaporative condenser with four removable 2-foot-long tubes. This will allow experimentation into tube materials, fouling rates, fouling removal, and establishment of sufficient engineering data for design of an interim-size development module. Construction of this module, however, is not scheduled for the proposed program.

The East Mesa Plant and the first production units will use evaporative condensers from the air-conditioning industry as an expedient. These condensers will perform the themodynamic functions well enough, but will require some amount of chemical suppression of fouling, perhaps periodic hand cleaning of tubes, and should be used with only the milder of brines. The amount of care required for these units will be determined during the upcoming tests. 


\subsubsection{HEAT EXCHANGER DESIGN}

Figure 15 displays the design of one of the tube bundle sections, 1000 feet of which, in two or three different tube sizes, would be deployed down the well in 40- or 60-foot sections. The tubes are deployed in concentric rings about the central riser as shown. For structural and thermodynamic reasons, the tubes will be wrapped around the riser at a slight angle from the vertical - an approximate 30 helix alternating in direction from one concentric tube ring to the next. There will be no space between rings, but spacing will exist between adjacent tubes in a ring. To bind the tubes against each other and the riser, and to protect the assembly, a 0.125 " thick shroud is wrapped around the outer tube ring. A "pig", a dumy heatexchanger section of one half the clearance and length, has been inserted and removed from the well without damage or binding.

Each sealing element of the double tube-sheet - welding, rolling, and sealant - has been separately tested. This quadruply redundant structure may seem like overkill, but it does not increase costs by very much and, on paper at least, increases the reliability of the assembly against leakage by a factor of several hundred.

The lower 1100 feet of heat exchanger (to a depth of 2100 feet) will be an annular structure (a pipe inside of a pipe), also in 40- to 60- foot sections. The turbine-pump unit is attached to the lowest annular sections with a seal between the pump and well casing, as covered in Section 3.5.

\subsubsection{ENTHALPY RECOVERY UNIT}

Figure 16 illustrates a multipurpose system termed "enthalpy recovery unit". It serves the following purposes.

- The main vessel is sized to contain the entire R-114 charge when this is required for plant repair purposes.

- The vessel contains in its lower level the reserve supply of R-114 .

- The vessel serves as the distribution manifold for the turbine exhaust, a function that reguires a large cross section to avoid excessive pressure losses in the low-density vapor stream.

- The turbine exhaust, in bubbling through the liquid above the bubble tray, is desuperheated, a function that otherwise would have to be performed by a separate device such as a spray desuperheater.

- Condensate subcooling which will occur in the condenser because of the residence time of the condensate in the tubes will be restored by superheat or latent heat from the turbine exheust.

- The pressure loss in the condenser will be restored in the barametric legs. 
- Water, oil, or other liquids entrained in the exhaust stream which are less dense than the R-114 will be extracted in the barometric legs.

Figure 17 is a pressure-enthalpy diagram illustrating these processes. Note that the stand-alone pump system, which will deliver hot brine to a conventional surface plant, benefits more by this device because the restoration of subcooling will permit the delivery of hotter brine. In the gravity-head system, restoration of subcooling will simply mean that brine temperature is not pulled down as far. However, without the ERU, subcooling preempts a part of the heat-rejection system and restoring the subcooling requires extra primary heat-exchange area.

\subsubsection{WELDED CONNECTIONS}

Each section of the heat exchanger will be welded at the wellhead to the one just below it in the well by autamatic equipment developed by Sperry Research Center with assistance from Airco. When necessary to remove the exchanger from the well, the weld is removed fram each connection by an arc gouging torch using the same automatic fixturing. The joint can be rewelded with little or no preparation. A $1 / 2$ " bead is being applied by submerged arc process at a rate of $12 \mathrm{~m} /$ minute, with $20 \mathrm{~m} /$ minute expected in the future.

our experience during our first field test demonstrated that large threaded joints, no matter how expensive, cannot be expected to be leakproof, and when removed fram the hole will be difficult to unscrew because brine intrusion will have corroded and bound the threads. In our experience, it took 20 to 30 minutes to uncouple each joint, while expenditures were going on at a rate of $\$ 6 /$ minute. Later on in the field test, a hand-welded seal bead was applied to the joints and leakage problems ceased. When the conduit was pulled from the well, the bead was removed by hand arc gouging, and the joint was unscrewed with no difficulty. In the pump test to precede this proposed program, we will use threaded joints with a seal bead. In later systems the confidence level should be high enough to el iminate the threads. Figure 18 shows the welded connection, and a photograph of the welding fixture appears in Appendix B.

\subsubsection{R-114 SCRUBBING}

The Freons $R$ (chloro-fluorocarbons) in comon with all organic fluids, will gradually decompose when subjected to geothermal temperatures, and at increasing rates when contaminated. Extensive laboratory tests at Allied Chemical an Sperry Research Center have shown that reasonable care at controlling contamination (vapor, liquid, and solid) will reduce this decomposition rate to well below $18 /$ year.

In the laboratory, water is used as a scrubbing agent to remove vapor and liquid contaminates from Freons $R$. During the pump test we are adapting this method to the use of DUCON scrubber (which sprays liquid water into a rotating vapor stream to remove particulates and liquid mist) to cleanse the turbine exhaust. This device, which will replace the normally used particulate filters, will be used continuously at start-up for several 
hours or days and then periodically (once a month?). It has the reputed advantage of removing particulates of submicron size rather than in the 10 micron size to be expected from a practical particulate filter system. It is permanently installed for the pump and gravity-head tests. In the future, it would be truck-mounted and used as a service.

\subsubsection{INSTRUMENTATION AND CONTROLS}

We have found no reason to depart from conventional utility and petrochemical instruments and controls for the core plant.

\subsubsection{CONTROL METHOD}

There are two proportional controls in the system: (1) variable nozzles on the reinjection pump which control brine flow and which are adjusted by an outside instruction (from a remote location if desired) and (2) the R-114 flow controlled by the large turbine nozzles which are instructed by a servo slaved to brine flow and modulated by condensing temperature.

In case of a load rejection, the turbine generator set will go onto internal speed control and the majority of the working fluid will be diverted around the turbine directly into the condensers, and only enough (10\% to $15 \%$ ) routed to the turbine to provide for house power. Conventional speed match and auto sync controls will reestablish the line connection when this is permissible.

\subsubsection{OPERATING MODES - FLOAT, CONSTANT OUTPUT, OR SPINNING RESERVE}

With each $O_{F}$ change in wet bulb temperature, plant output will change approximately 0.78 with $355^{\circ} \mathrm{F}$ brines, an effect that varies inversely with brine temperature. In the proposal exercise, the gravity-head plant has been analyzed as operating at close to the point of peak efficiency - the lowest specific brine consumption in $1 \mathrm{~b} / \mathrm{kWh}$. If the generator is suitably sized, it is posible to increase the brine and working fluid flows and thereby increase power to the bus bar by $30 \%$ or more, but with increased specific brine consumption. This degree of freedom could be used to maintain a level output in spite of changes in heat sink temperatures, or alternatively, be held as spinning reserve.

\subsubsection{WELLHEAD VERSUS GATHERING PLANTS}

All energy from wells must be gathered in any case, either electrically or in pipes. SRC has been investigating the matter for eleven years and can find no compelling or even significant reason favoring a large, central gathering plant. Conversely, there are reasons favoring the alternative, given correct design of the well-head plant. 
(1) The well head plant will not be less efficient.

- Correct choice of working fluid (a heavy molecule) renders MV single-stage organic turbine as efficient as a large, low-temperature, multi-stage steam turbine.

- The small generator of a well head plant will be a point or so less efficient, but this will be belanced by the smaller loss in the electrical lines vs. the heat and flow losses in the distribution piping of the gathering plant.

- The effectiveness of the heat exchangers and heat rejection system is not size dependent.

(2) Piping costs more than electrical lines.

(3) A factory-manufactured module plant is cheaper per KW capacity perhaps $30 \%$ less - than a large field-manufactured plant.

(4) Start-up reliability will be better in the module plant.

(5) Plant availability is improved because modules can be quickly replaced.

(6) Time from first dollar spent to first dollar earned is improved by a matter of years.

(7). Smaller reservoirs can be economically exploited. Depending on the proximity of the electrical network, we believe that a cluster of five plents ( $25 \mathrm{MW}$ ) will be of acceptable size. If the reservoir proves to be larger, more plants can be installed.

(8) Module plants can be moved.

(9) When one plant goes down, only a small increment of power is lost.

\subsubsection{FIELD ASSEMBLED PLANT}

Figure 19 is a plot plan of the essential elements of the East Mesa Plant. It is in a category (field-assembled) between a field-manufactured plant and a module plant, in that it is composed of modules (the down-hole heat exchangers, the evaporative condensers, the ERT, the turbine generator set, etc. are all modules), but there is still a large field-lebor content in the surfact portion. Installation of the many small condensers, wiring, piping, switchgear installation, and debugging is all field work. Nevertheless, the first commercial plents (say 25 to 50) would not differ much from the East Mese Plant. They would be autometed with brine-flow control remoted to a central controller. From our studies, a cluster of five (to be brought on-line sequentially over a period of 15 months) would be well down the operating cost curve, and singles or clusters could be added thereafter. 


\subsubsection{FACTORY MODULE PLANT}

Figure 20 displays the projected factory module plant with the evaporative condenser principle adapted to our purpose. The surface plant consists of probably eleven of the largest modules that can be trucked, as listed below:

- The turbine generator set (TGS).

- The house for the TGS, which will also contain the mimic board, preinstalled.

- Three structural-steel units upon which the condenser sections will be mounted and each of which will contain a length of the ERU. The center unit will contain most of the pumps, switchgear, wiring, and special gear.

- Three evaporative condenser units as specially developed for our purposes.

- Three fan sections to fit on top of the condensers.

The down hole part of the plant will consist of the following:

- A well of standard profile for the first 2200 feet.

- A standard well head.

- A standard turbine-pump module with a selection of turbine wheels and impellers to meet different well conditions.

- A varying mix of the two or three standard tubular heat-exchanger sections.

- Standard annular sections.

R-114 is the optimm working fluid between $3300_{\mathrm{F}}$ and $375^{\circ} \mathrm{F}, \mathrm{R}-216$ seems suitable between $375^{\circ}$ and $425^{\circ}$. Below $3300_{F}$, a mix of $R-114$ and $R-115$ will perhaps serve. 


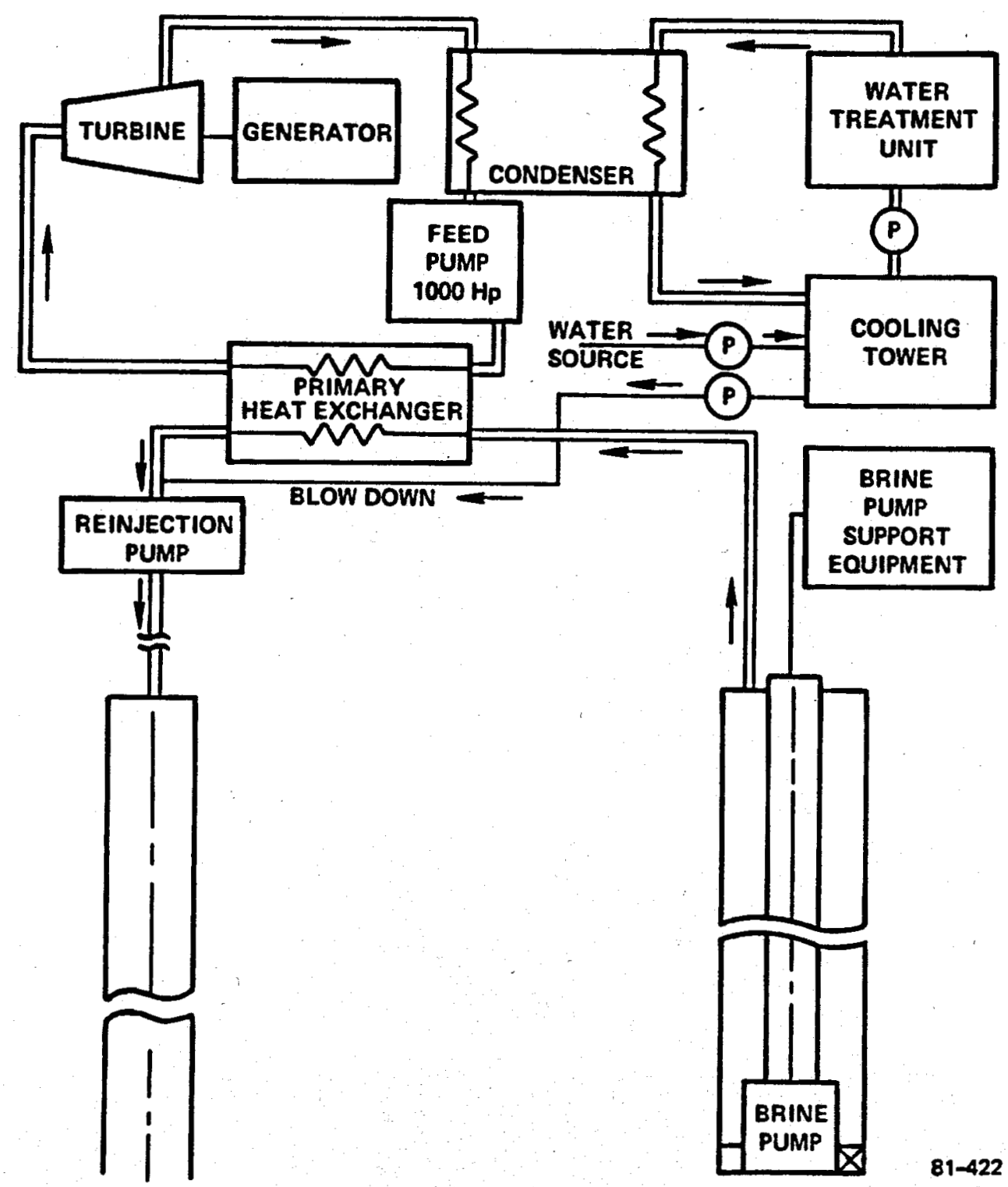

FIG. 1 Conventional binary power plant. 


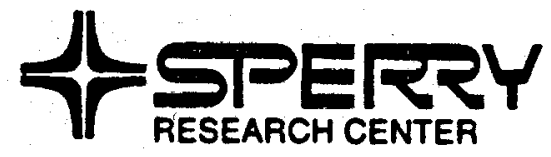

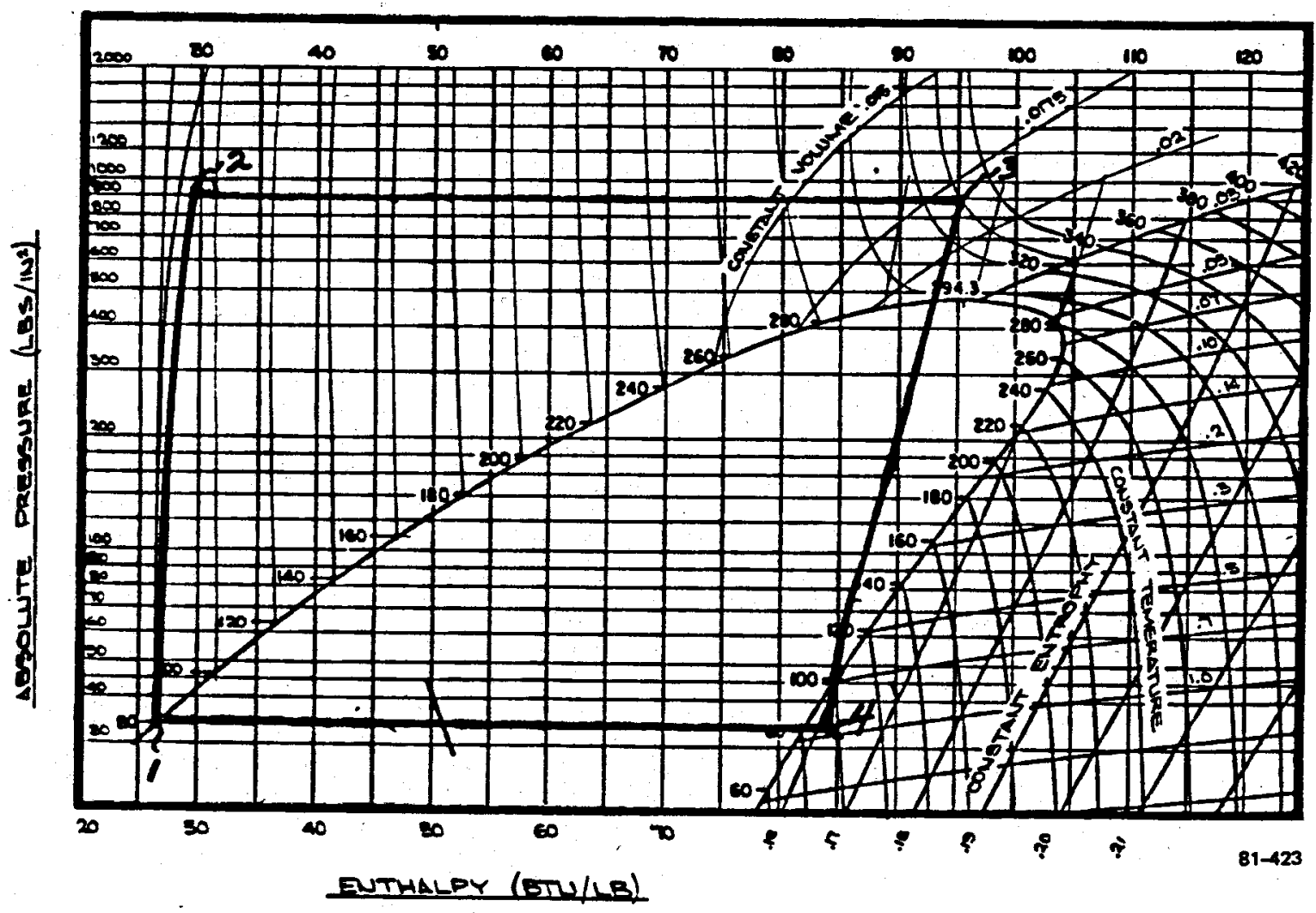

FIG. 2 Cycle diagram for conventional Rankine cycle - R-114 fluid. 


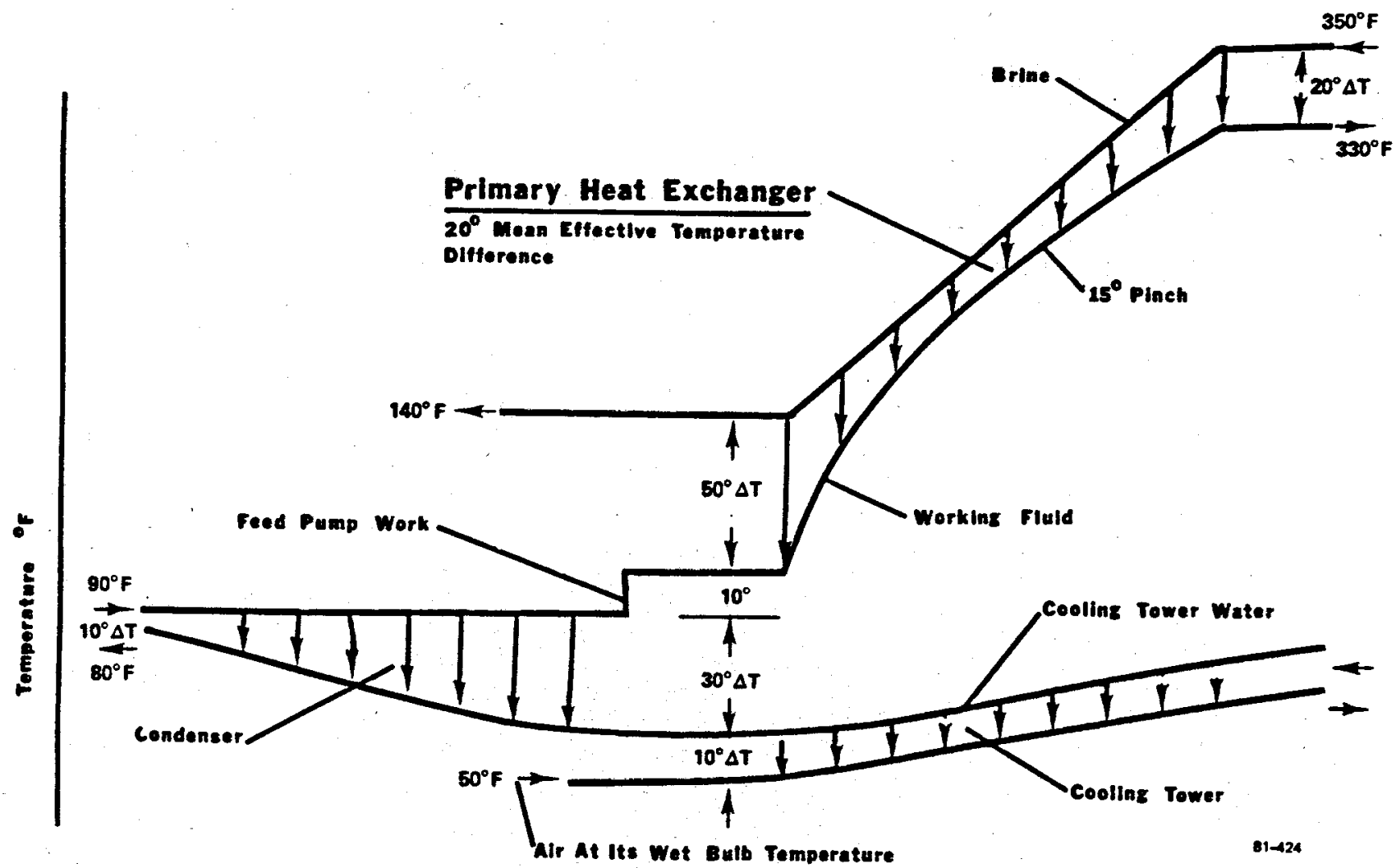

FIG. 3 Heat transfer diagram for conventional binary system supercritical Rankine cycle. 
SUBCRITICAL ORGANIC RANKINE CYCLE
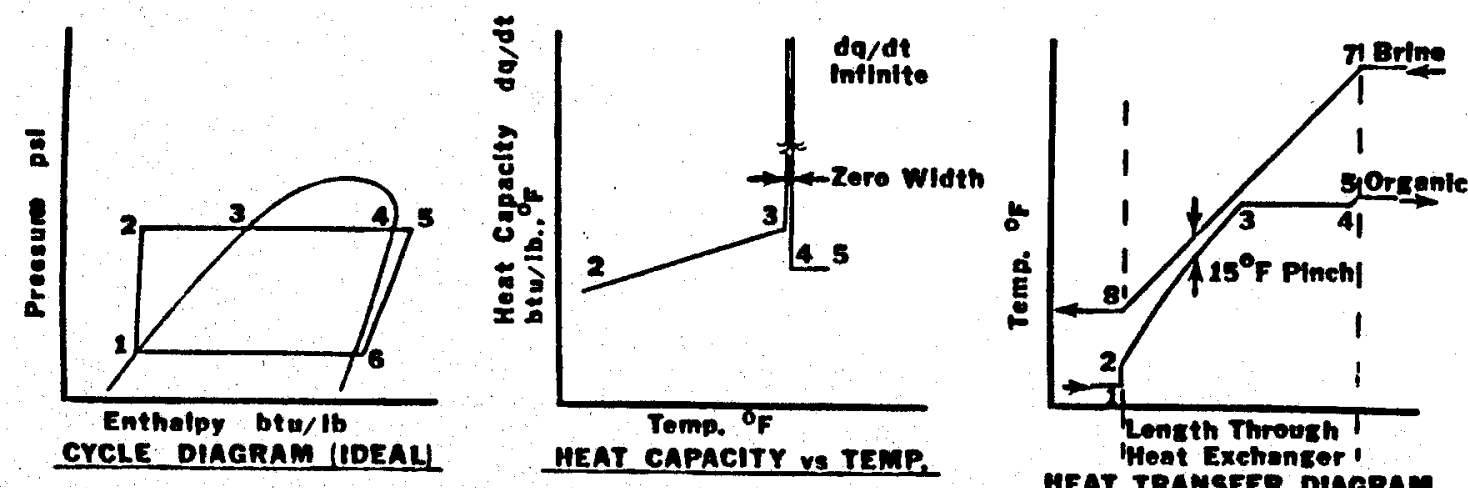

macesses

1-2 FEED PUMT WORK

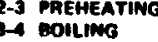

4-5 SULERHEATIMG

So EXPANSAON UN TUMAINE

i-8 EXTRACTION OF MEAT FAOM

STATE POANTS PON HYPOTHETHCAL

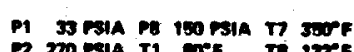

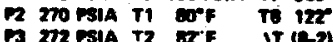

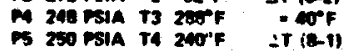

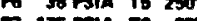

MEAT TRAMSFE DIMeRAM BRINE To workino FlUID

SUPERCRITICAL ORGANIC RANKINE CYCLE
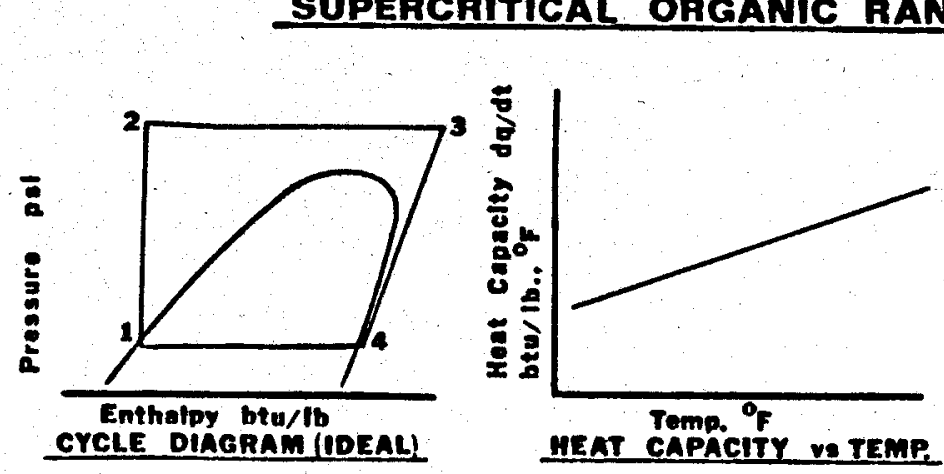
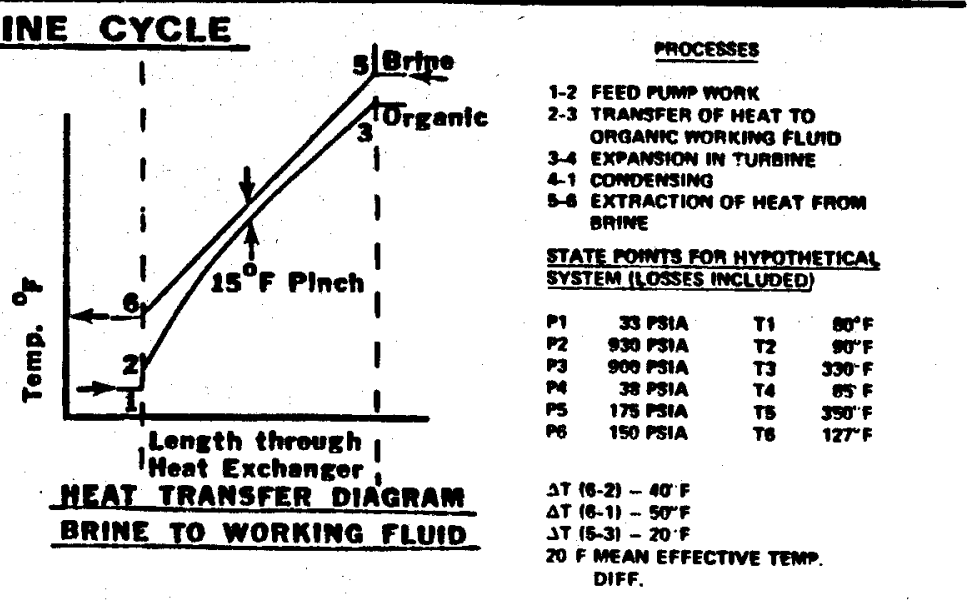

$81-425$

FIG. 4 Thermodynamic diagrams. 


\section{A}

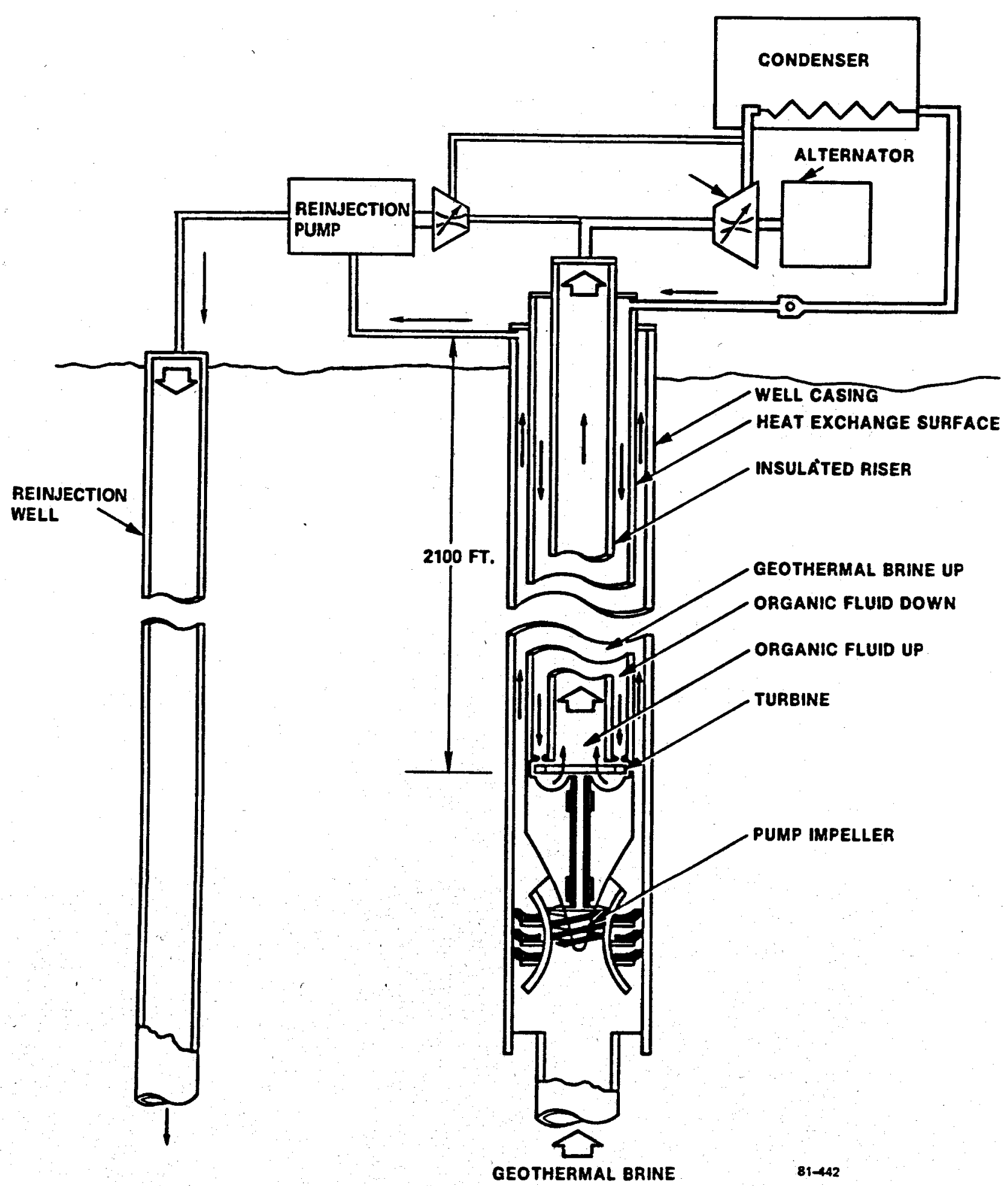

FIG. 5 Gravity-head system. 


\section{t7}

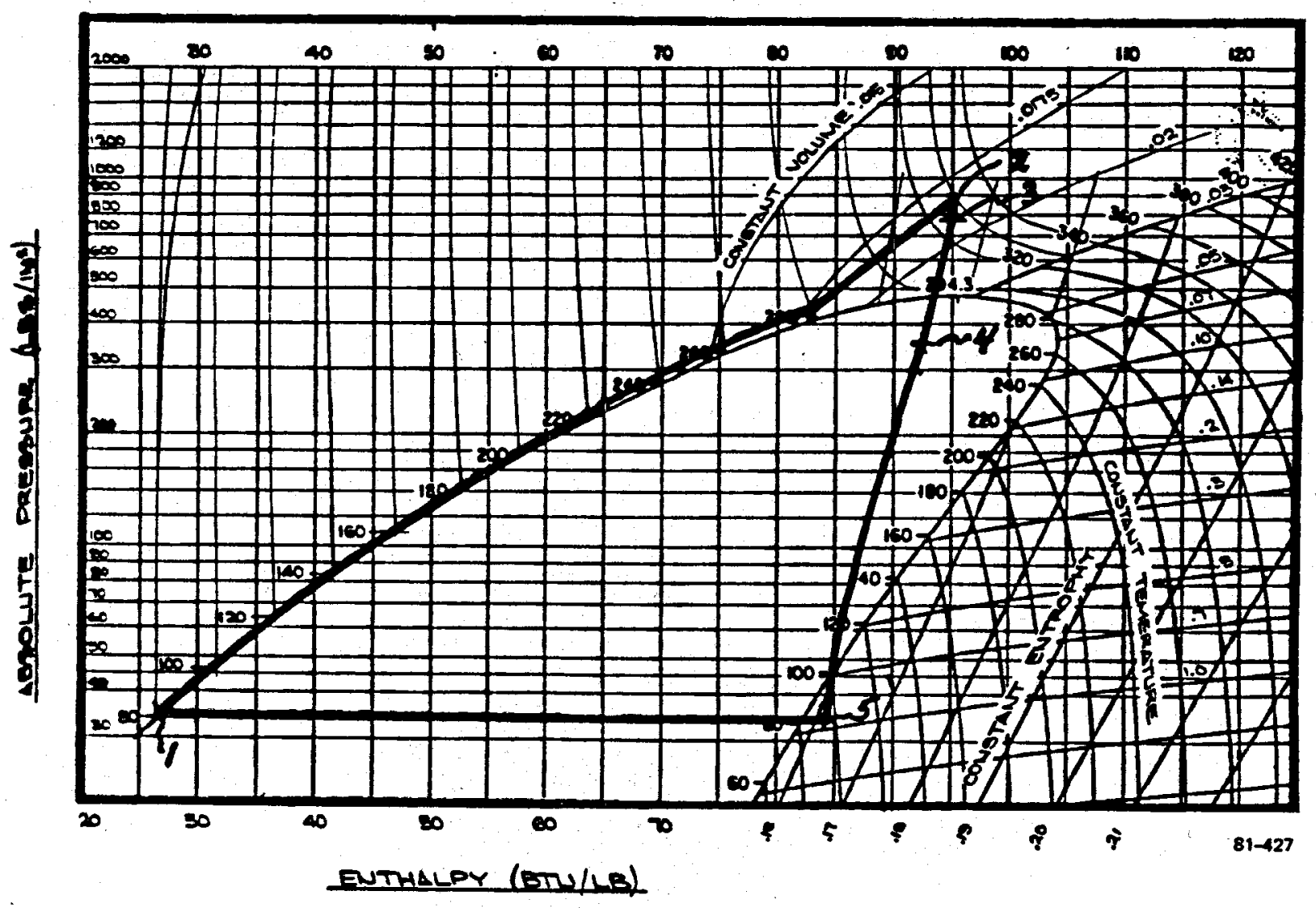

FIG. 6 Gravity-head cycle - R-114 fluid. 
GEOTHERMAL GRAVITY HEAD CYCLE
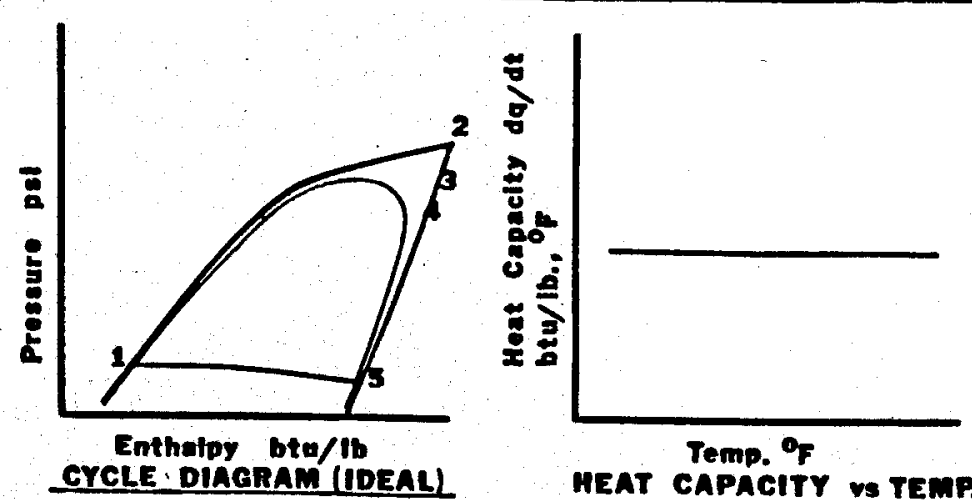

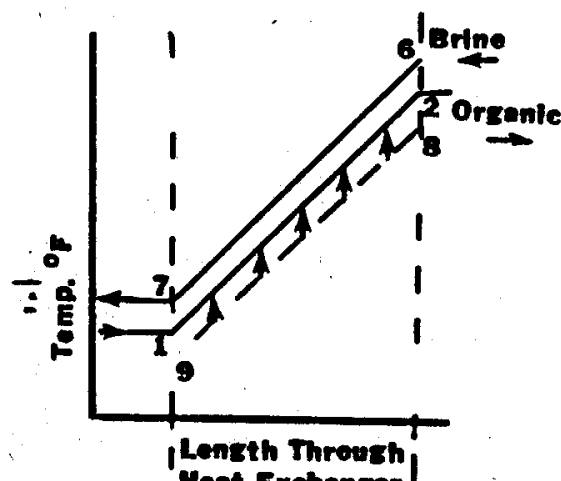

Lensth Throush, HEAT TRANGFER DIAGRAm BRINE TO WORKIne FLuID 1-2 TRANSFER OF HEAT TO 2- BAINE WUMP TO RAISE ofgamic to suptace 4. EXPANSHON IN TURBIME $\rightarrow \rightarrow$ EXTRACTIOM OF HEAT FROM BAINE LIFT WOAK RETUAMEd AS TATE MONTS FOA IMPOHETICA SYSTEM LLOSSES IMCLUDED)

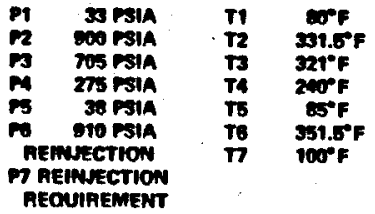
REOUIREMENT

$\Delta T(6-2)-200 F \quad \Delta T(7-1) 20^{\circ}$
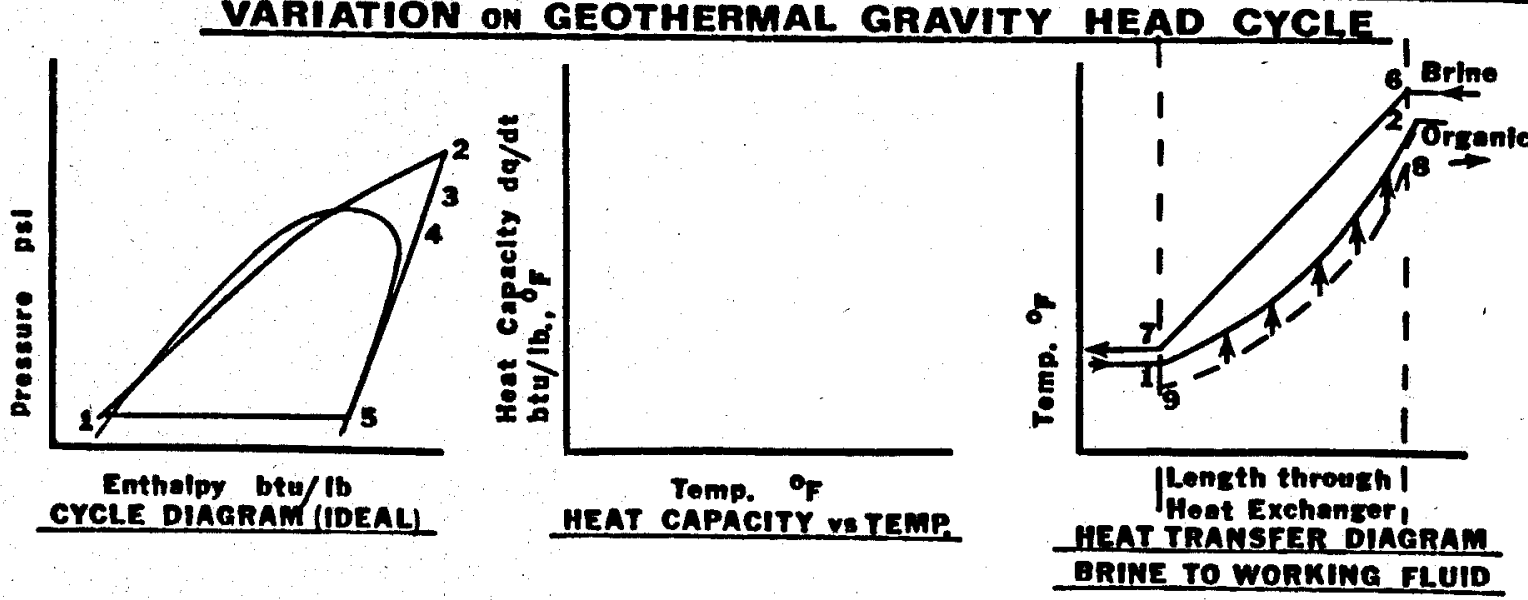

\section{MOCESSES}

1-2 MEAT TMANSFER TO OAGANIC mOAKINO FLUTO 23 BANE MUIP

IIN TO RaISE

a. Expansion in TuReme

$\rightarrow 7$ EXTRACTION OF HEAT FROM

a- LIFT WoAx

Crt wonk returmed as

ITATE POMTS FOA HYPOTHETICAL SYSTEMILOSSES IMCL LOED

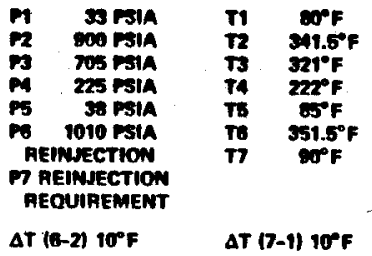

$\triangle T(a-2) 100^{\circ} \mathrm{F}$

at 17-1) 10F

81-428

FIG. 7 Thermodynamic diagrams. 

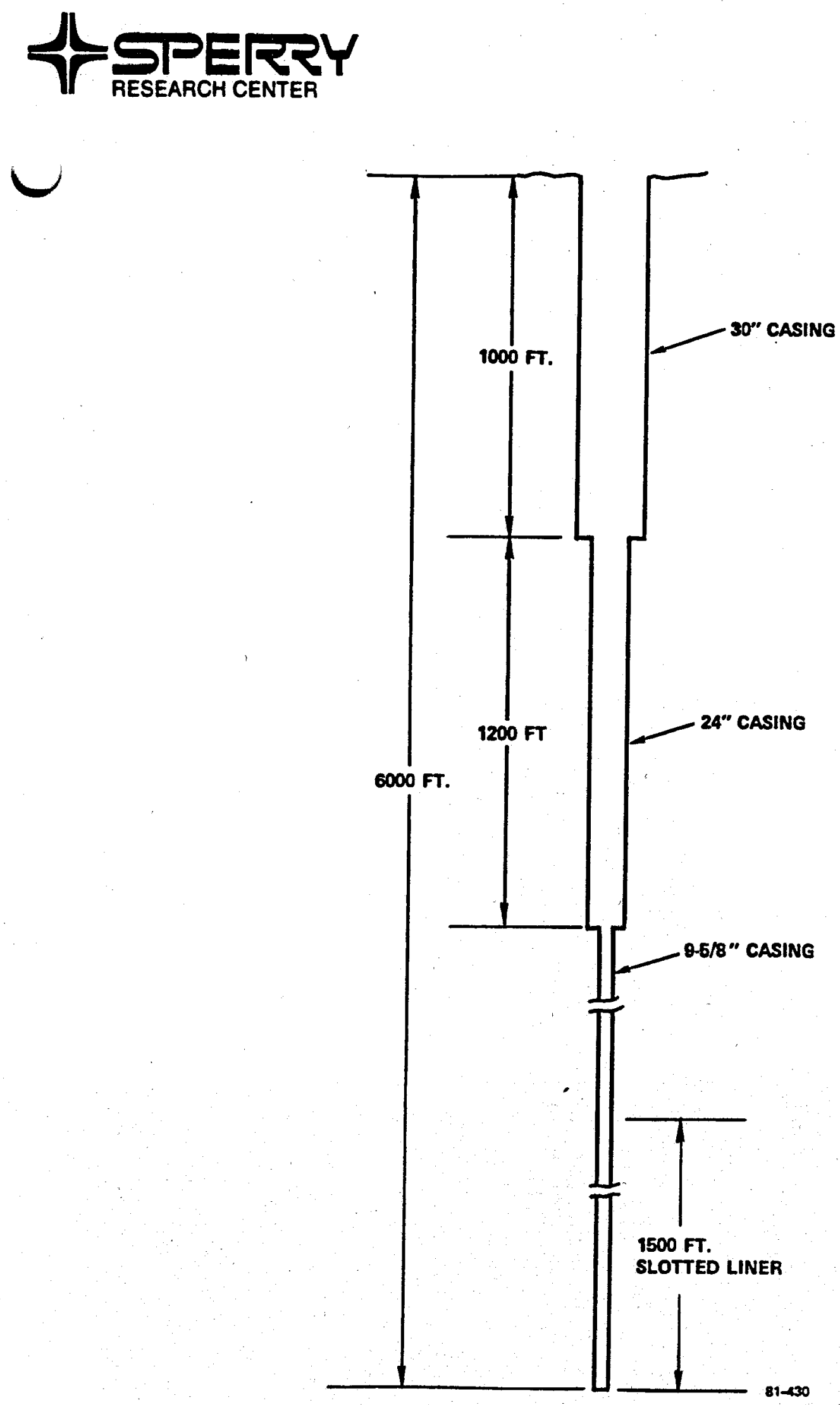

FIG. 8 Casing profile. 


\section{t) SIPERER}

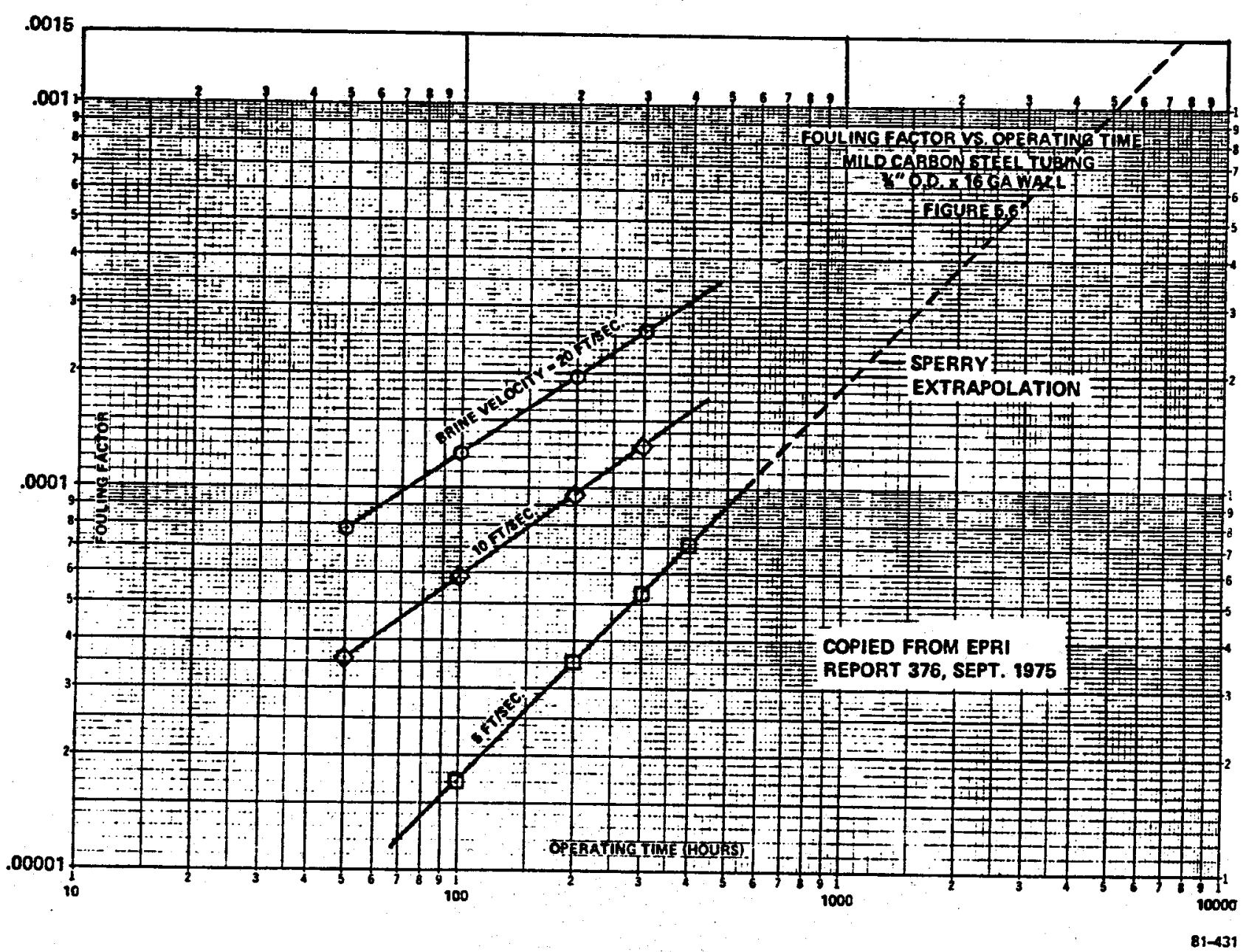

FIG. 9 Fouling factor extrapolation. 

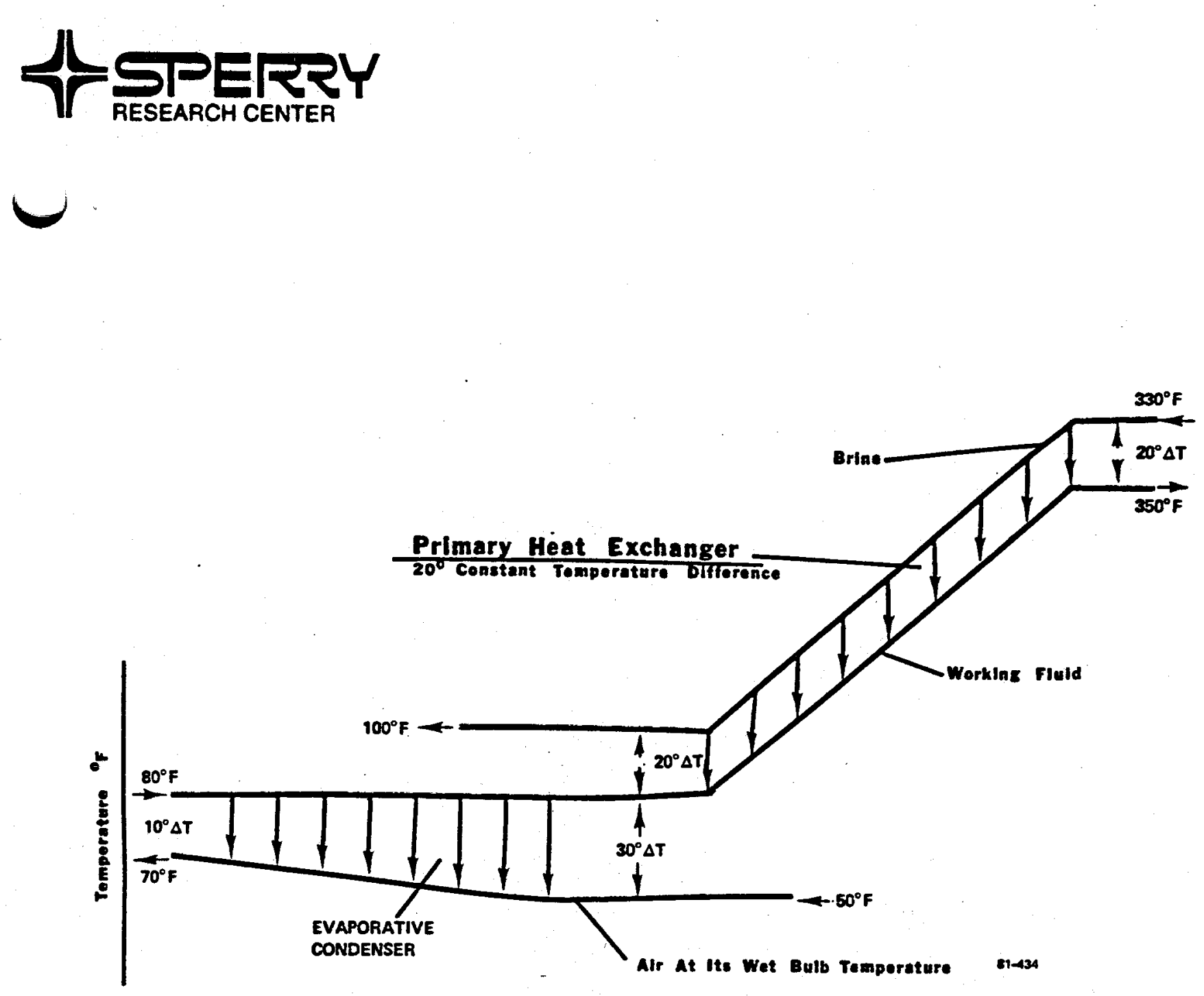

FIG. 10 Heat transfer diagram for gravity-head cycle with combined heat rejection unit - constant working fluid heat capacity vs temperature. 


\section{4t}

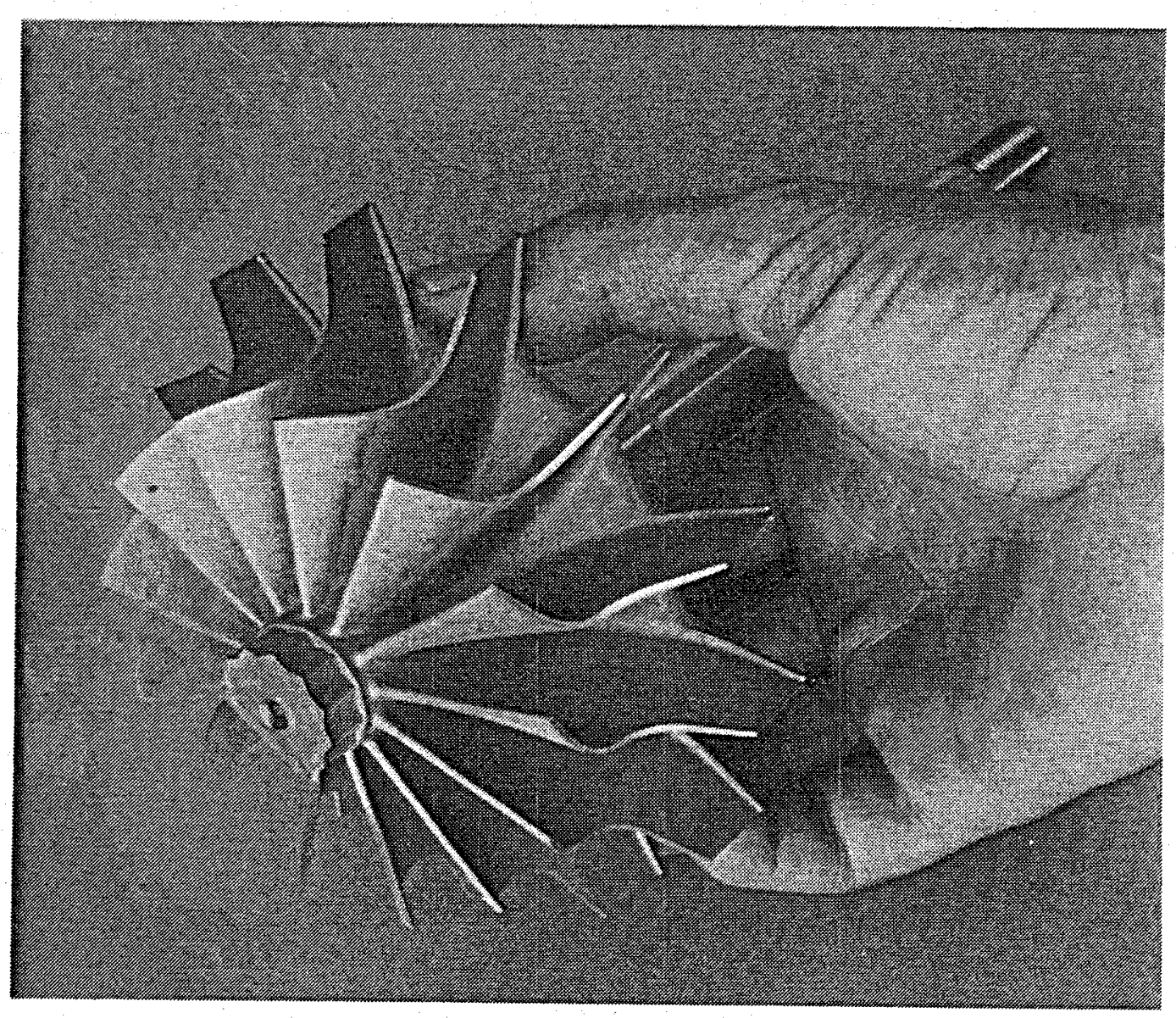

81-432

\section{FIG. 11 Radial inflow turbine.}




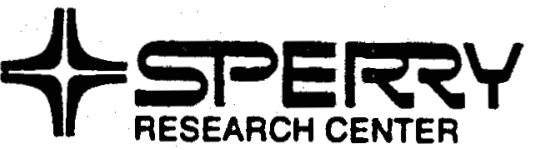

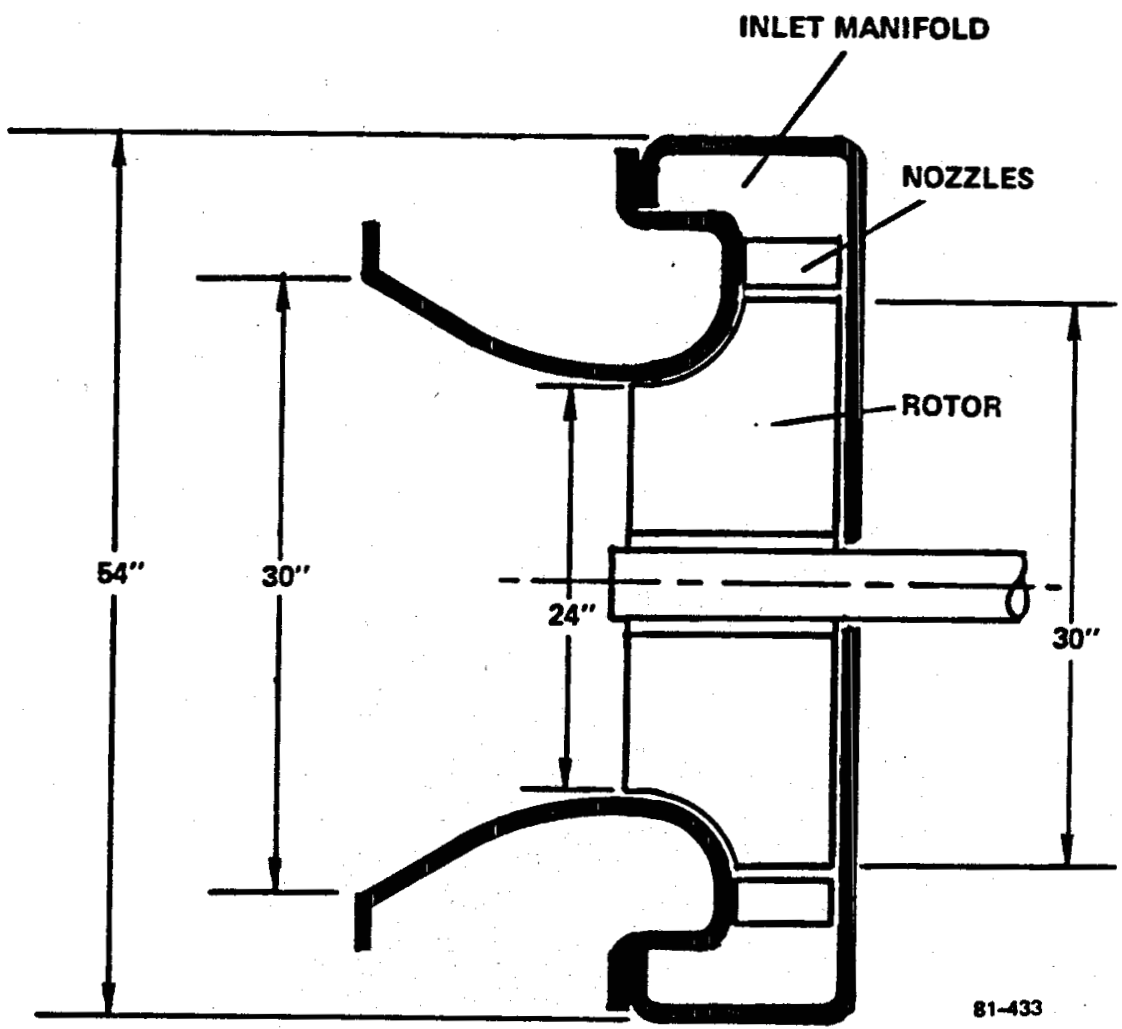

FIG. 12 Preliminary radial inflow turbine sizing. 

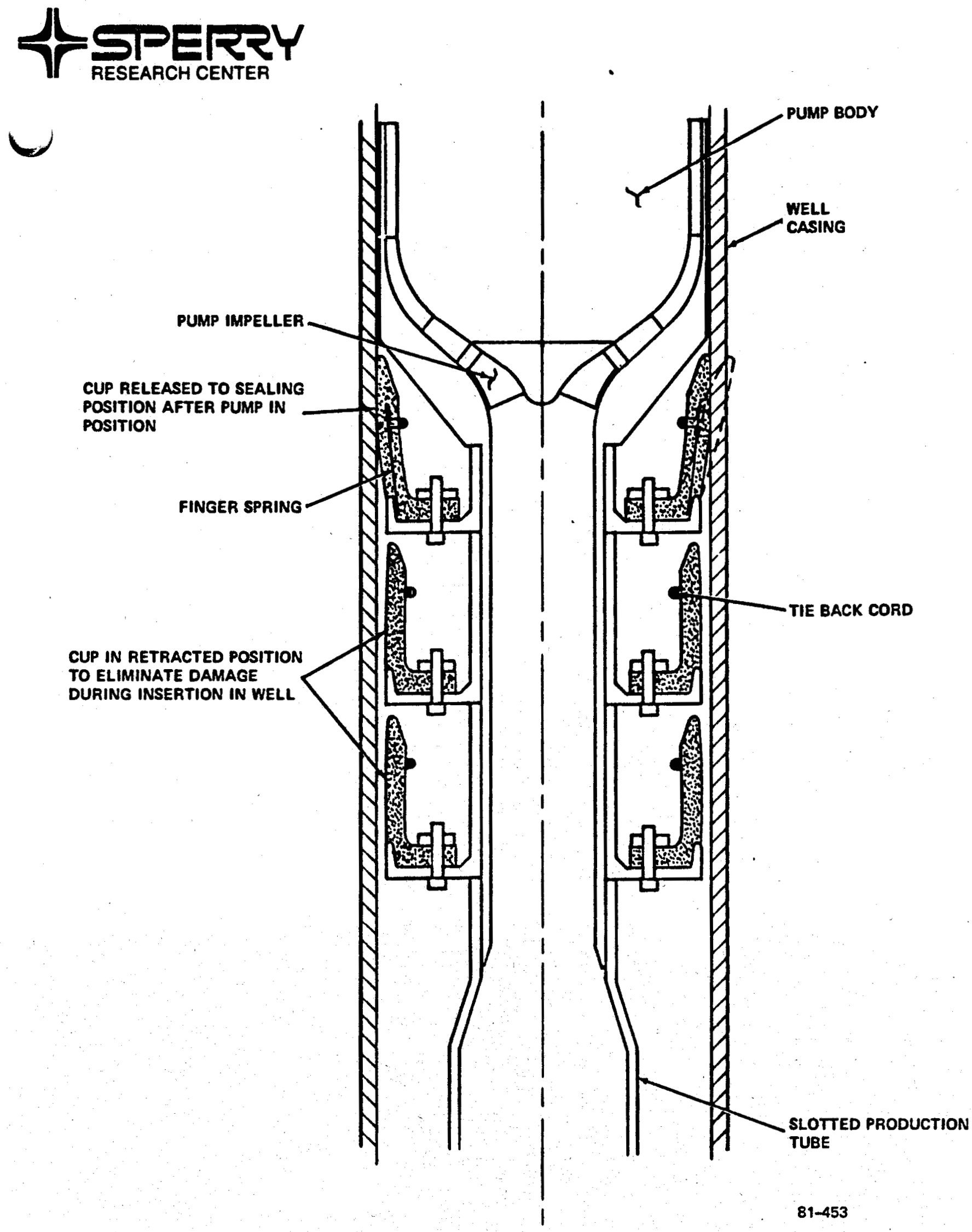

FIG. 13 Automatic deploying cup-type packer for geothermal pump. 
t) STRPERRY

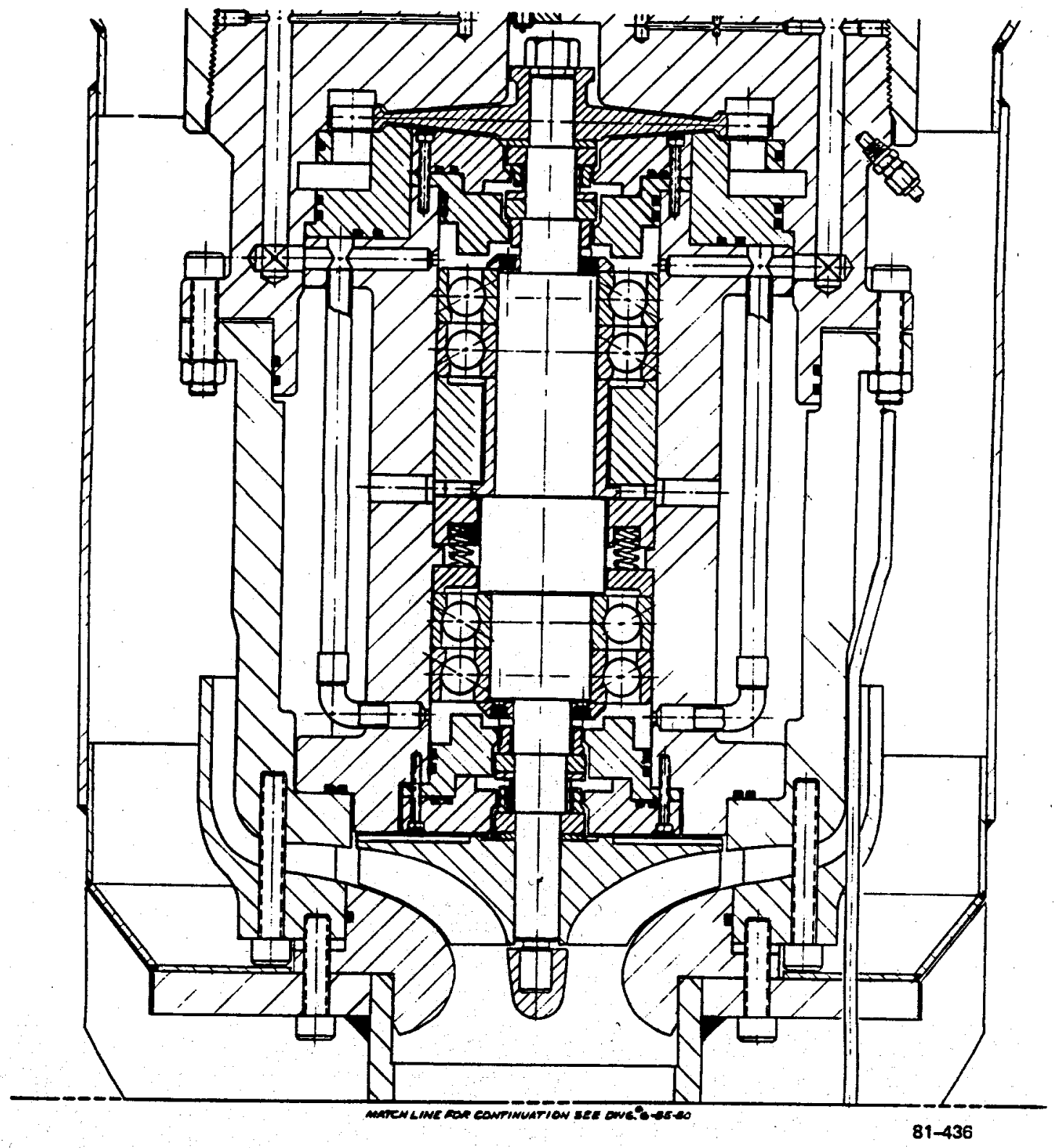

FIG. 14 Sperry stand-alone pump. 

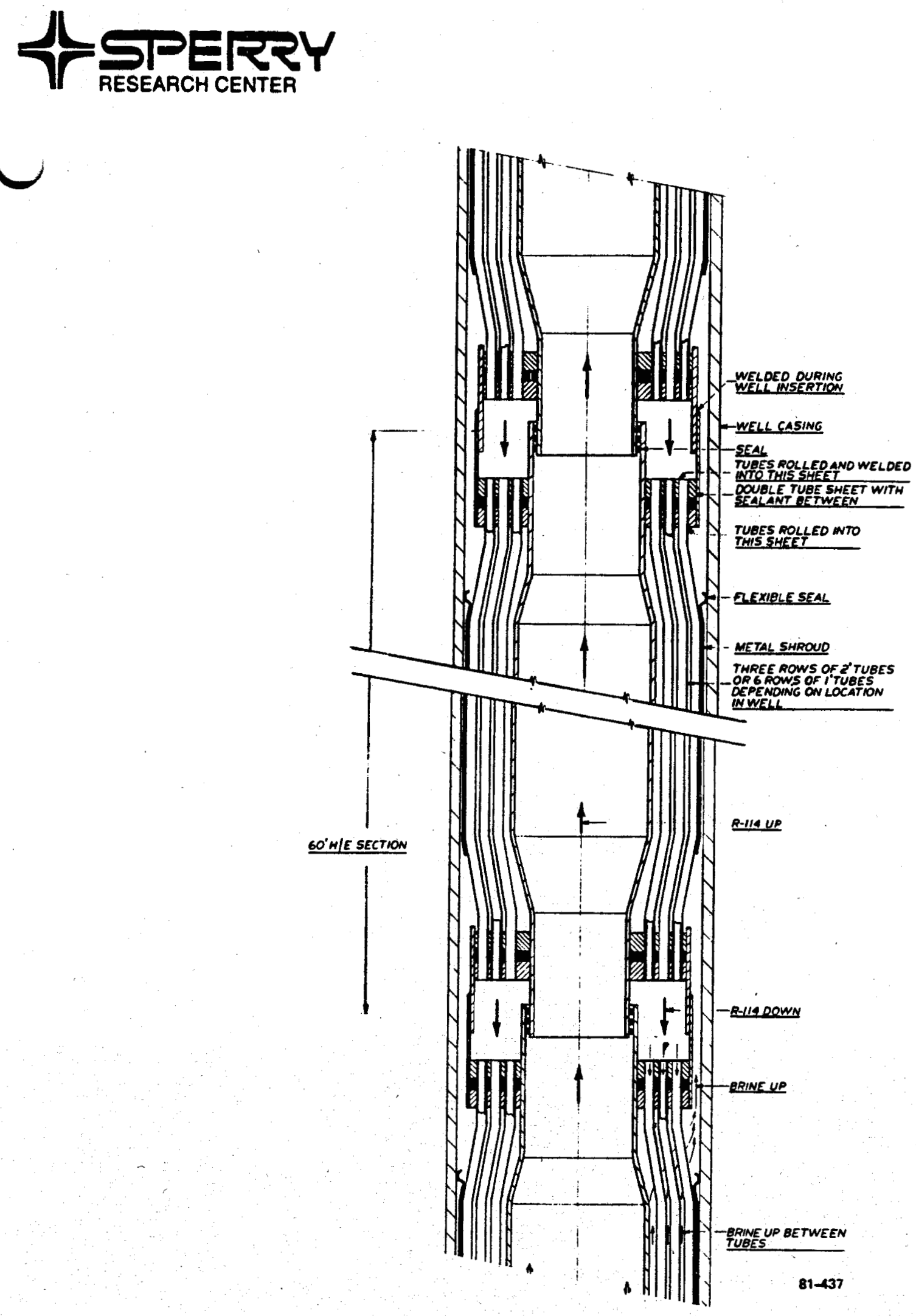

FIG. 15 Typical tubular heat exchanger section. 


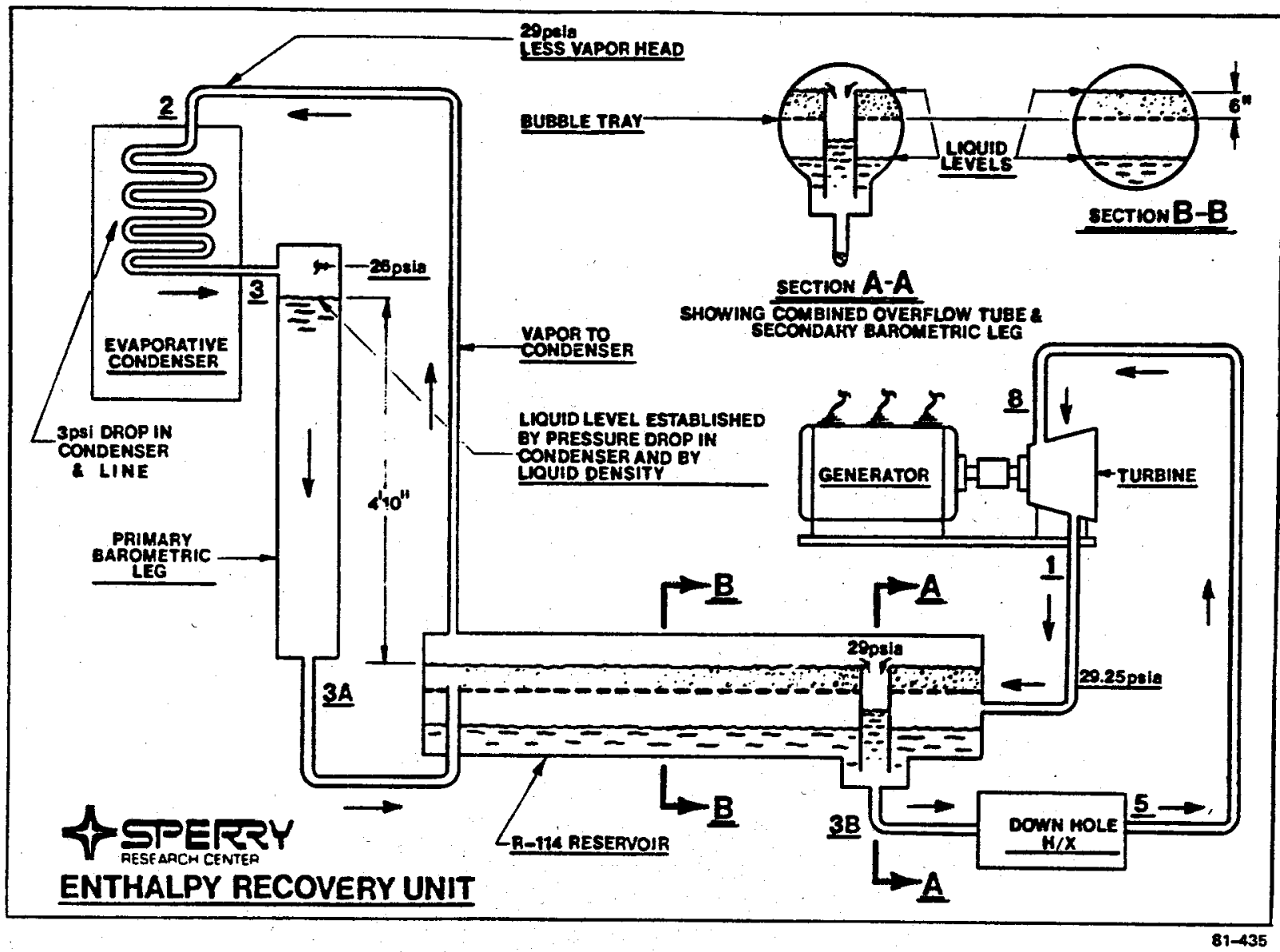

FIG. 16 Enthalpy recovery unit. 

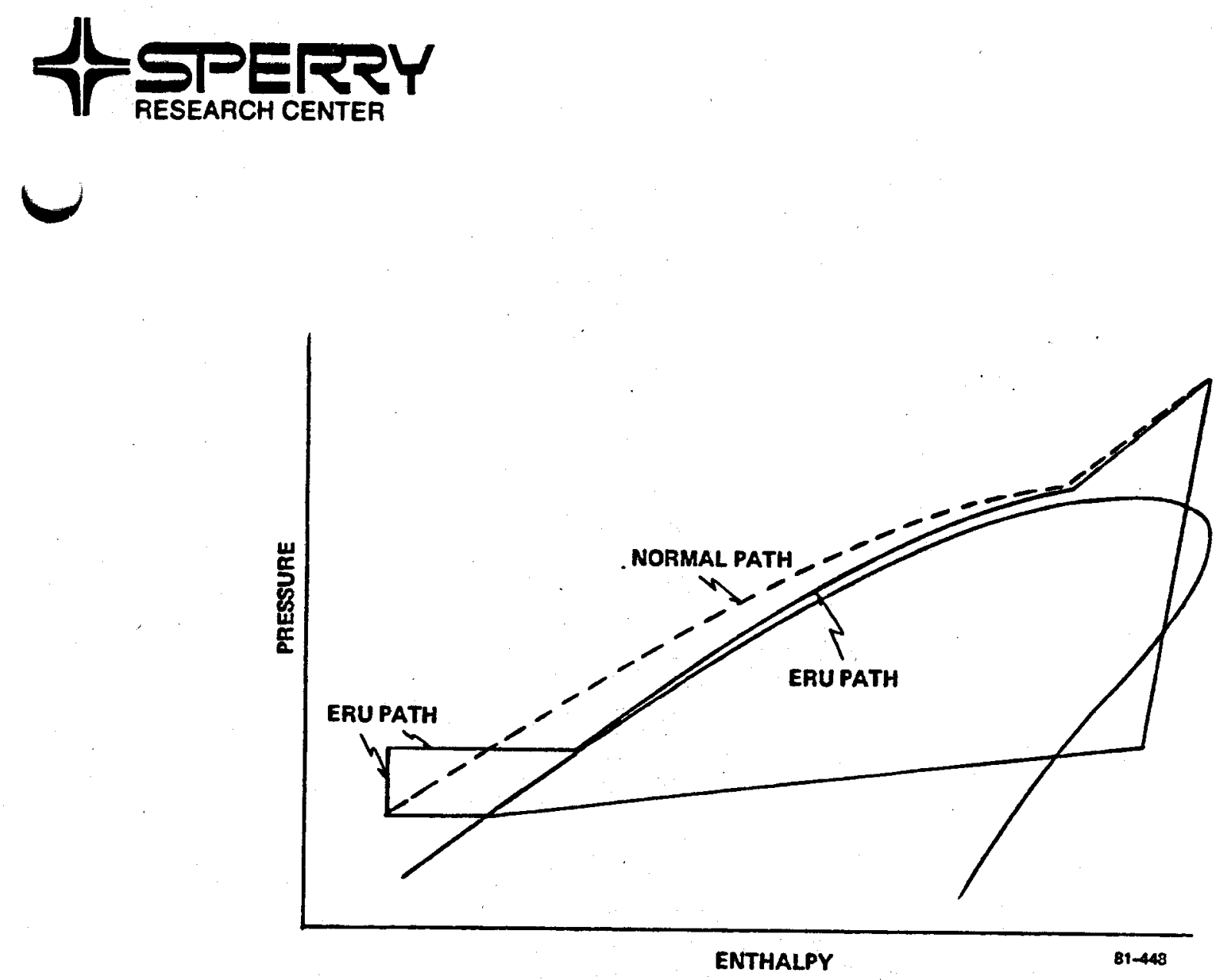

FIG. 17 Pressure-enthalpy diagram for enthalpy recovery unit. 

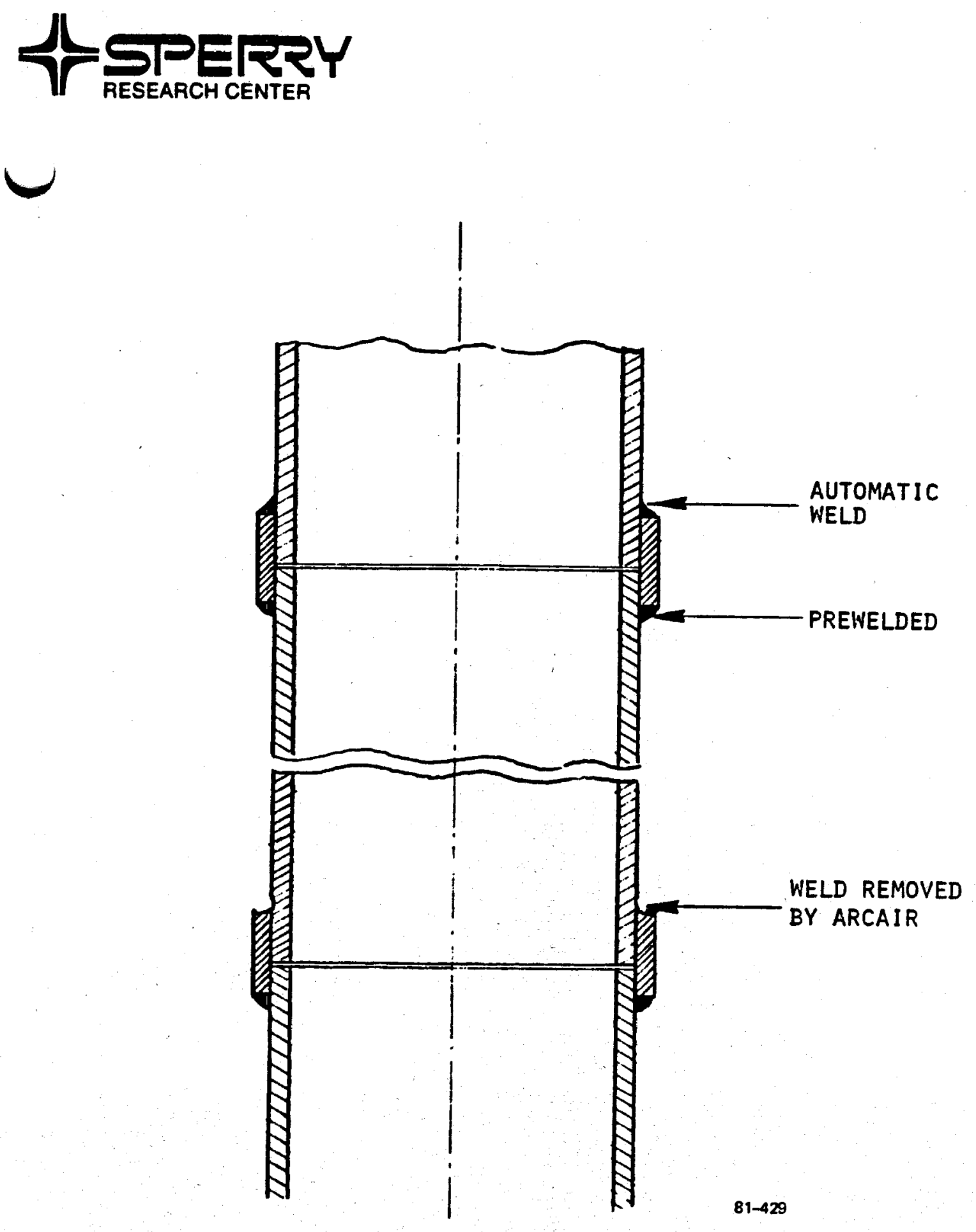

FIG. 18 Welded connections for down-hole pipe string. 

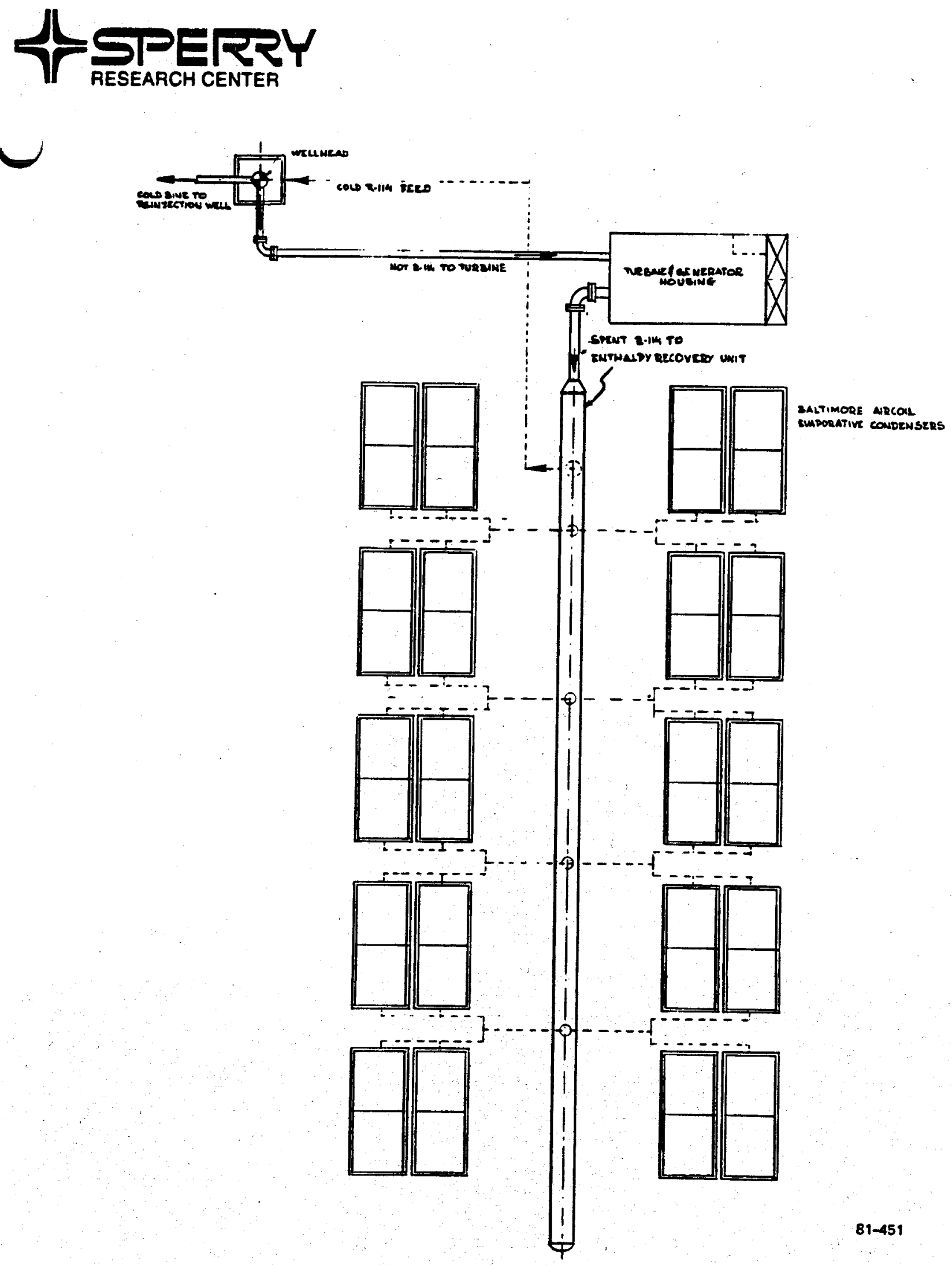

FIG. 19 Plot plan of East Mesa plant. 

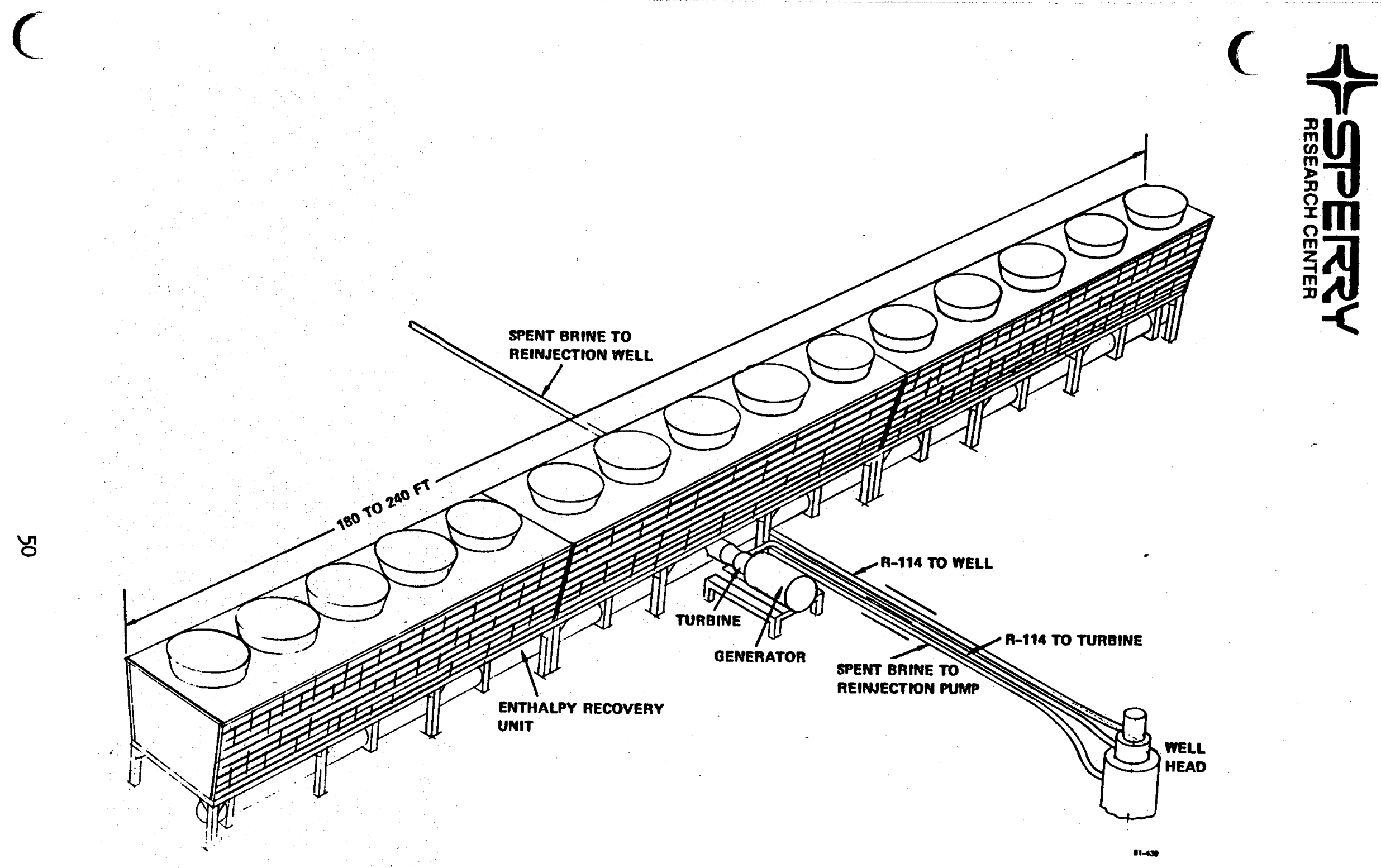

FIG. 20 Factory-manufactured modular plant. 
4 G

APPENDIX A

ON-SITE PHOTOGRAPHS

LOW-TEMPERATURE GEOTHERMAL CONVERSION SYSTEM 


\section{t) STEERTY}

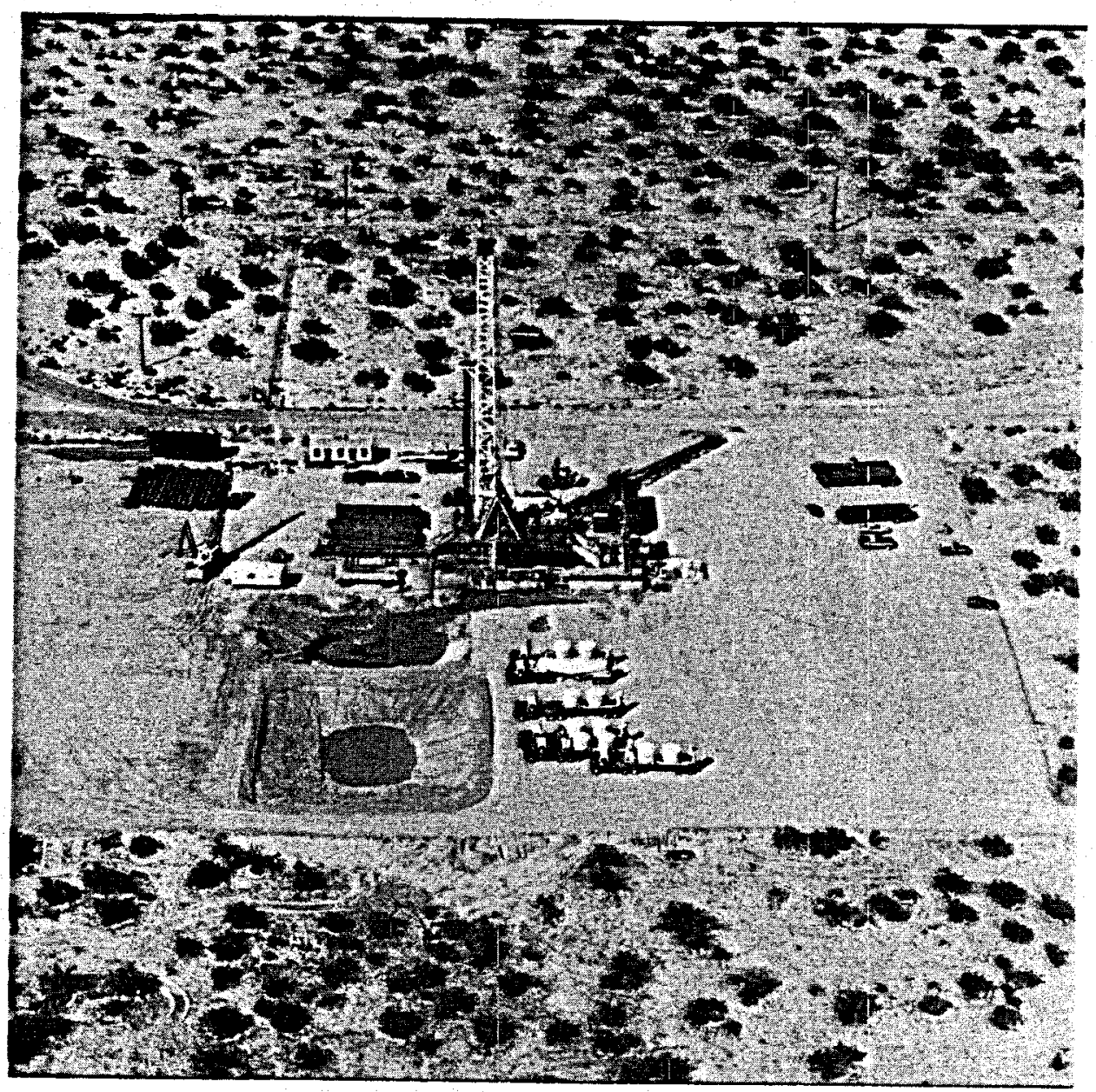

Drilling the Well.

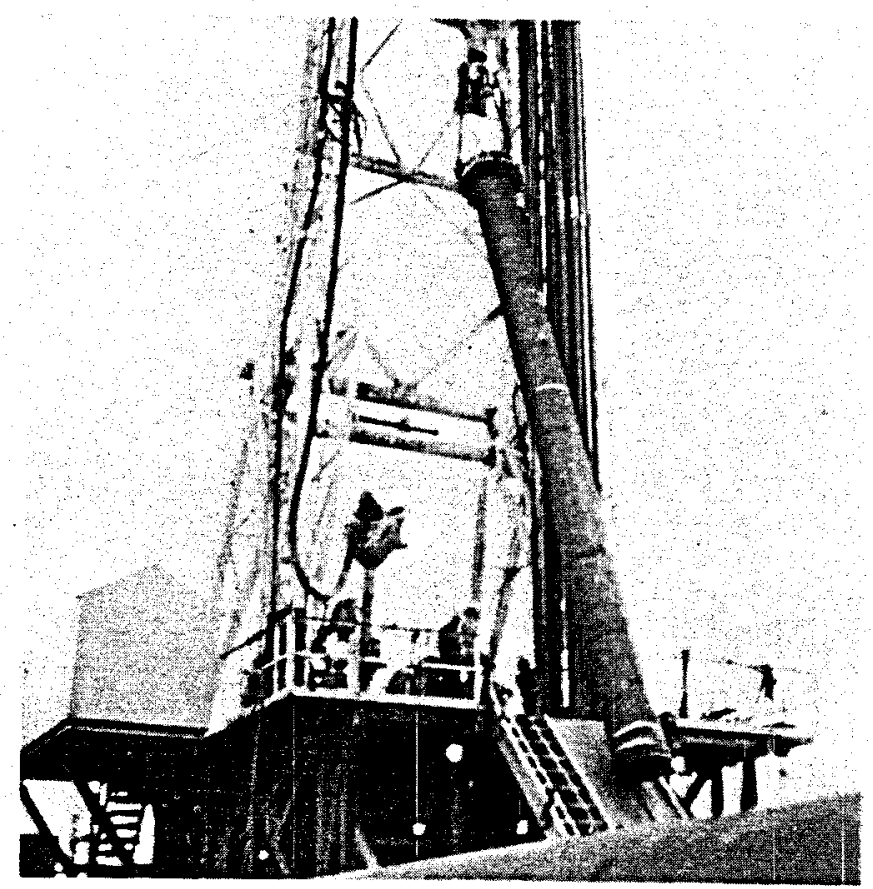

Lifting a Section of 30" Casing to Drilling Platform. 


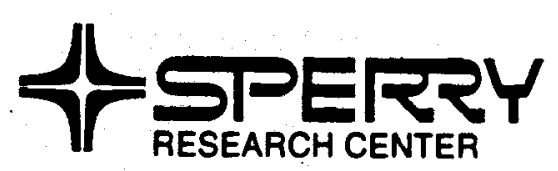

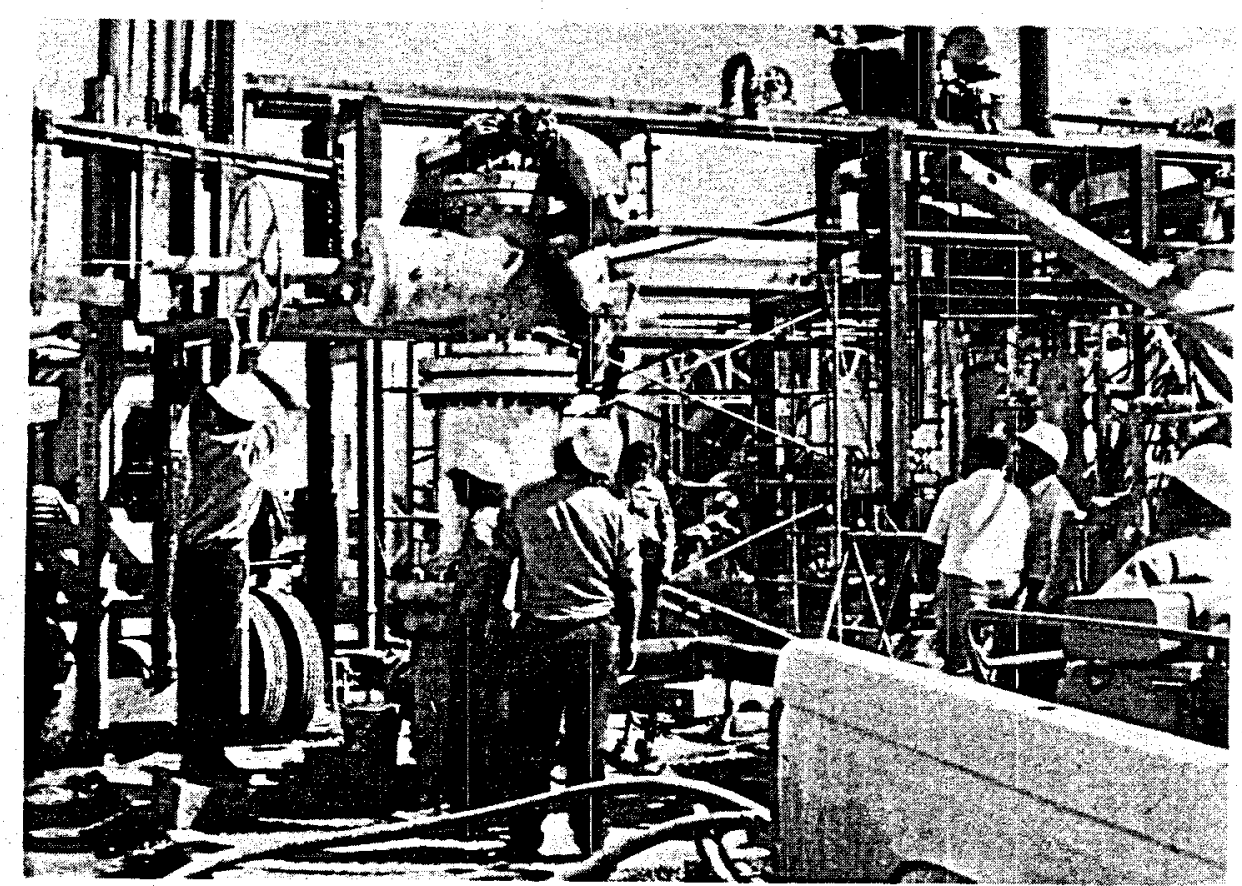

Production Well - Sperry 87-6"

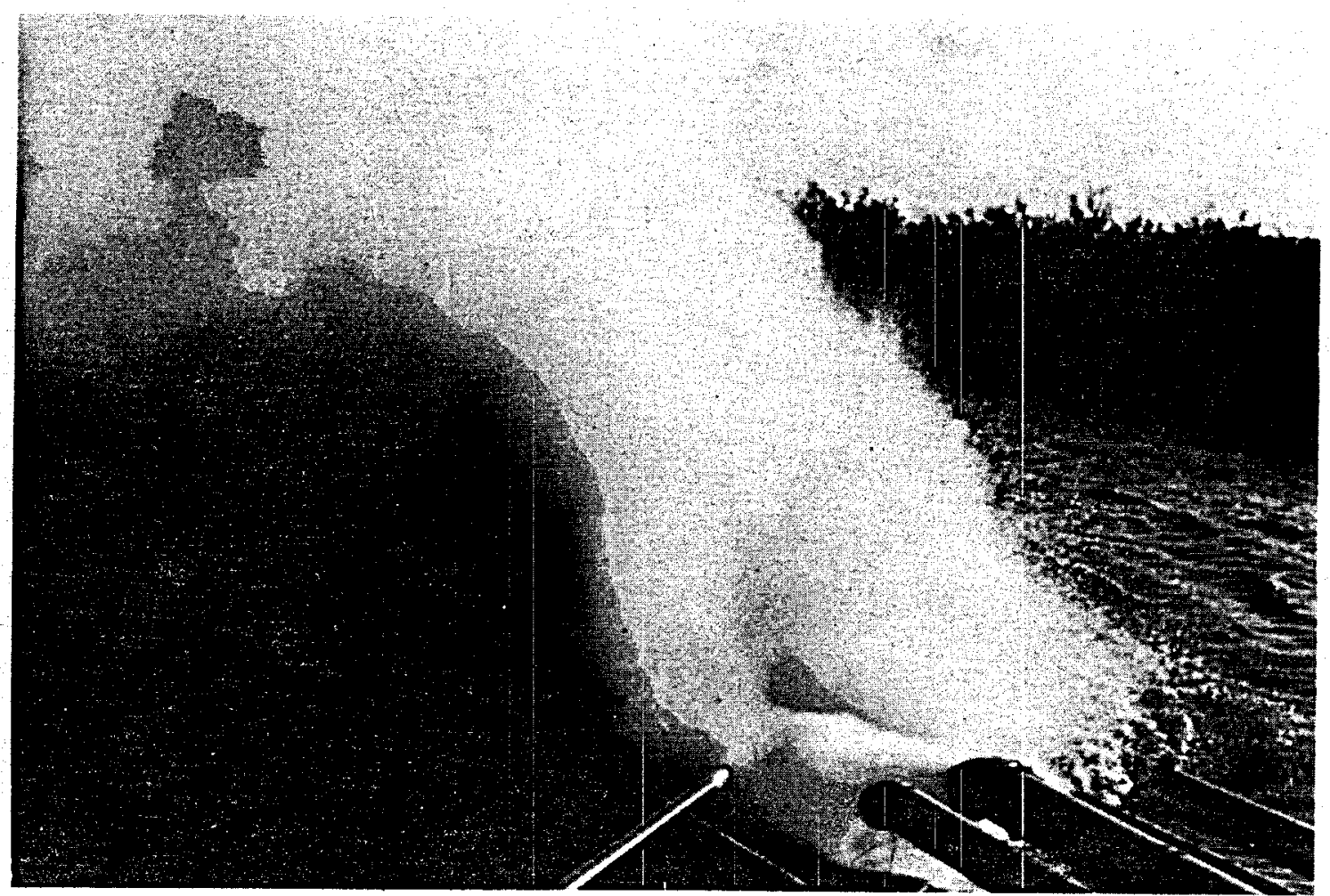

Flashing Well into Pond 
th

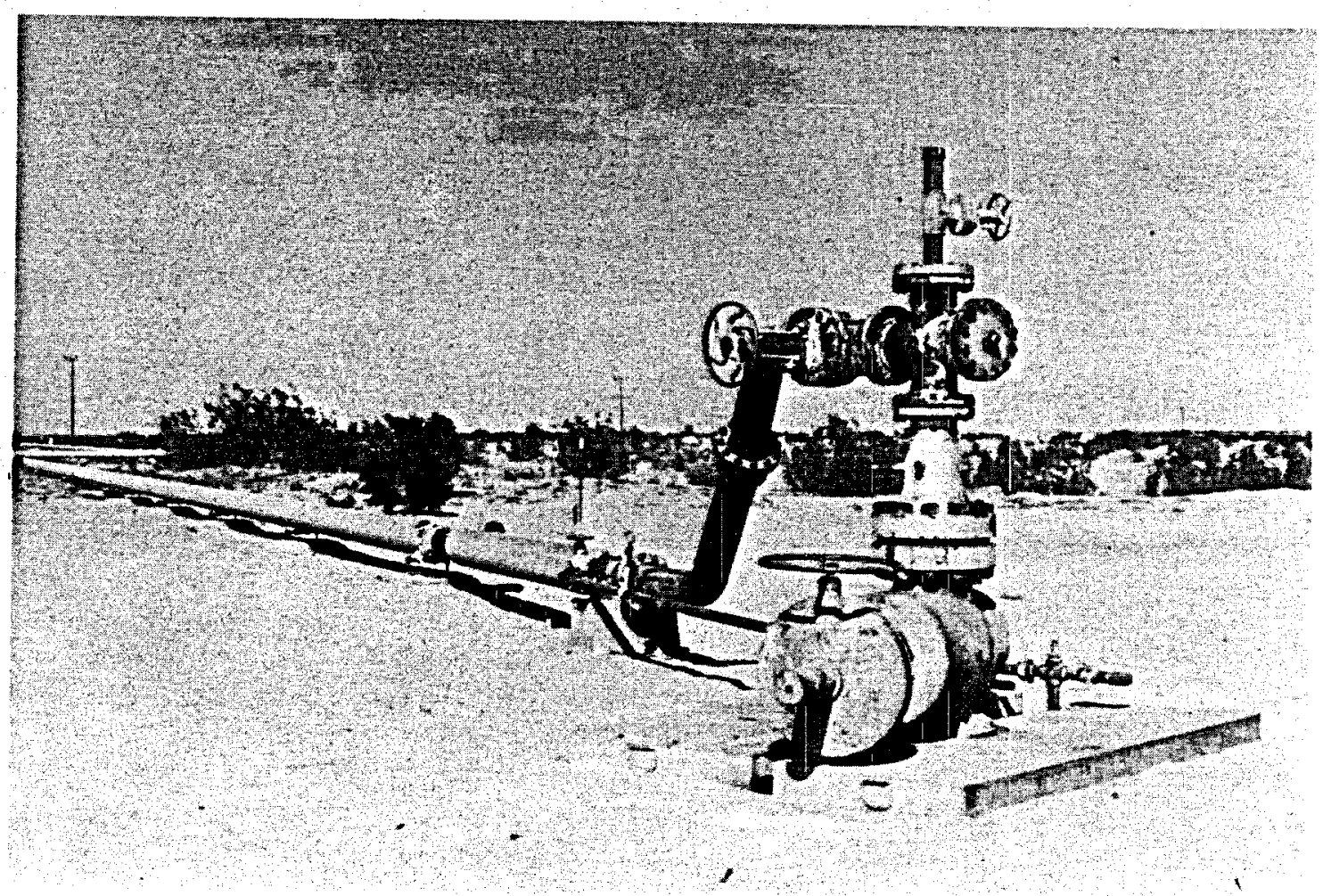

Reinjection Well

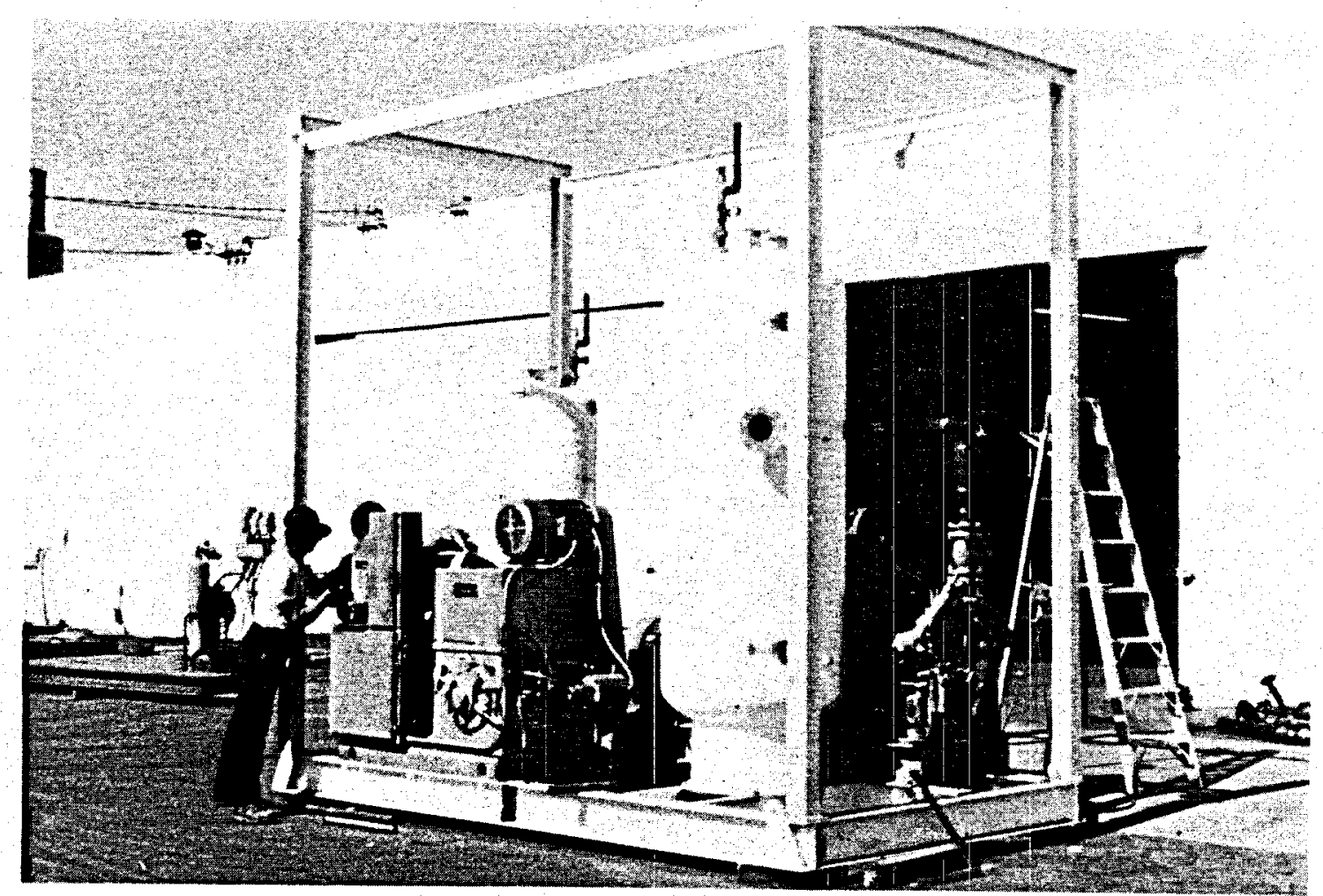

Portable System for Evacuating R114 or Air from Vessels and Conduits. 


\section{th SREEEREY}

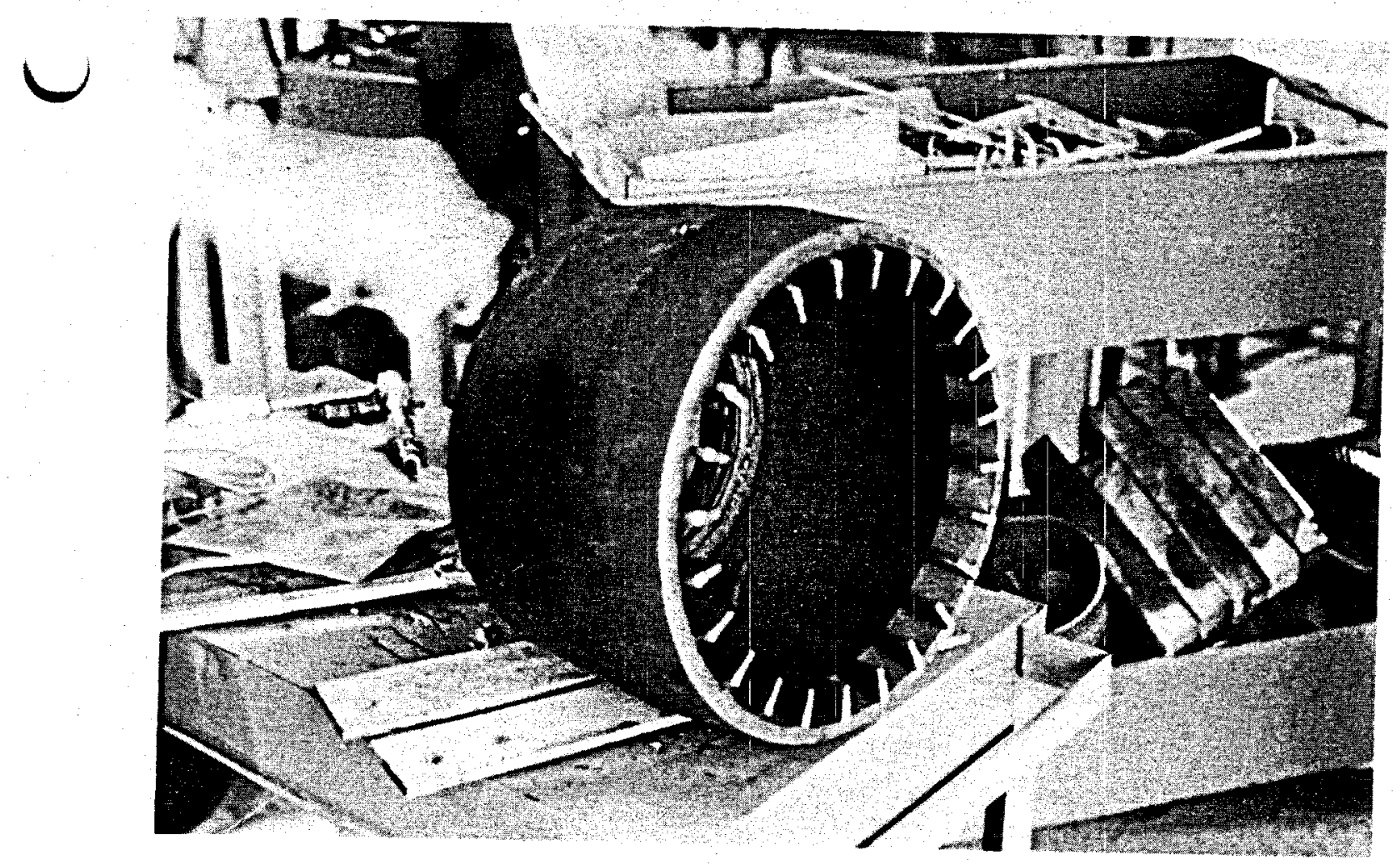

Packer Cup

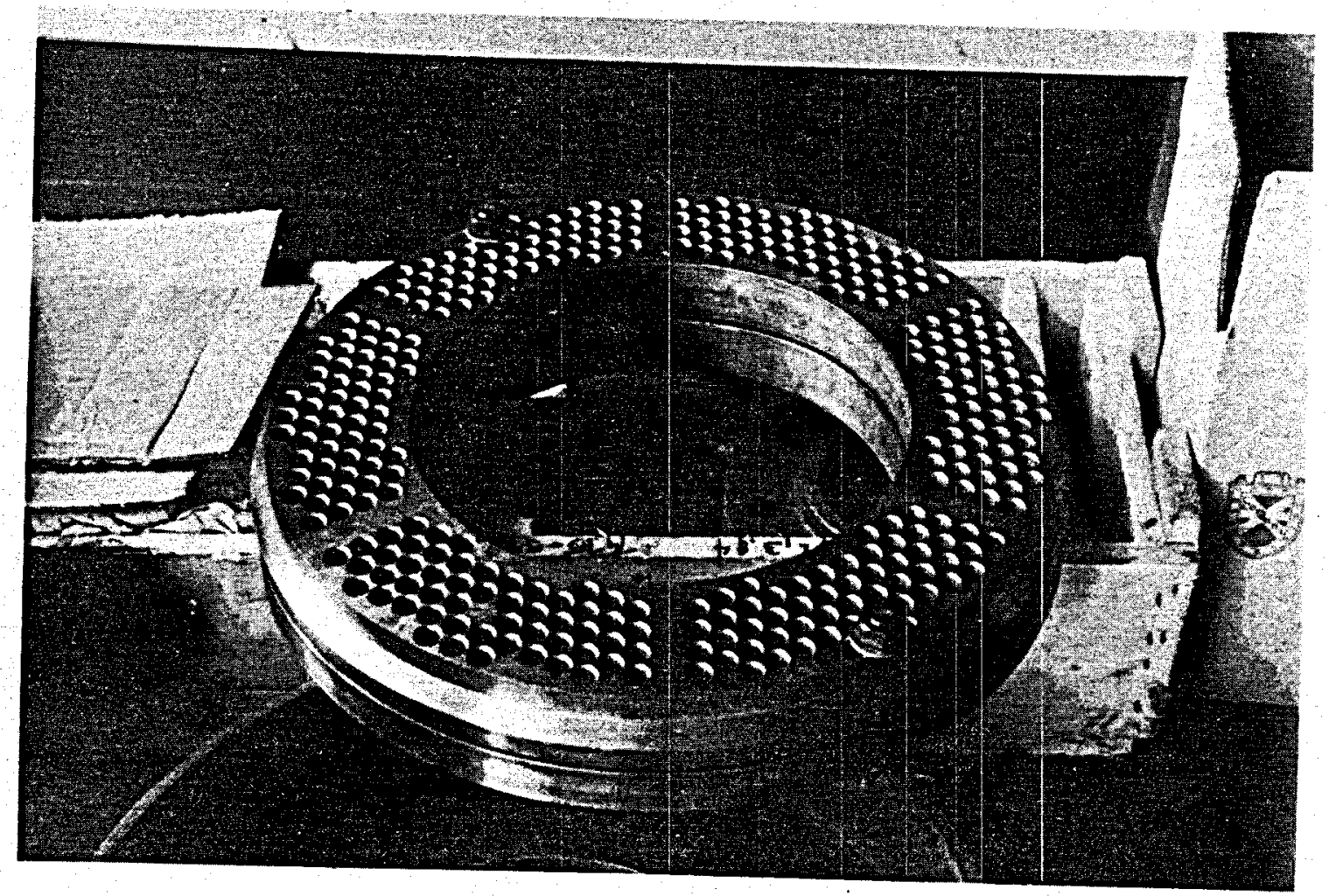

Double Sheet for Heat Exchanger 


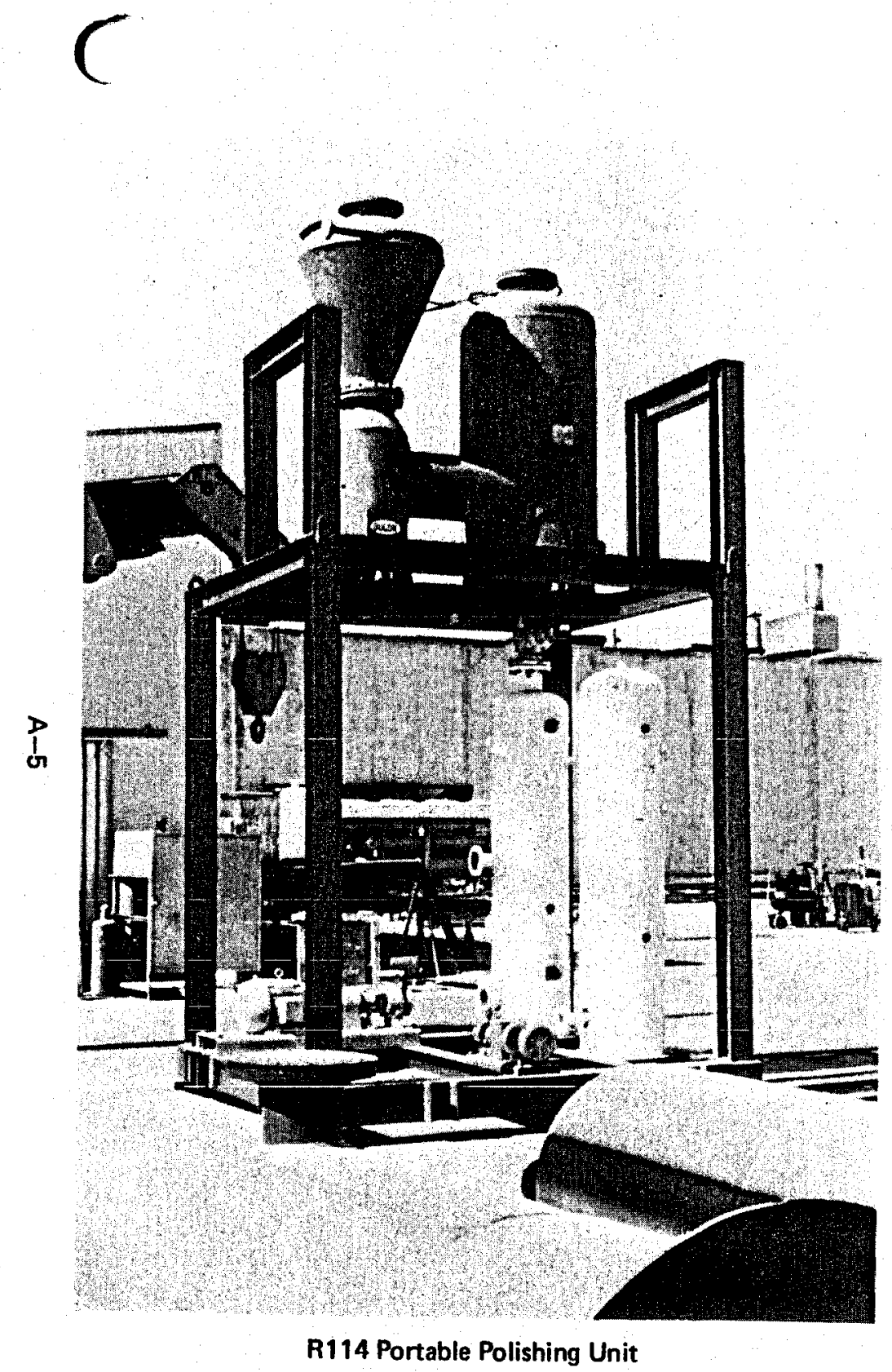

$c \leadsto$

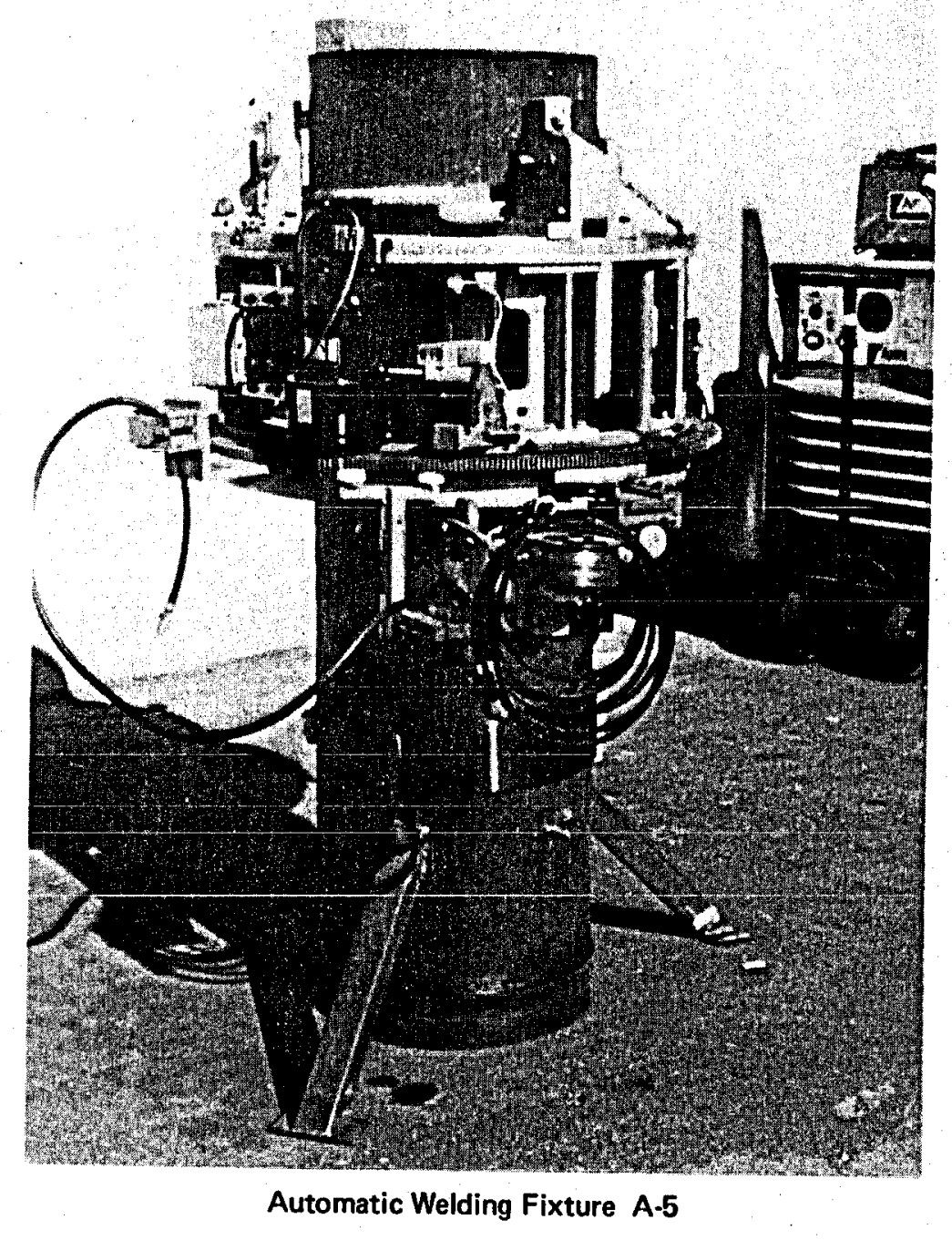

甭】 


\section{t)}

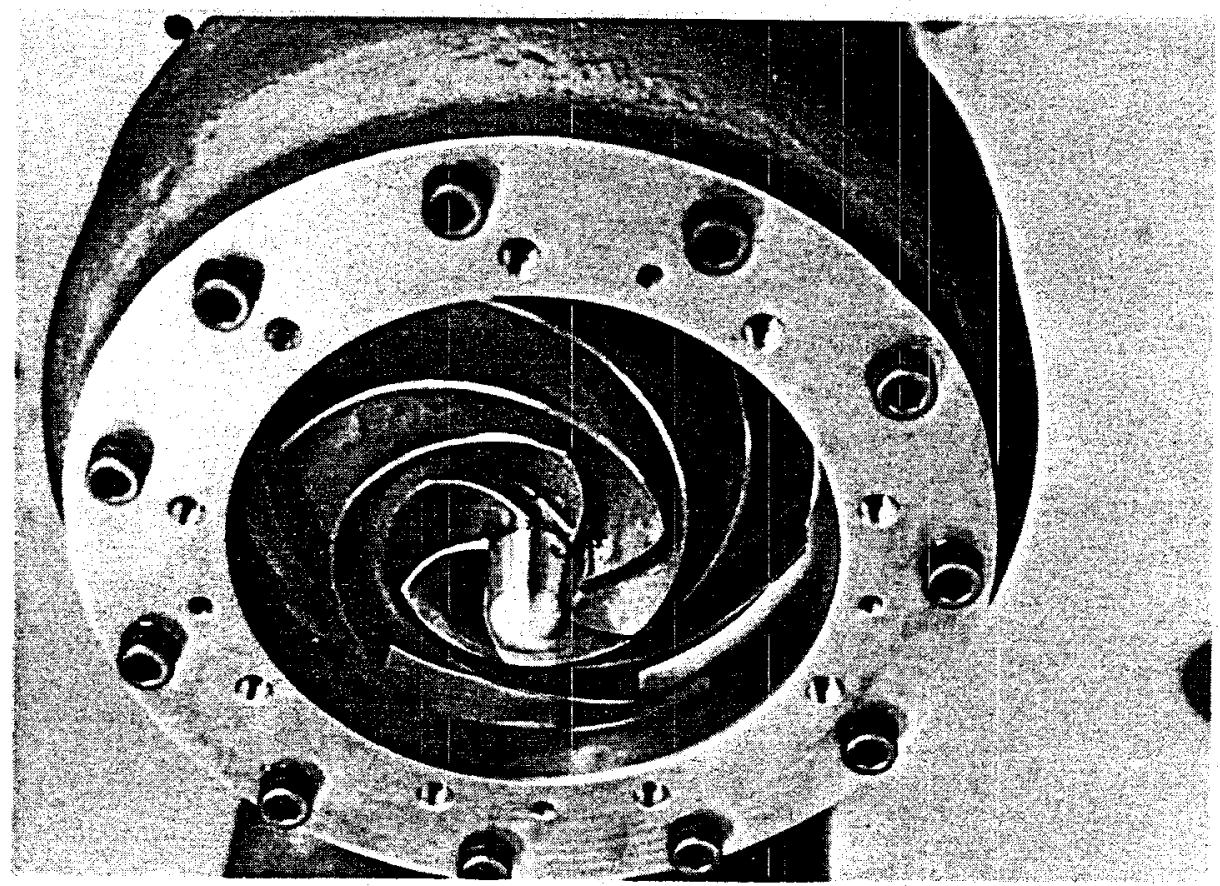

Down-Hole Pump Impeller

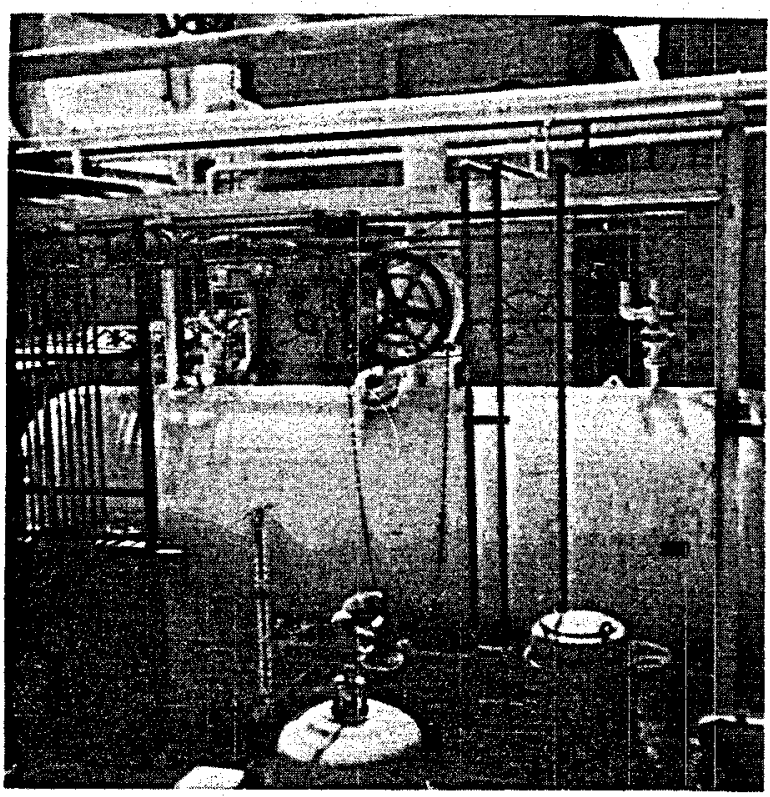

Enthalpy Recovery Unit for Pump Test 


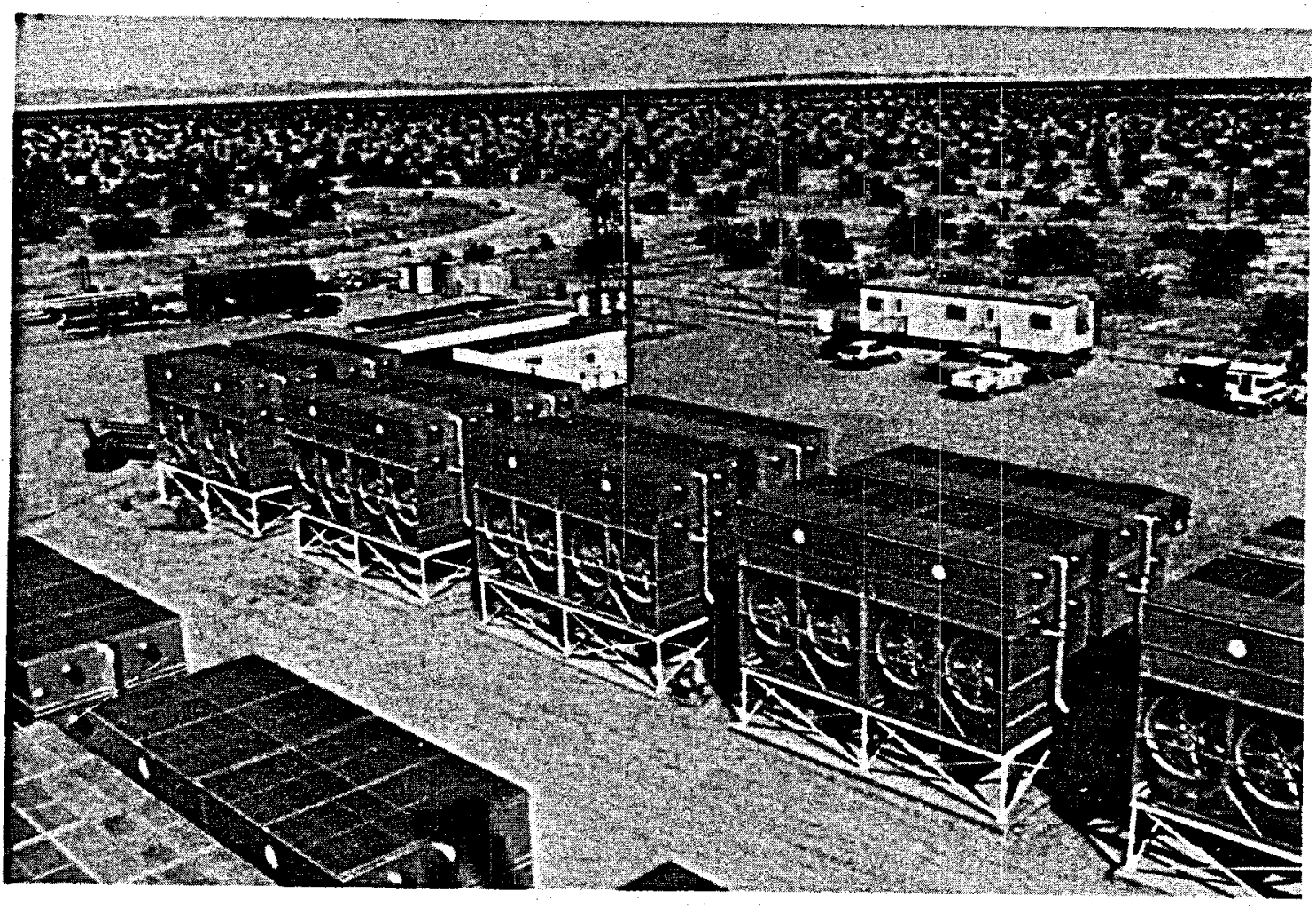

Evaporative Condensers

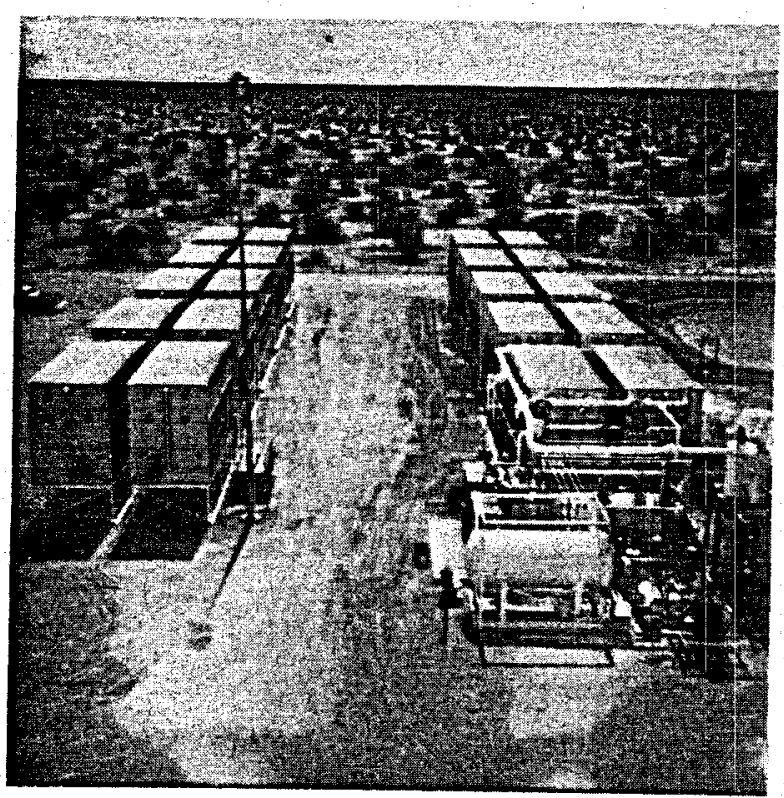

Evaporative Condensers with Experimental

Process Equipment in Right Foreground. 


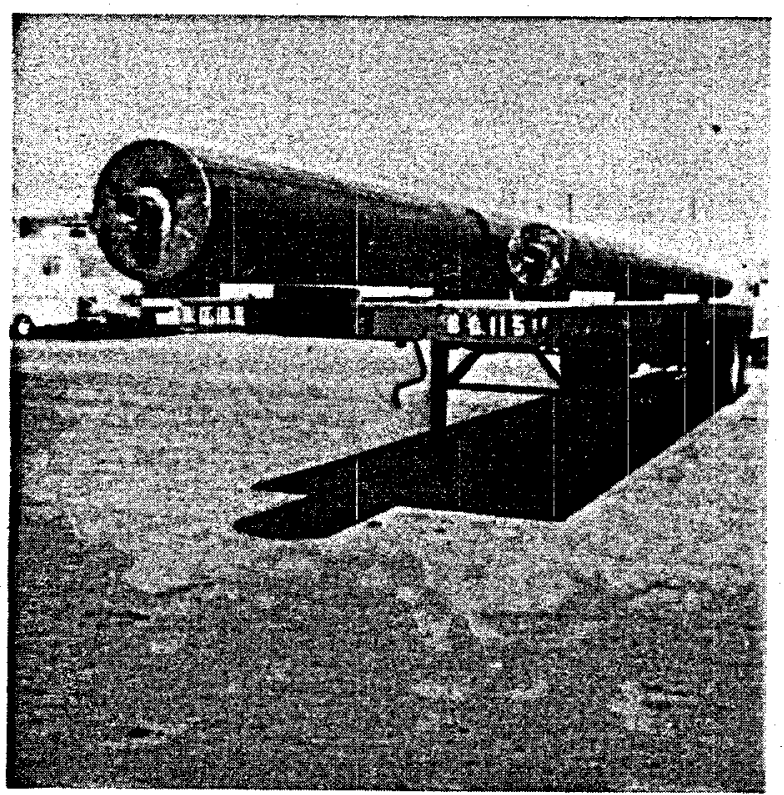

"Pigs". Before Insertion in Well to Check Clearances

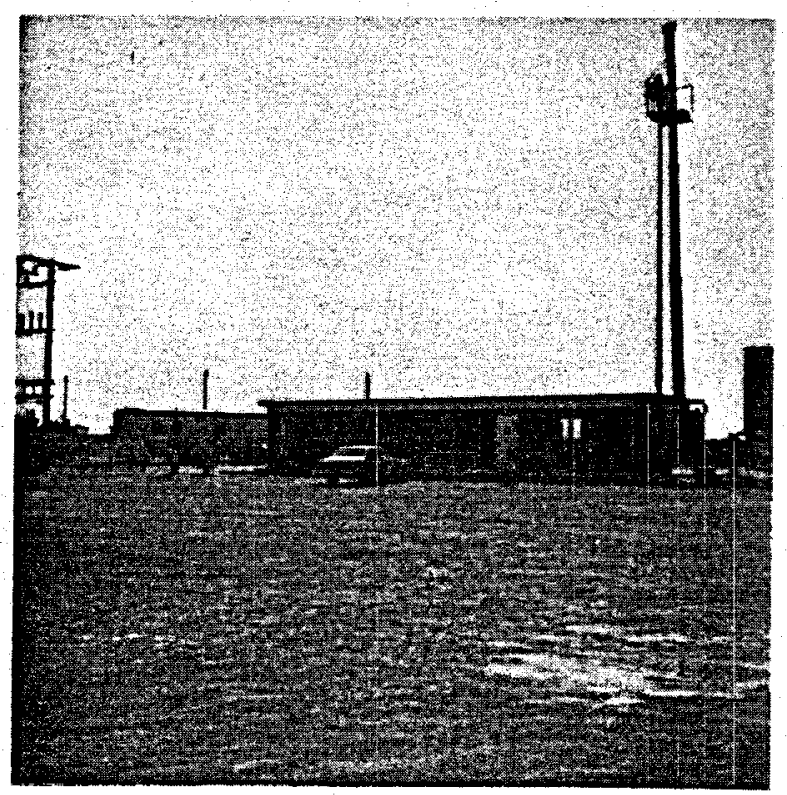

Control and Office Builing 


\section{t)}

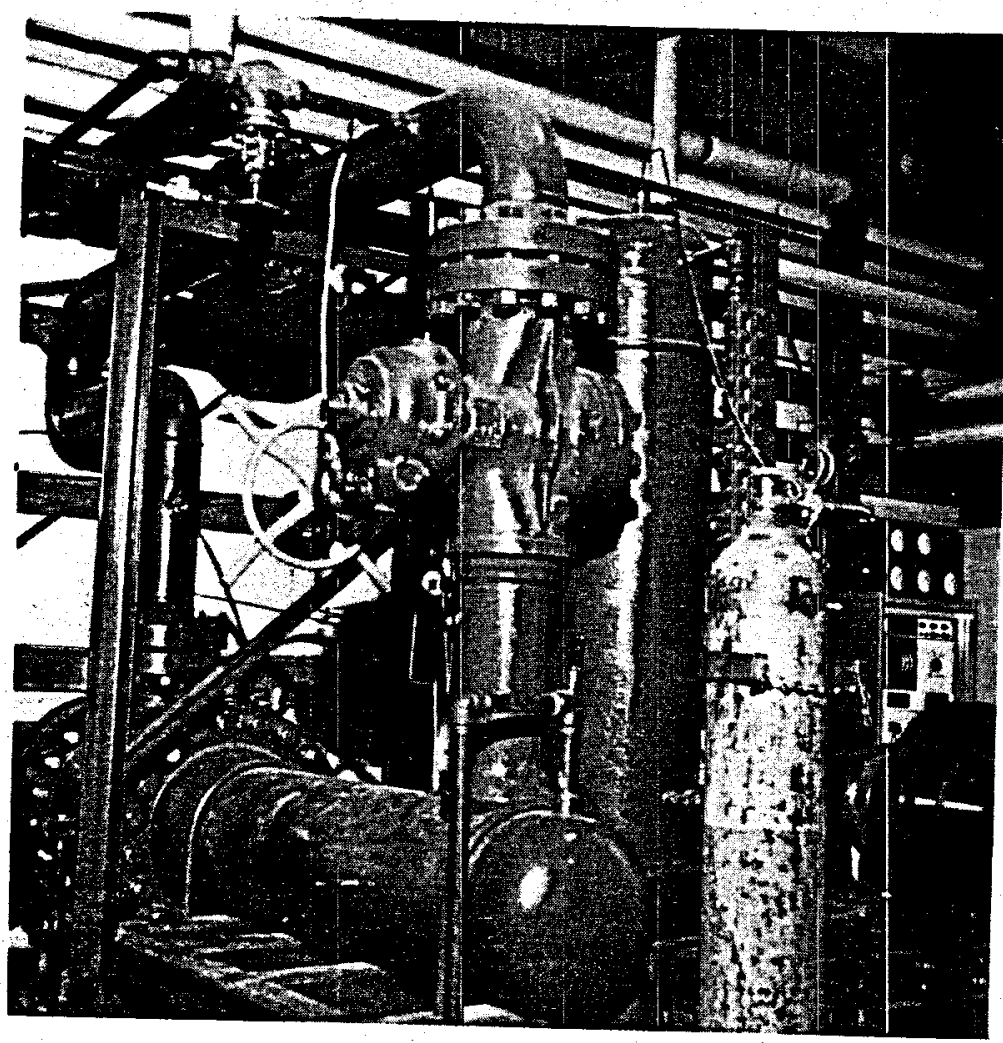

Pump Inpeller Test Rig

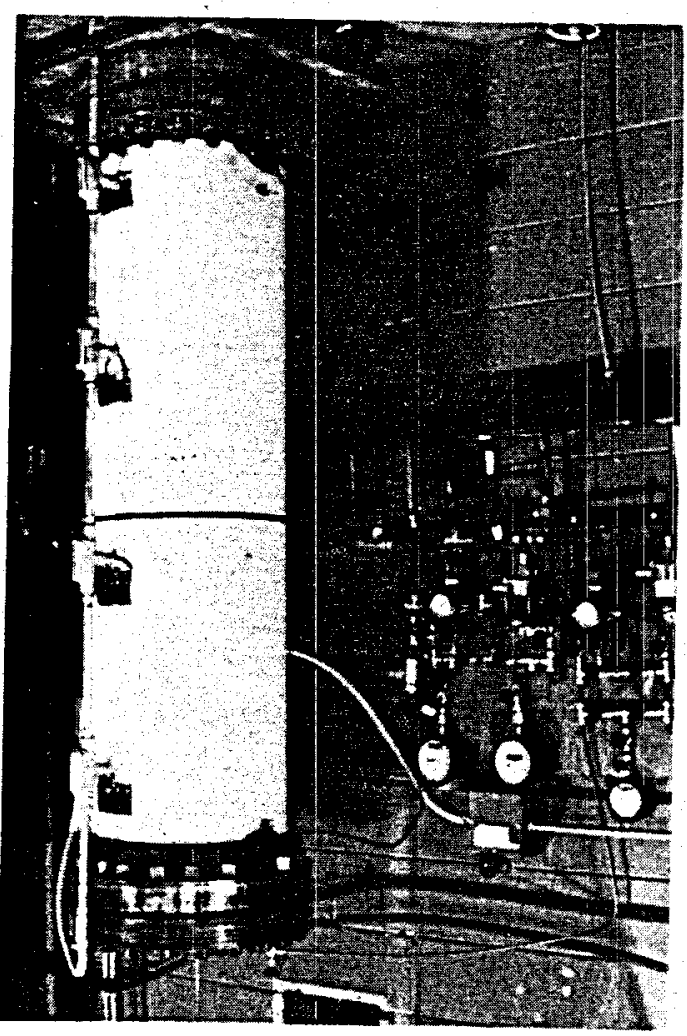

Packer Test Rig 


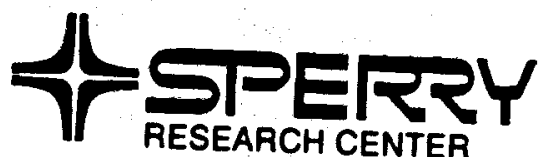

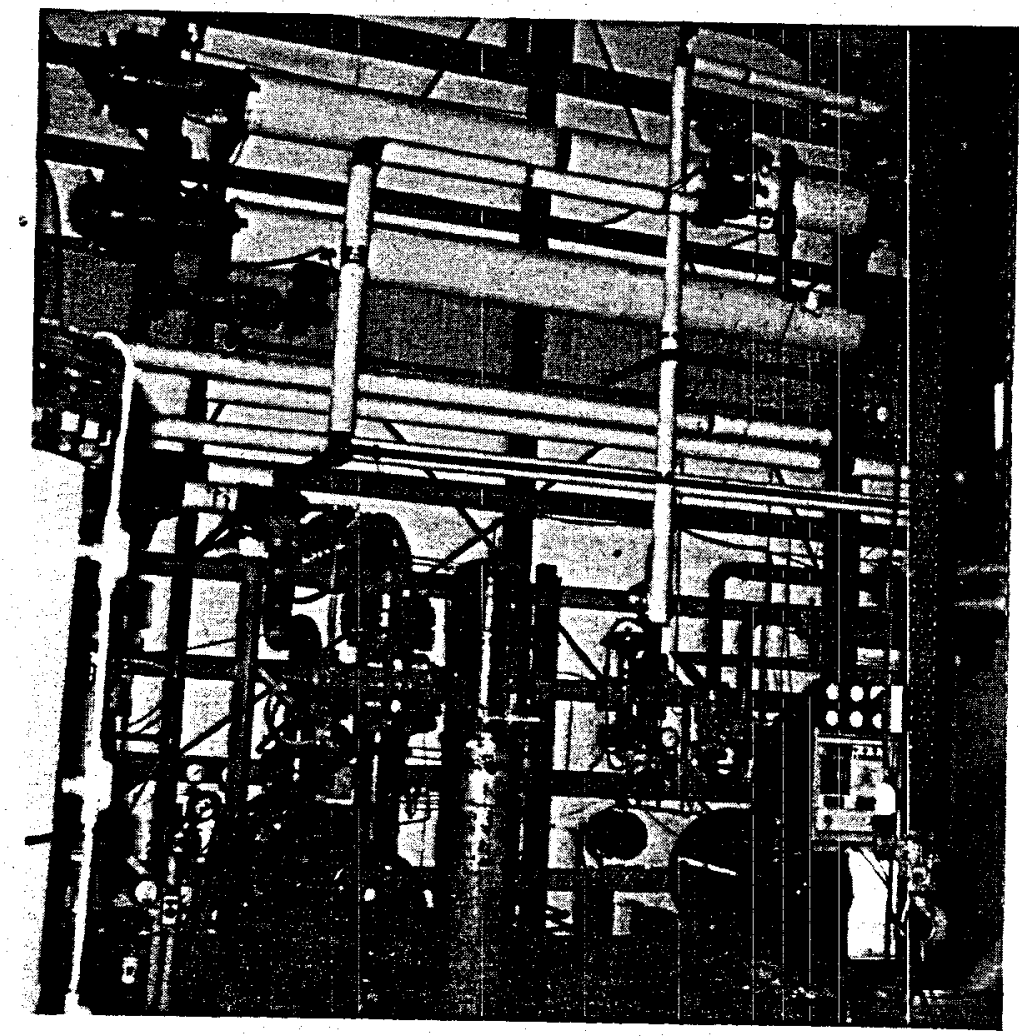

Part of R114 Test Loop

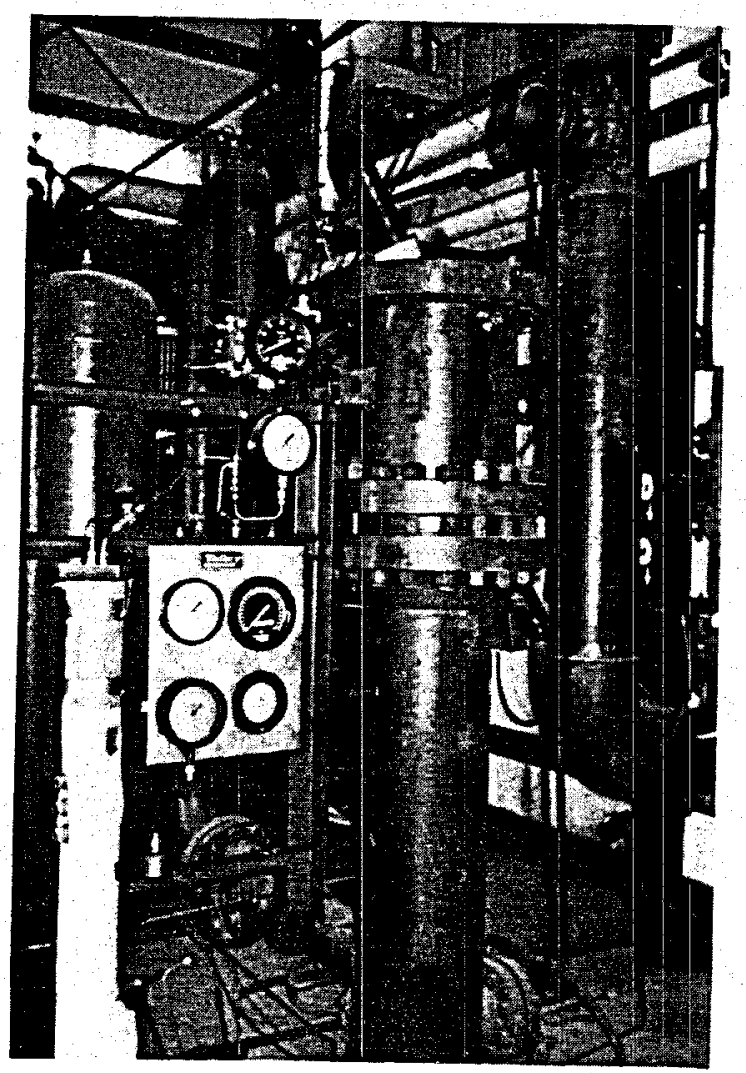

Sliding Seal Test Rig 


\section{th}

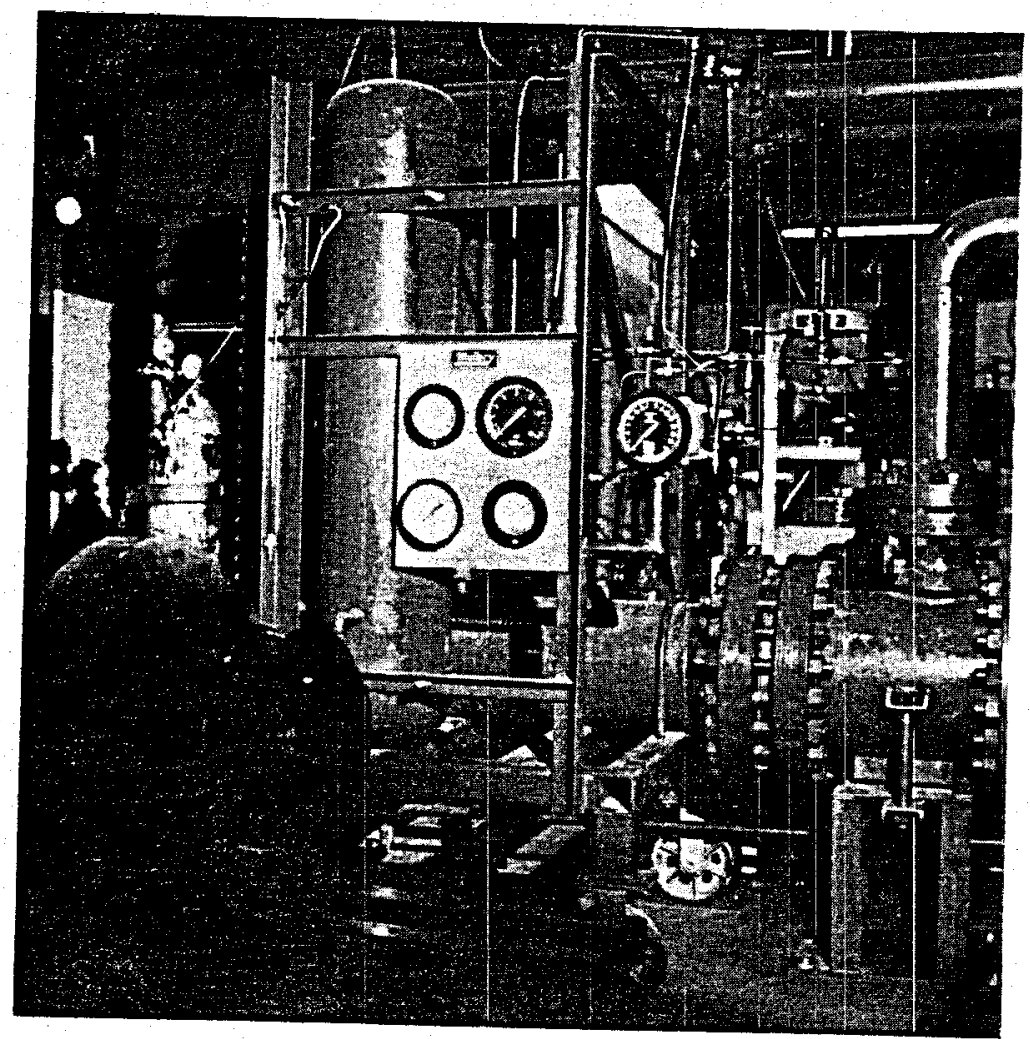

Pump Test Loop

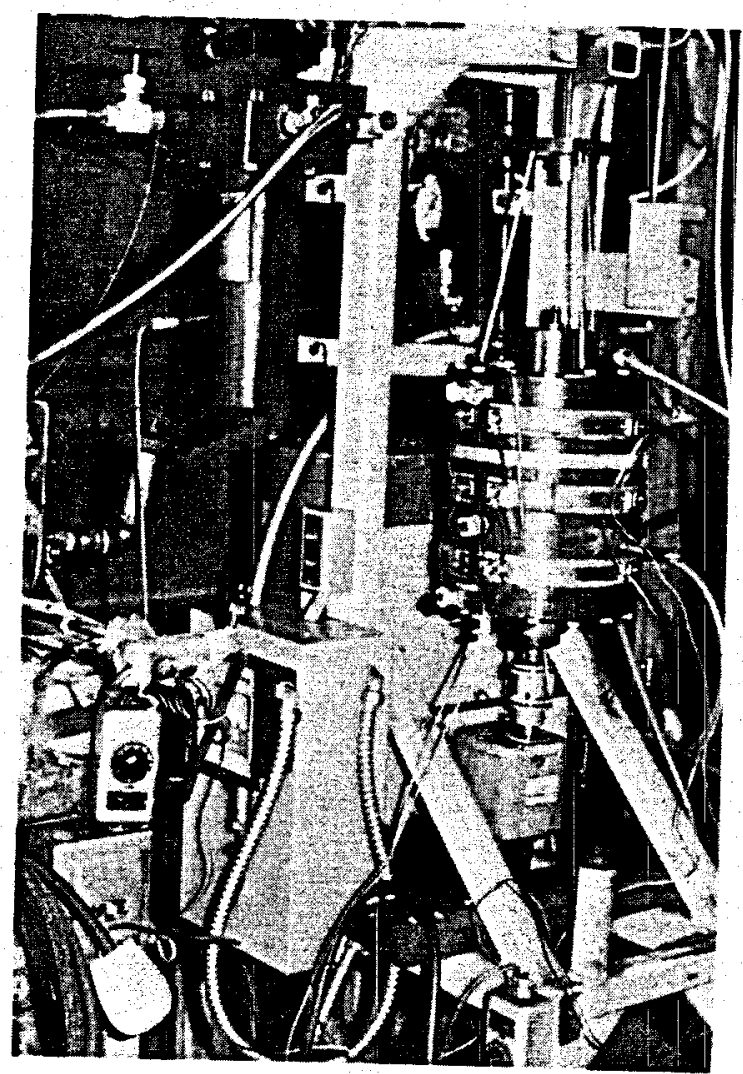

Bearing Test Rig 


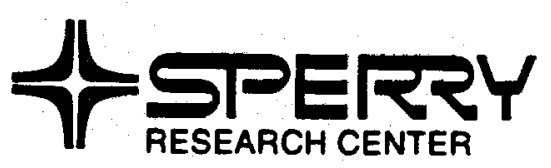

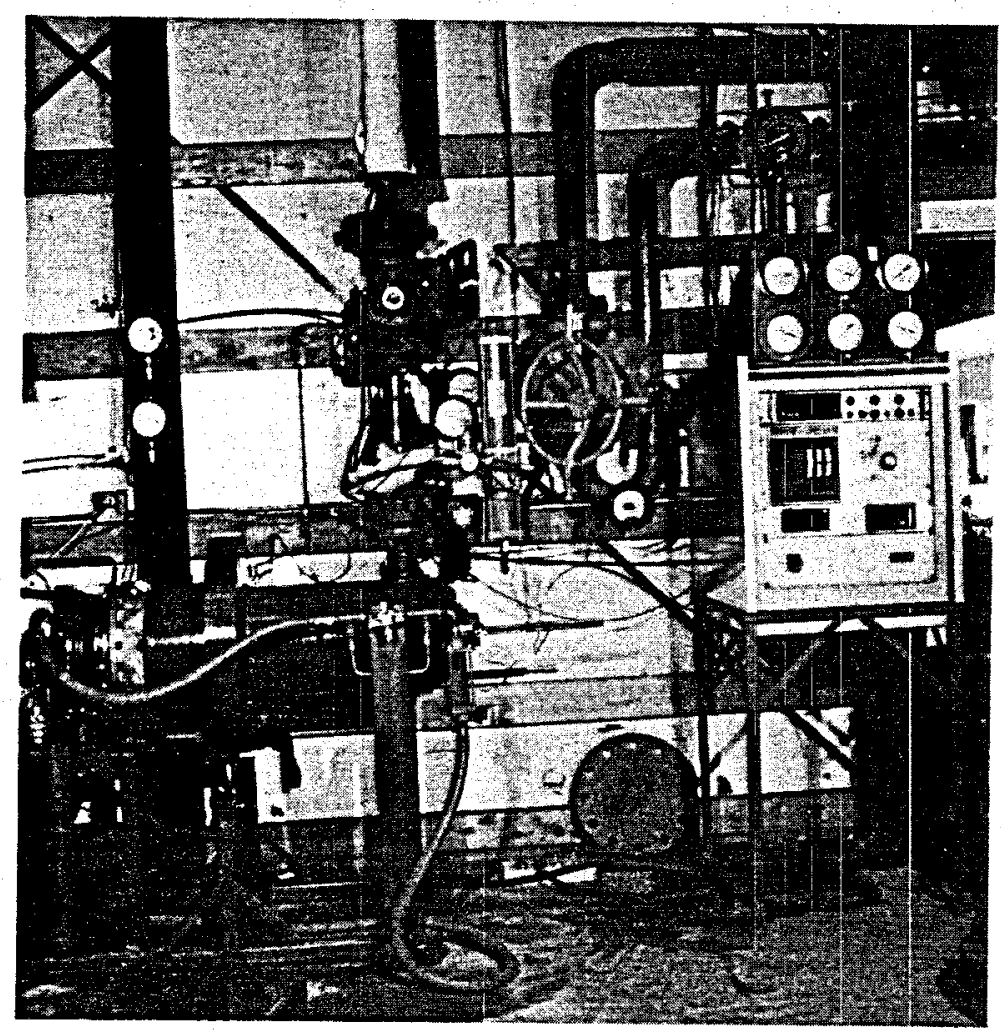

Water Brake Pump Turbine Test Rig

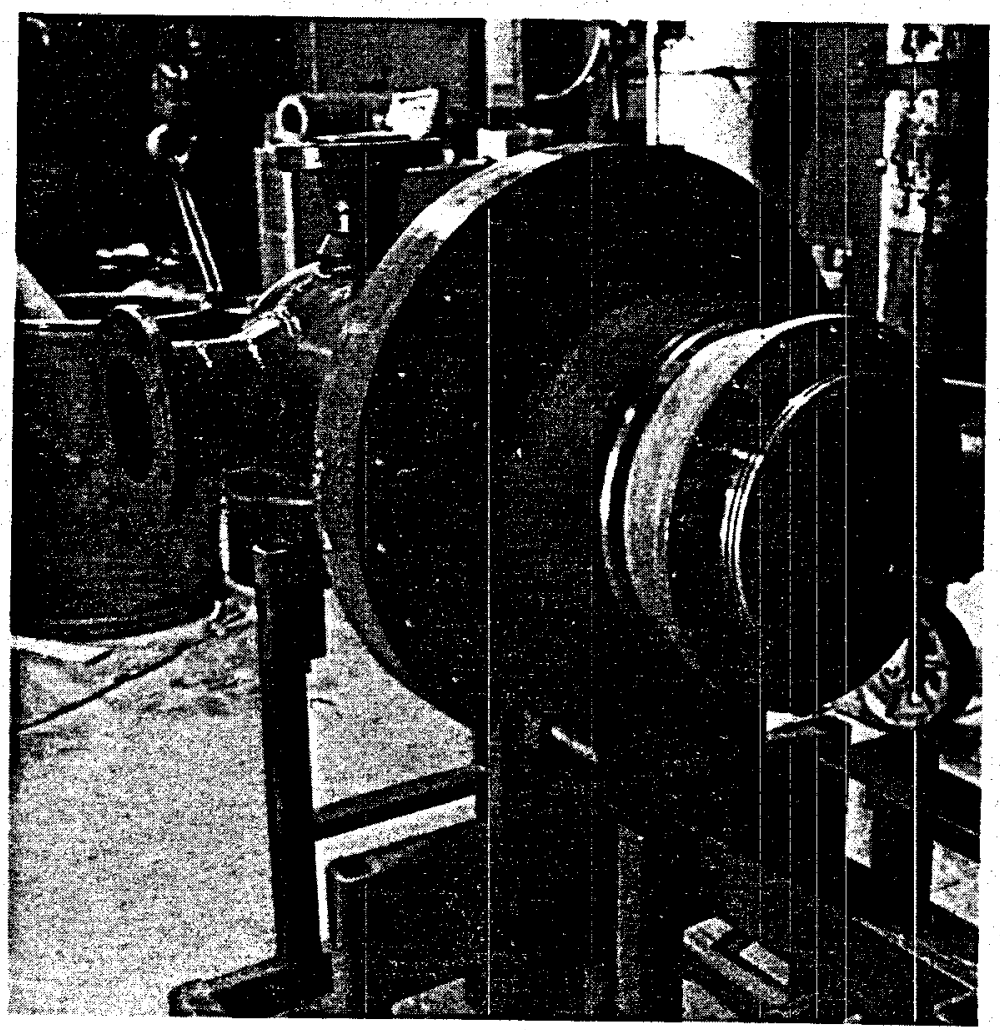

Turbine Test Input Manifold 


\section{t)}

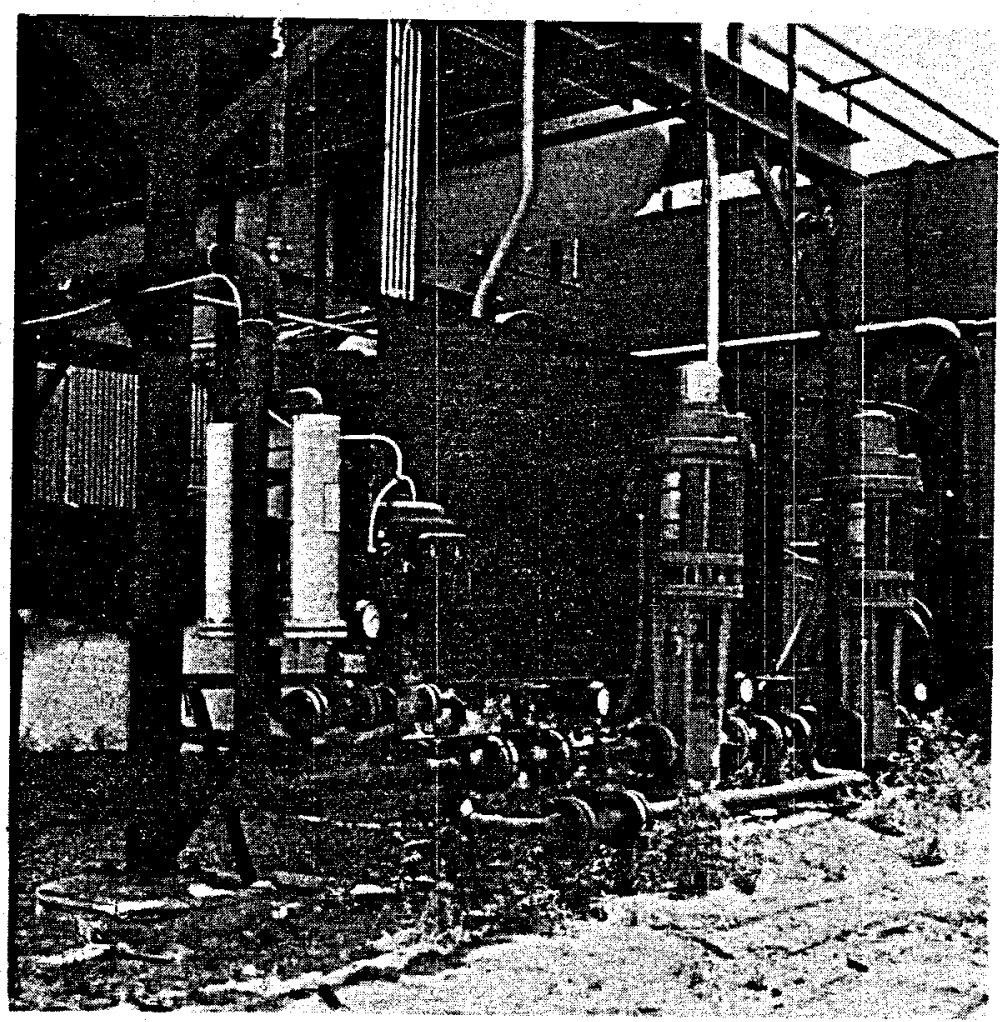

Part of R114 Test Loop

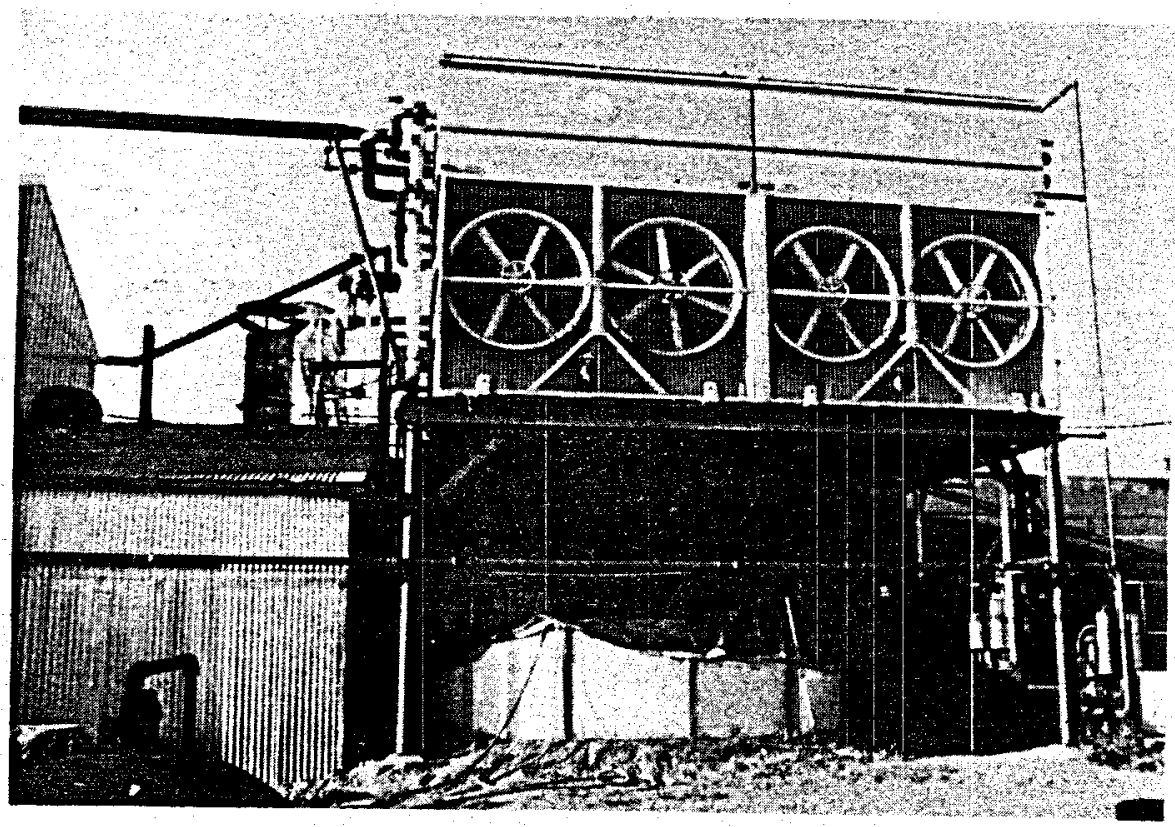

Evaporative Condenser (Part of R114 Loop) 

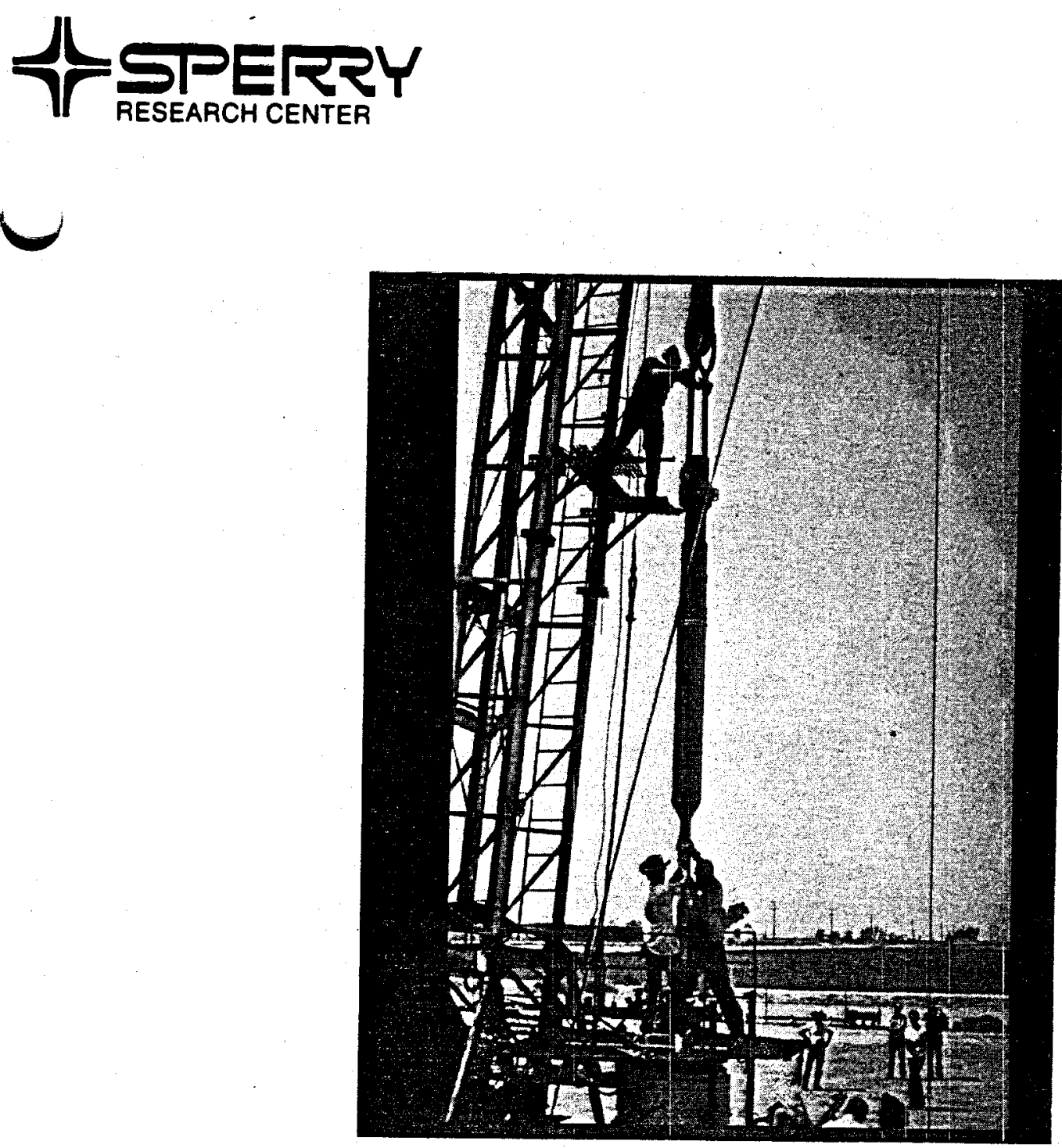

Heber Pump Test - 1976

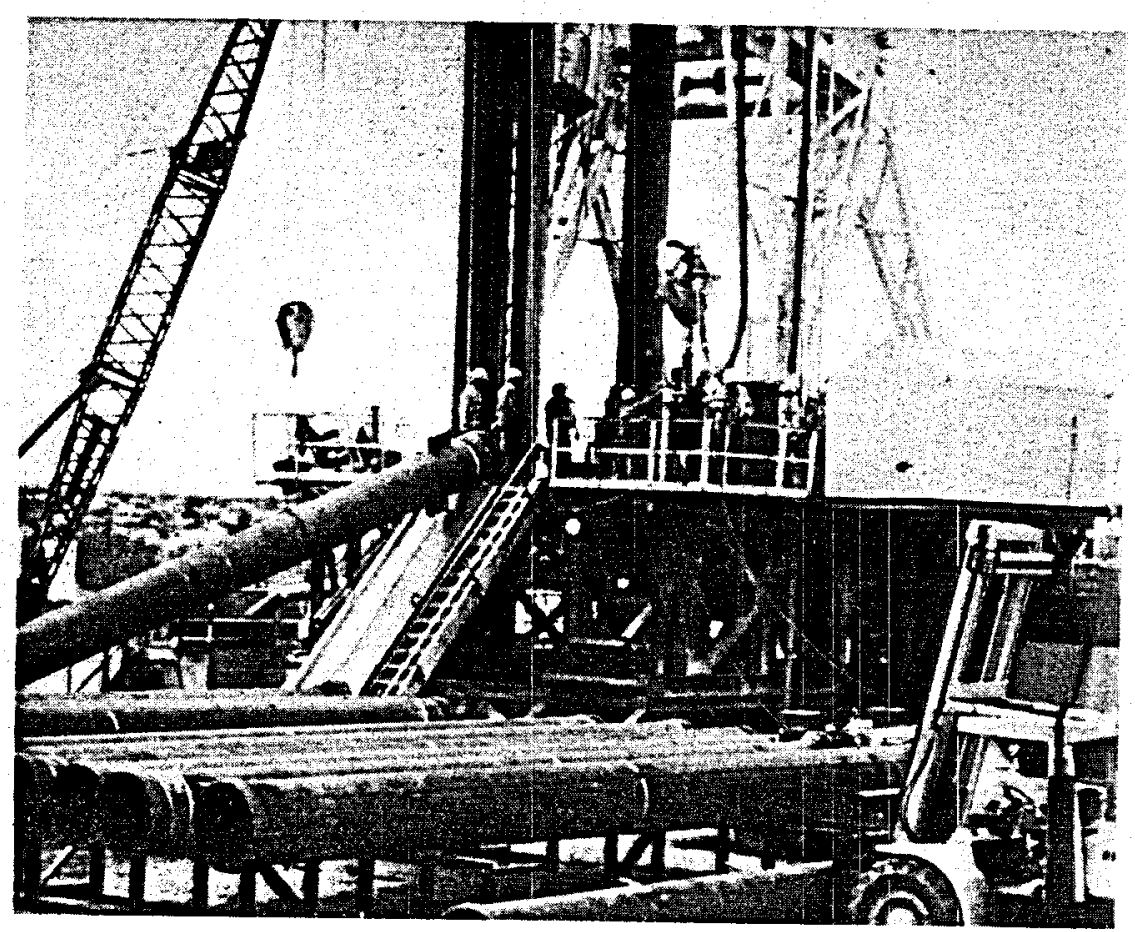

Well Drilling - East Mesa, 1980 

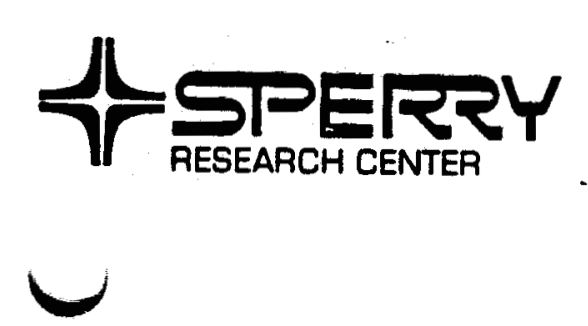

\author{
APPENDIX B \\ FEASIBILITY DEMONSMRATION \\ OF THE SPERRY DOWN_WELL PUMPING SYSTEM \\ EXECUTIVE SUMMARY \\ OF THE FINAL REPORT
}

May, 1977 


\section{INTRODUCTION}

Down-well pumping (vs. free-flowing) of geothermal hot water wells offers several potential benefits:

- Inhibition of precipitation and scaling by prevention of flashing and $\mathrm{CO}_{2}$ release.

- Higher wellhead brine temperature and, hence, conversion efficiency.

- Enhanced flow.

To achieve these benefits, a down-well pumping system must have the following features:

- Highest possible efficiency (Hydraulic Output/Brine Thermal Input).

- Deep setting (at least 2,000 feet).

- Compatibility with geothermal temperature, chemistry, installation, and operating environment.

- Cost effectiveness in terms of initial installation. operation, and maintenance costs.

In July 1972, Mr. Hugh B. Matthews of Sperry Research Center invented a novel system approach to geothermal down-well pumping which inherently offers advantages over other approaches with respect to these features. A Sperry-funded study over the next two years resulted in the granting of 11 patents (others pending) and an NSF grant in July 1974, to pursue laboratory experiments to be followed by a concept feasibility demonstration in a geothermal well. In 1975, ERDA assumed support of the field 
experiment which was completed in 1976. This report is an executive summary of the system and program descriptions and of laboratory and field test results and conclusions. The companion Final Report (SCRC-CR-77-48, May 1977) provides more detail. 
DESCRIPTION OF PUMPING SYSTEM

The basis of the Sperry down-well pumping concept is that the downhole pump obtains its energy to pressurize the brine directly from the heat of the brine itself. The principle involved is shown in Figure 1. A small quantity of working fluid (less than 2 percent of the brine flow) is pumped from a surface system down to the pumping unit through a downhole heat exchanger, which consists of two annuli formed by the well casing and two concentric lengths of standard oil field casing. The working fluid flows down the inner annulus, and the hot brine flows up the outside annulus. The intimacy of these streams results in heat being transferred from the brine across the boiler wall and into the working fluid, resulting in its vaporization. The working fluid vapor is used, to drive a turbine, which in turn drives the pump impeller. This extraction of thermal energy from the hot well water downhole at the site of the pump minimizes the number of energy conversions necessary to power a pump. The steam exhaust is returned through the exhaust casing to the surface, where it is condensed and then sent back downhole for another cycle. The working fluid is contained in its own closed loop. and the brine is excluded from this subsystem.

A small portion of the working fluid is conveyed down to the turbine-pump unit under pressure and in the liquid state to lubricate the turbine bearings. Since this liquid is at a higher pressure than the brine, the contaminated brine is excluded from the bearing cavity.

Figure 2 is a schematic of the downhole turbine pump unit (TPU). The TPU consists of a mixed flow pump and a two-stage axial-flow turbine configured on a common shaft. The shaft is supported by two, three-element ceramic radial bearing assemblies located near the turbine and pump impeller. The shaft thrust load is carried by a six-element ceramic thrust bearing near the middle of the shaft. A ball bearing was provided to carry the reverse thrust that exists low pump speeds during startup and shutdown. The 
bearing cavity is sealed from the brine flow by ace seal located behind the pump impeller. Excess bearing leakage is controlled by a similar seal located at the turbine end of the TPU. The turbopump assembly with the pump cover housing removed for clarity is shown in Figure 3 . The TPU housings were fabricated from Monel 400 while the shaft, turbine and pump impeller, and other higher stressed components were made from Armco 15-5 PH. The water lubricated bearing surfaces, both static and runners, were made from high purity Alumina ( 99.9 percent).

Two basic pump configurations were designed and fabricated: one for $2,270 \mathrm{l} / \mathrm{min}(600 \mathrm{GPM})$ and one for $3,400 \mathrm{l} / \mathrm{min}$ ( $900 \mathrm{GPM}$ ) brine flow, i.e., 20,000 and 30,000 BPD, respectively. Both units were laboratory tested, but only the $3,400 \mathrm{l} / \mathrm{min}$ pump was used in the downhole testing. Design specifications common to both units are as follows:

\begin{tabular}{ll} 
Speed & $17.000 \mathrm{rpm}$ \\
$\Delta P$ & $149.2 \mathrm{~N} / \mathrm{cm}^{2}(216.4 \mathrm{psid})$ \\
& \multicolumn{1}{c}{ or } \\
& $175.7 \mathrm{~m}(576.5 \mathrm{feet})$ head \\
NPSH & $61.7 \mathrm{~m}(202.5 \mathrm{feet})$ or \\
& $52.4 \mathrm{~N} / \mathrm{cm}^{2}(76.0 \mathrm{psi})$
\end{tabular}

The impeller blade angle is a constant $20^{\circ}$ throughout the impeller measured at the RMS diameter. This low blade angle was chosen to minimize pump cavitation. An open impeller design was selected to simplify manufacturing. Thrust balance was accomplished by venting the back side of the impeller to pump inlet pressure as shown in Figure 4.

The turbine consists of an inlet nozzle block, two rotating blade rows, and a stator located between the moving blade rows. After expansion through the turbine, exhaust steam must be turned and sent back to the surface. To accomplish this within the available package size, the steam is routed back through the center of the turbine hub section. To minimize the losses of passing the flow through the hub, it was designed with air foil 
section spokes. Steam flow was assumed to enter the blades axially, and the blade angle was chosen to provide an angle of attack such that head rise equals pressure loss. Two turbine configurations were developed to match the power requirements of the high and low flow pump. Figure 5 is a schematic showing the design geometry for the higher power turbine.

The above ground support hardware which closes the pumping system loop is referred to as the surface system. The surface system is a skidmounted assembly for condensing the turbine exhaust steam and for supplying boiler and bearing water. It also serves as a means to start, control, and stop the downhole turbine pump unit. Figure 6 is a photo of the surface system awaiting installation at Heber. To understand the functioning of the surface system, a simplified schematic is provided in Figure 7.

The downhole boiler consists of a liquid preheater annulus and an evaporator annulus with the preheater beginning at the wellhead and being separated from the evaporator by a circular plate with carefully sized orifices. The pipe sizes for the downhole boiler were selected on the basis of pressure drop calculations using minimum wall thicknesses suitable for Hydril Flush Joint low-pressure-drop couplings. The boiler was formed by $\therefore$ the pipe sizes shown in Figure 8 , with the hot brine flowing upward between the $32.042 \mathrm{~cm}(12.615-i n c h)$ I.D. well casing and the boiler pipe. The figure shows the $27.305 \mathrm{~cm}(10.75-\mathrm{inch}) 0 . \mathrm{D}$. evaporator pipe which is located below the $24.448 \mathrm{~cm}$. (9.625-inch) 0.D. preheater pipe. The outer pipe size is reduced in the preheater to increase the water velocity and heat transfer coefficient. The preheater is approximately 12.8 meters (42 feet) long, and the evaporator section is 246 meters ( 808 feet) long. for a total boiler length of 259 meters ( 850 feet).

Fluid control devices in the downhole boiler are used to: (1) maintain the preheater full of water, and (2) direct the evaporator liquid fraction to the hot, outer pipe wall. To direct liquid water from 
the exhaust pipe to the hot, outer evaporator wall, the evaporator uses swirl vanes or "swirlers." The swirlers, attached on the 0.D. of the 21.9 $\mathrm{cm}(8-5 / 8 \mathrm{inch})$ casing direct the liquid to the outer wall (inner wall of the $27.3 \mathrm{~cm}(10-3 / 4 \mathrm{inch}))$ casing by a combination of centrifugal force and by providing a "ramp" along which the water can run. Design of the swirlers was based on toss fraction, low pressure drop, ease of fabrication and assembly of downhole concentric pipes, and their ability to fit in the minimum annulus defined by dimensional limits on the boiler exhaust pipes. 


\section{LABORATORY TEST PROGRAM}

The maj or objective of the TPU laboratory test program was to establish the overall performance of the TPU operating on steam with conditions similar to those anticipated in a geothermal well. In addition, since little in the way of downhole instrumentation was anticipated at the test site, it was further required that extensive laboratory tests be conducted prior to field installation to establish the TPU's performance and to take sufficient data such that field performance of the unit could be inferred and controlled from surface measurements.

The test program followed quite closely the following scenario. It first verified that the bearings and shaft power losses were approximately $1.5 \mathrm{KW}(2 \mathrm{hp})$ at design speed as predicted. The next step was to add the pump impeller and measure pump performance over a speed and flow range. The pump head-flow performance and efficiency data could be measured since the unit, at this point, was being driven by shaft power rather than the steam turbine. Input power was determined by a torque meter installed on the drive shaft. During these shaft-driven tests, the thrust load was measured and design modifications made to bring the resultant thrust to a value compatible with the load capacity of the water thrust bearings. Pump suction specific speed performance and net positive suction head (NPSH) requirements were also evaluated during the shaft-driven tests. The performance of the high flow pump is shown in Figure 9. The pump efficiency measured at $Q / Q_{D}=0.92$ is 77 percent. This total to static efficiency is approximately three points lower than measured for the low flow impeller. The lower static efficiency is due to the higher fluid velocities leaving the pump. If the pump discharge area was increased by 50 percent, the efficiencies of the low and high flow pumps would be essentially the same. 
After the pump was calibrated, it served as a dynamometer to evaluate the performance of the turbine during the steam testing of the overall unit. The steam tests, therefore, provided overall TPU performance data and component performance data at the same time.

The TPU was operated in the laboratory steam test facility for a total time of 252 hours. The turbine inlet steam conditions were essentially saturated during this testing, and the adiabatic head was determined as the isentropic expansion of steam between the turbine inlet pressure and exhaust pressure. The product of adiabatic head and turbine flow rate measured by an ASME orifice give the ideal turbine power. The pump and bearing power as a function of speed and flow as measured by the shaft-driven tests were used to provide a measure of turbine efficiency $\left(\eta_{t}\right)$. Turbine efficiency was also measured using a simple air test rig. Values of deduced turbine efficiency from Run 3 and the air test data are shown in Figure 10. As may be noted, an excellent correlation exists between the air turbine tests and the deduced turbine efficiency, thereby lending substantial credence to the measured values of component efficiencies and parasitic losses.

The TPU overall performance exceeded the design goals. Design pump flow rate and pressure rise were achieved at less than design turbine steam consumption rates. Turbine performance was lower than predicted; however, the increase in pump efficiency and lower shaft and bearing losses more than compensated for the low turbine performance. 
GEOTHERMAL NELL TEST

The selection of test site was critical decision and was made only after having extensively studied the Known Geothermal Resource Areas (KGRA) in the Imperial Valley in southern California. A study of the geothermal facilities at the existing wells in these areas quickly narrowed the choice down to the Salton Sea KGRA and the Heber KGRA. The Salton Sea KGRA has a bottom hole temperature (BHT) on the order of $288^{\circ} \mathrm{C}\left(550^{\circ} \mathrm{F}\right)$ and salinity on the order of $300,000 \mathrm{ppm}$ total dissolved solids (TDS), while those in the Heber KGRA are on the order of $177^{\circ} \mathrm{C}\left(350^{\circ} \mathrm{F}\right) \mathrm{BHT}$ and $15,000 \mathrm{ppm}$ TOS. Considering the documented problems encountered at the Salton Sea, the lower temperature and salinity of the Heber field made it a more prudent selection for the initial pump tests even though the brine temperature was at about the minimum for a steam-driven pump, leading to low efficiency.

The site selected in the Heber KGRA is a joint venture of the Cherron Resources Company, San Diego Gas and Electric Company, and Magma Power Company, with daily field operations the responsibility of Chevron Resources Company. The production well is identified by the name, J.D. Jockson, Jr., \#1, and the re-injection well is named Holtz \#2.

The field test portion of this program covered approximately 240 days calendar time, of which only 42 days were spent conducting pump tests. Problems with the new equipment were anticipated, but those with the oil field hardware were not. This point should not be overlooked. As again demonstrated, the problems of the geothermal field are dramatically different from those of the oil field. Successful exploitation of geothermal resources will require hardware specifically developed to operate in its envi ronment.

The TPU attained the nominal level of performance in laboratory testing. However, the downwell performance fell considerably short of the 
nominal, the most representative performance being $1.5001 / \mathrm{min}$ (400 GPN) brine flow with $129 \mathrm{~N} / \mathrm{cm}^{2}$ (187 psi) pressure added at a speed of $13,000 \mathrm{rpm}$ at $0.77 \mathrm{~kg} / \mathrm{s}(1.7 \mathrm{lb} / \mathrm{s})$ feedwater flow rate. The main reasons for this shortfall were that the inlet brine temperature was $180^{\circ} \mathrm{C}\left(357^{\circ} \mathrm{F}\right)$; the well productivity varied from 20 percent to 50 percent of what had been designed for; and the boiler performance was about 40 percent of design (probably because of difficulty in tossing the liquid fraction of the two-phase flow to the outer, hot wall).

The total downwell operating time was 42 days, mostly in two continuous runs of 27 and 10 days' duration. However, the conditions of the unit after the 27-day run left little doubt that it could have continued at least another 30 days with little performance change if a storm and electric power outage had not shut down the operation long enough for the magnetite in suspension in the working fluid to settle into the TPU, preventing a restart. Except for sand erosion of the leading edge of the impeller vanes and the labyrinth seals, there were no indications of wear or erosion on which to base a failure time prediction. Basically, the TPU appears to be capable of at least 10,000 hours of life. It also survived very well the rugged field assembly/disassembly operations.

The Sperry pump system as tested was designed solely as a vehicle to gain experimental data and demonstrate mechanical feasibility. Efficiency of operation was at all times subordinated to the overriding consideration of simply being able to operate in a new environment. As a result of this plan plus the particular test conditions encountered at any given time, the highest efficiency observed corresponded to removal of $11^{\circ} \mathrm{C}\left(20^{\circ} \mathrm{F}\right)$ from the brine for each $69 \mathrm{~N} / \mathrm{cm}^{2}$ (100 psid) added.

There were three sources of energy loss in the test which are independent of brine flow rate and which could easily be corrected in a future system. These were (1) nonrecovery of superheat in the exhaust steam in the conduits; (2) heat transfer to the bearing lube water; and (3) subcooling of the condensate before re-admission to the boiler. 
Another reason for low performance in the test was operation of the condenser at atmospheric pressure. A future system would use water cooled condenser supplied by a wet cooling tower. All of the above changes are clearly feasible and relatively straightforward and inexpensive to implement and reduce the brine temperature drop required for pump operation to $3.7^{\circ} \mathrm{C} /\left(69 \mathrm{~N} / \mathrm{cm}^{2}\right)$ or $\left(6.7^{\circ} \mathrm{F} / 100 \mathrm{psi}\right)$. 


\section{CONCLUSIONS}

At the outset there was considerable doubt as to whether a pump based on this system concept could be started and run at a stable operating point. Concept feasibility in this sense was certainly proved by this test. The pump could be started without any auxiliary inputs or equipment and ran with negligible performance variation continuously for 27 days with so little attention and adjustment that unattended normal operation is clearly possible with an elementary control system.

Sufficient data were taken under a wide enough range of conditions to calculate a closed set of performance characteristics from surface measurements only. These data verified that the TPU was operating downwell on the characteristic curves measured in the laboratory. The Sperry pumping system using steam as the working fluid is a viable candidate for application in hydrothermal wells at temperatures from $180^{\circ} \mathrm{C}\left(360^{\circ} \mathrm{F}\right)$ to $240^{\circ} \mathrm{C}$ $\left(460^{\circ} \mathrm{F}\right)$. Although there is no inherent upper temperature limit of application, above $240^{\circ} \mathrm{C}\left(460^{\circ} \mathrm{F}\right)$ material problems are anticipated, and performance requirements might be different enough to require development efforts.

At temperatures below $180^{\circ} \mathrm{C}\left(360^{\circ} \mathrm{F}\right)$ a correctly chosen organic working fluid would be necessary to achieve acceptable efficiency. In fact, use of an organic working fluid would improve efficiency at higher brine temperatures as well. Figure 11 is a generalized curve of calculated pump efficiencies plotted against brine temperature. It assumes the correct choice of working fluid and system parameters for each temperature range. 


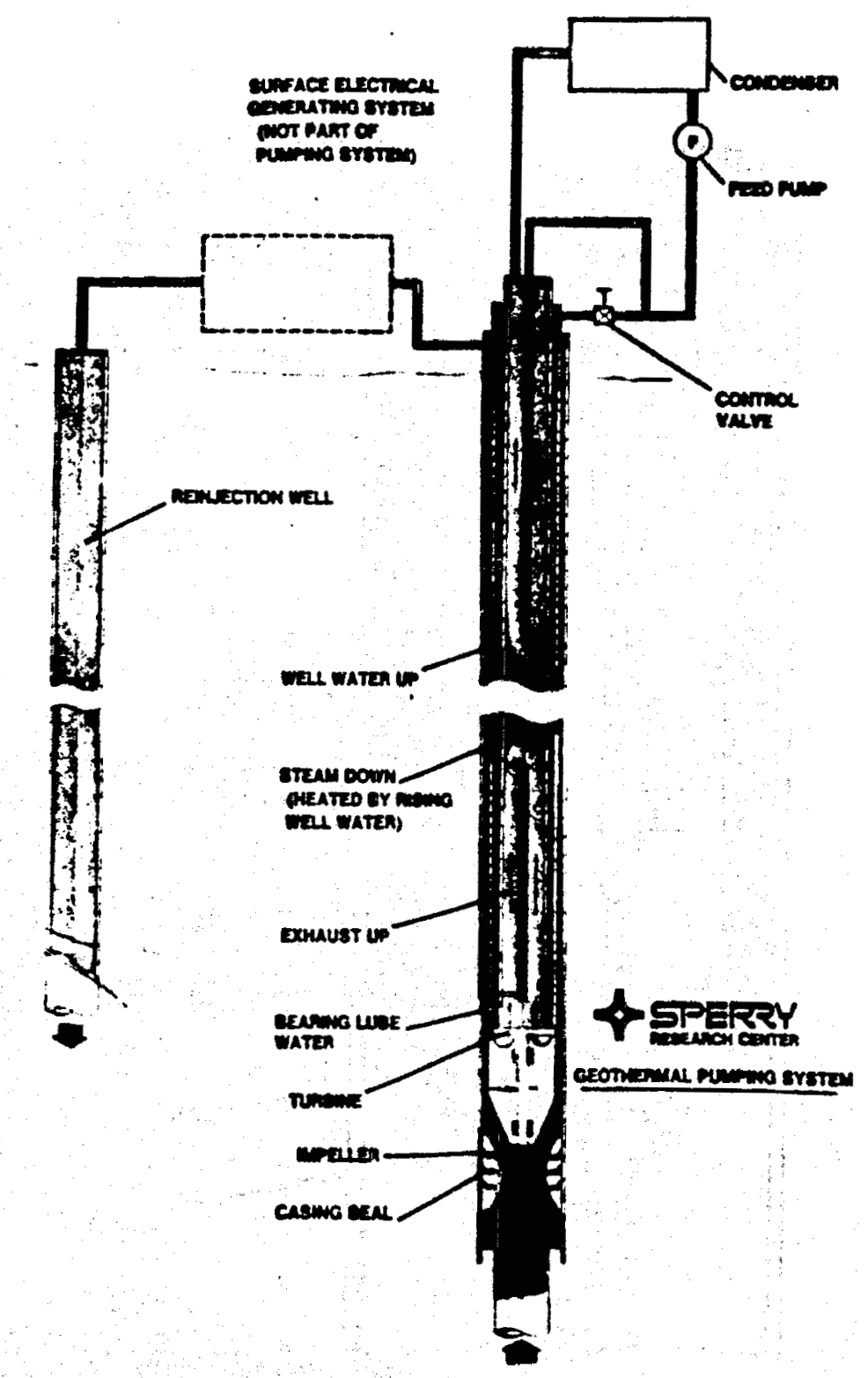

FIG. 1 Schematic of Sperry pumping system for geothermal well. 


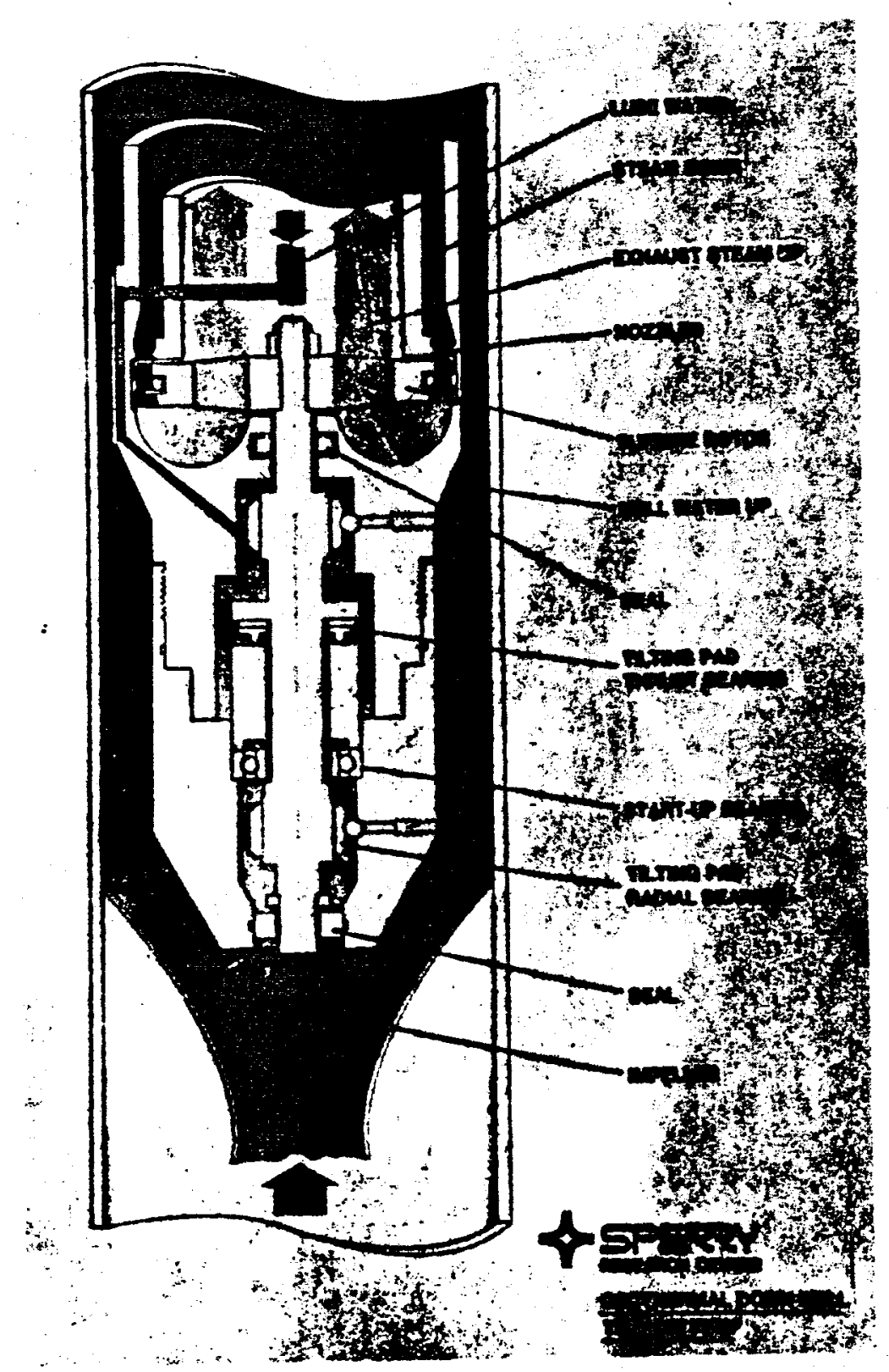

FIG. 2 Schematic of the turbine pump unit (TPU). 


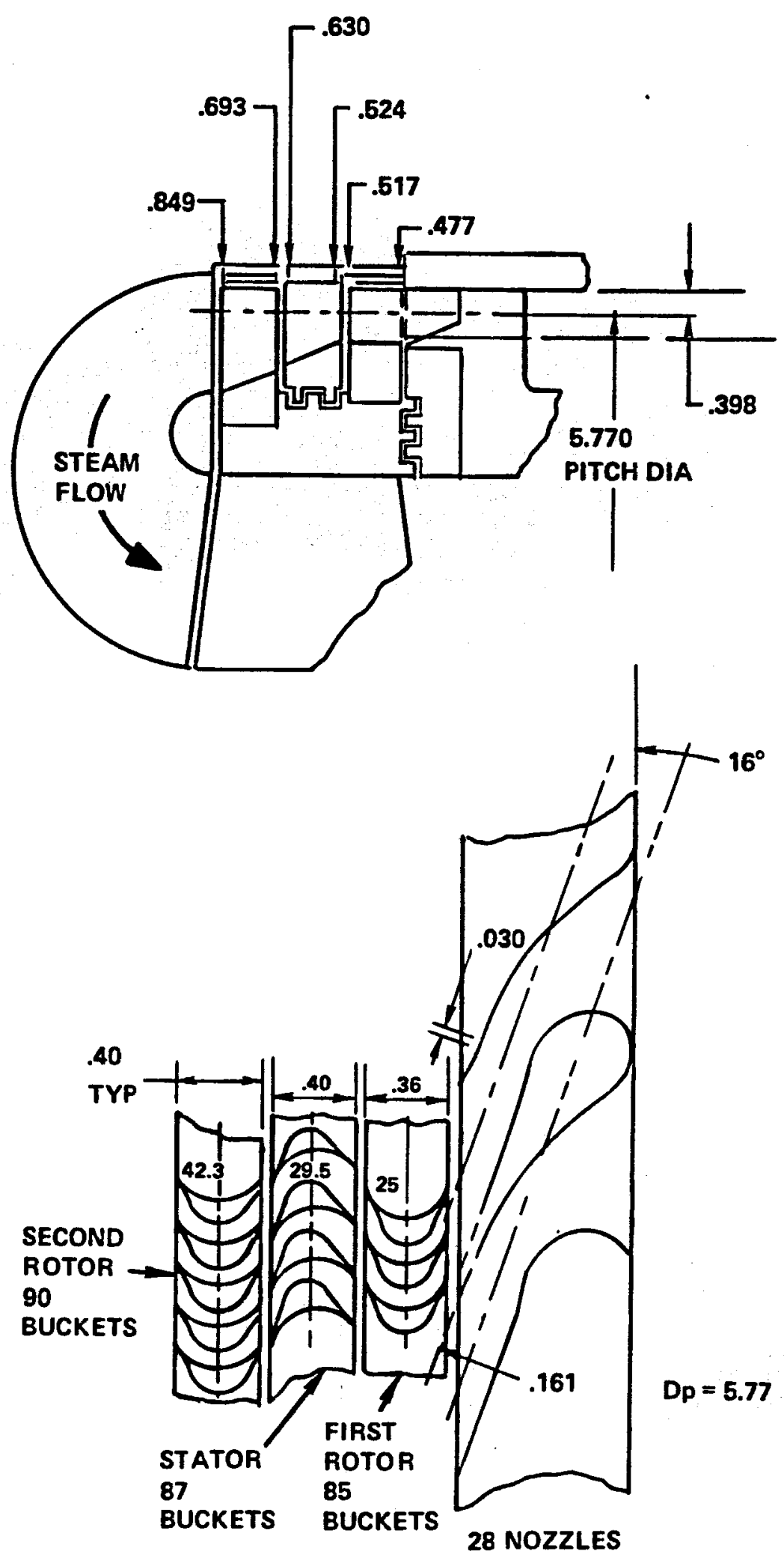

FIG. 5 Turbine design geometry. 


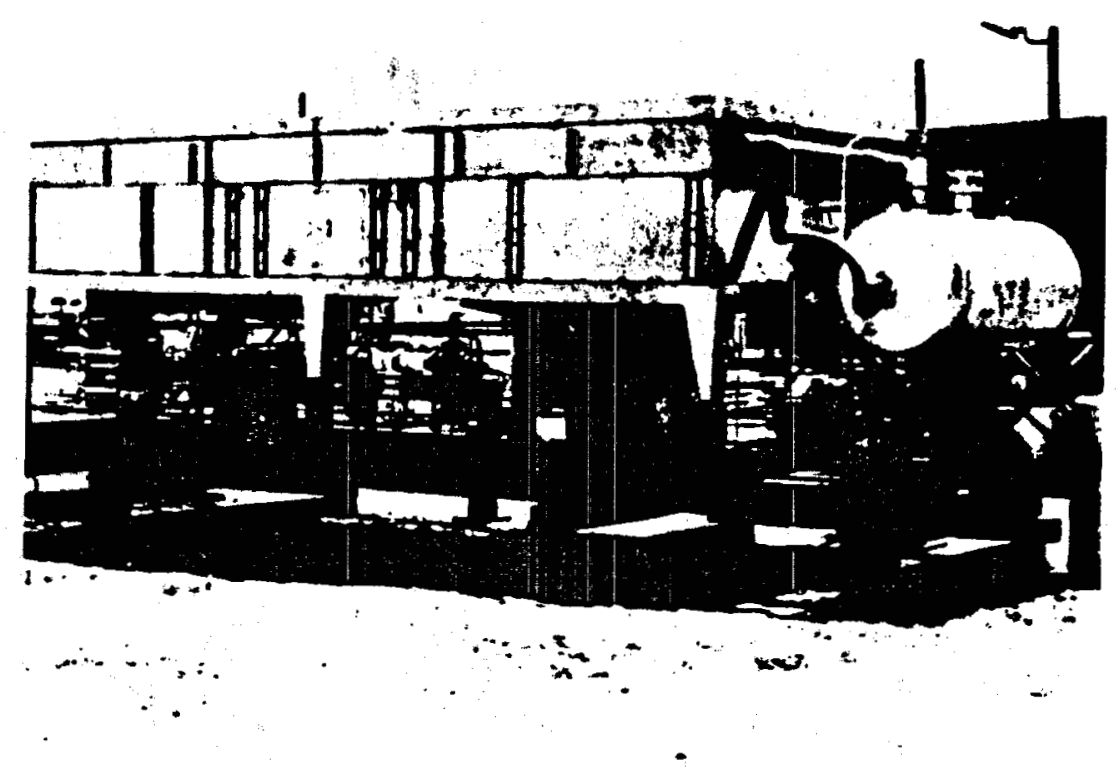

FIG. 6 Surface system.

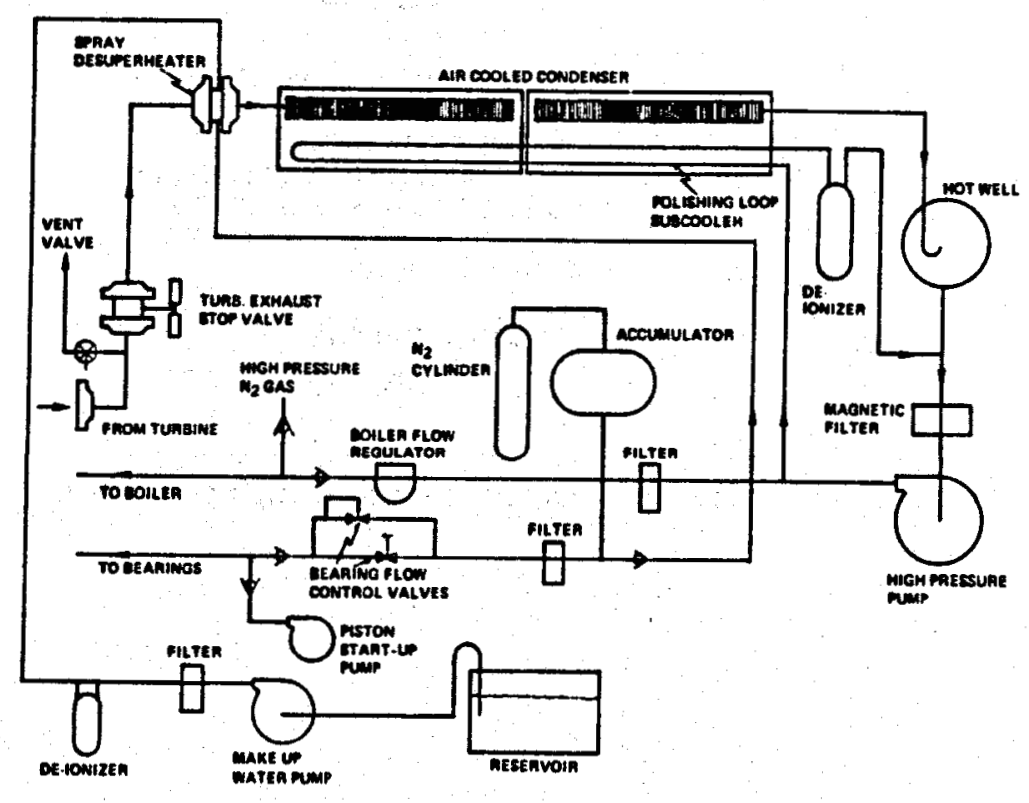

FIG. 7 Surface system schematic. 


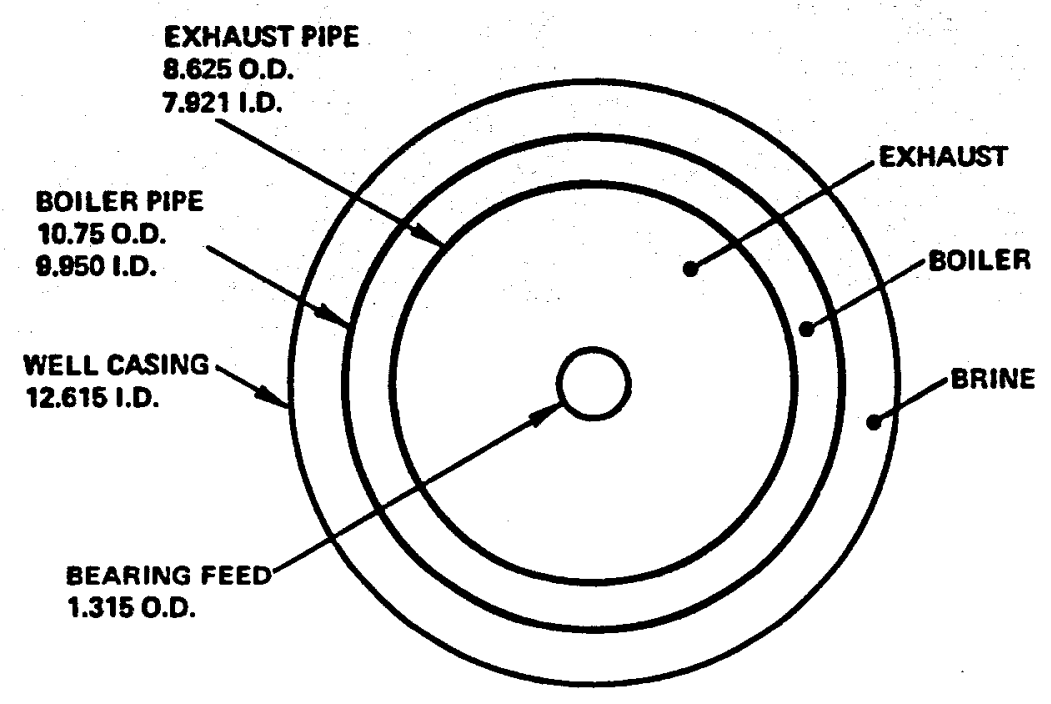

CROSS SECTION OF ASSUMED

DOWNHOLE BOILER TAKEN

ACROSS EVAPORATOR

PREHEATER IS SIMILAR EXCEPT

BOILER PIPE SIZE IS CHANGED

FROM 10.75 O.D. X 9.950 I.D. TO

9.625 O.D. X 8.835 I.D.

LENGTHS: BOILER $=808 \mathrm{FT}$

PREMEATER $=42 \mathrm{FT}$

FIG. 8 Downhole boiler pipe geometry. 


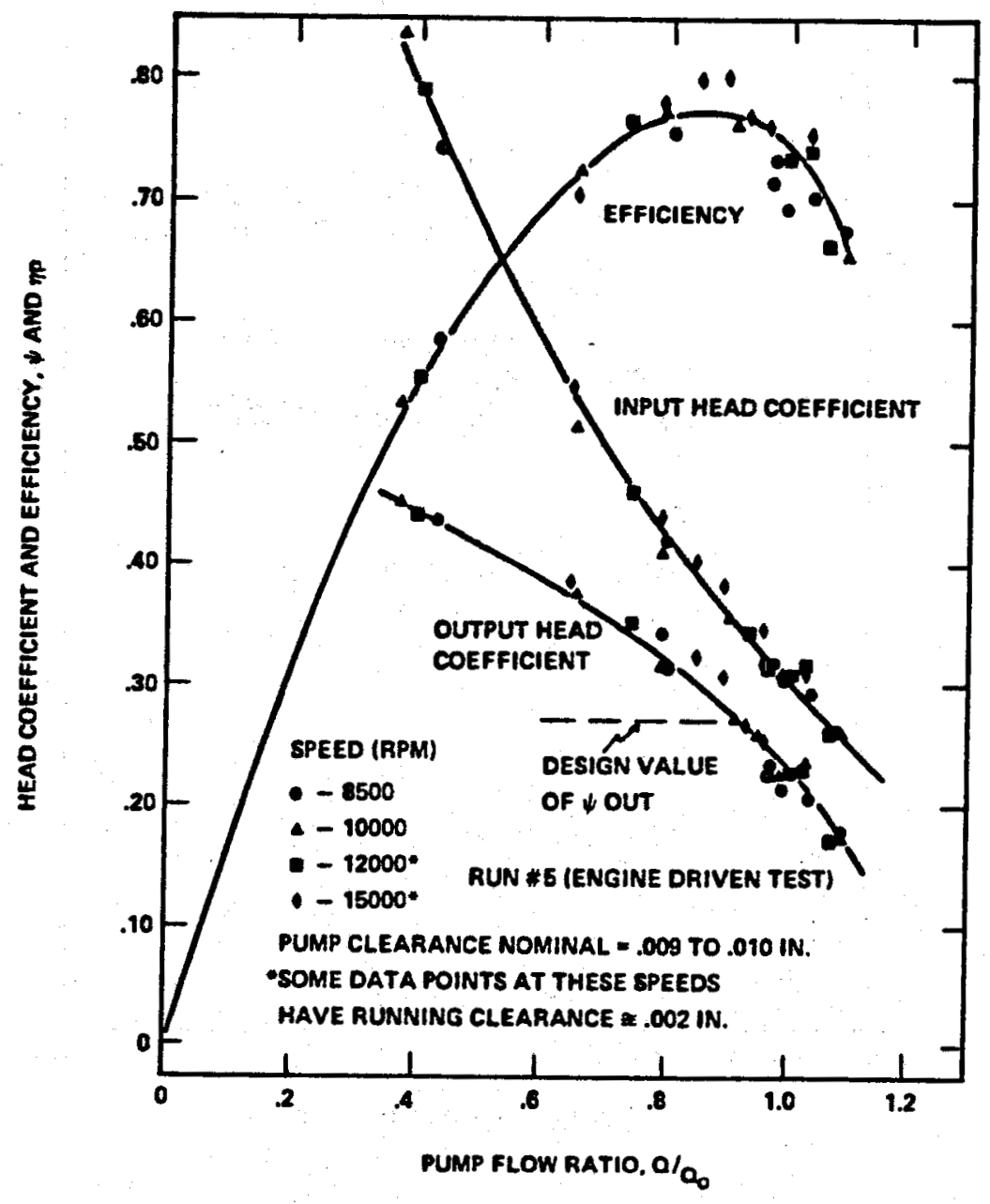

FIG. 9 High flow pump performance. 


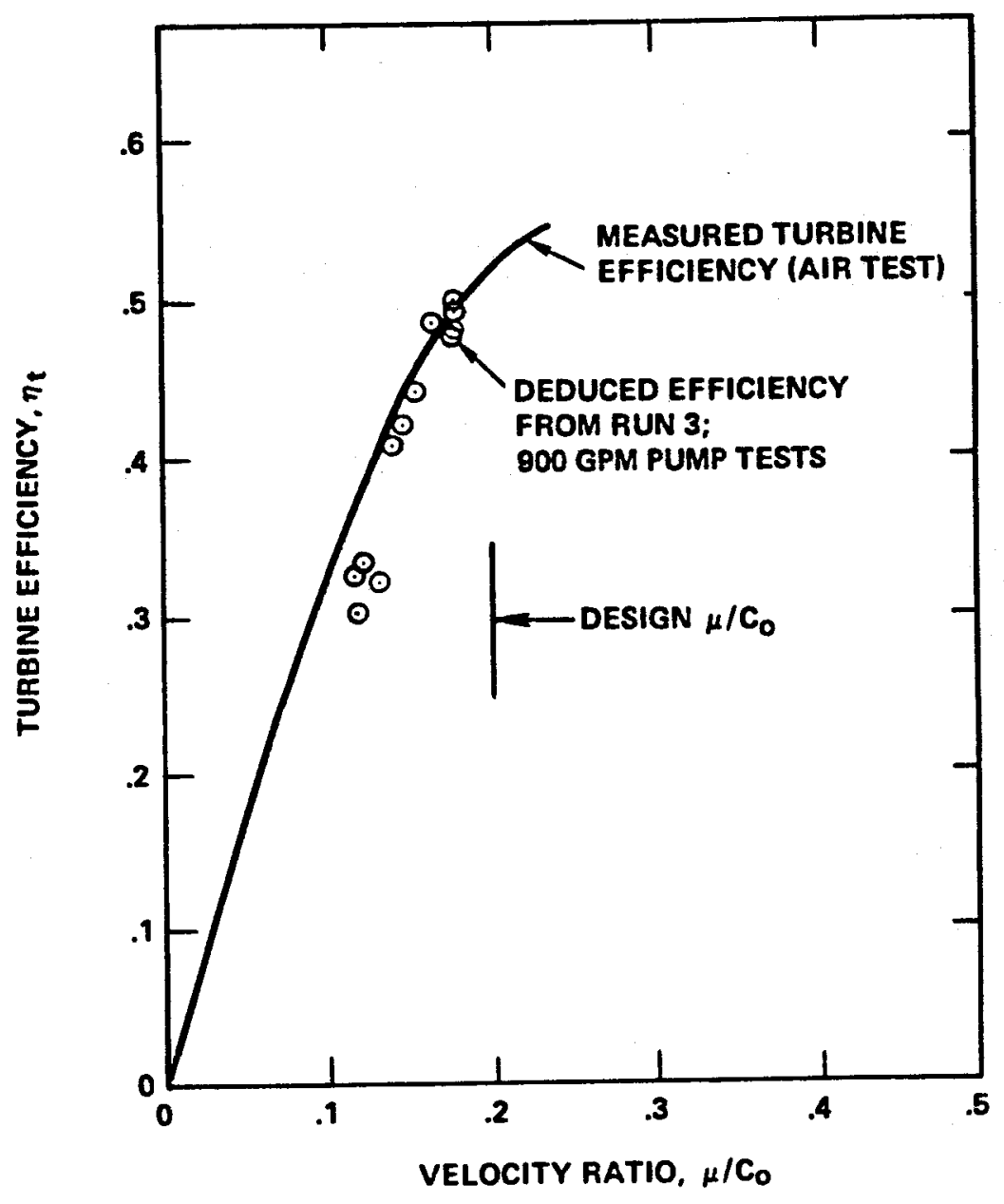

FIG. 10 Turbine performance. 


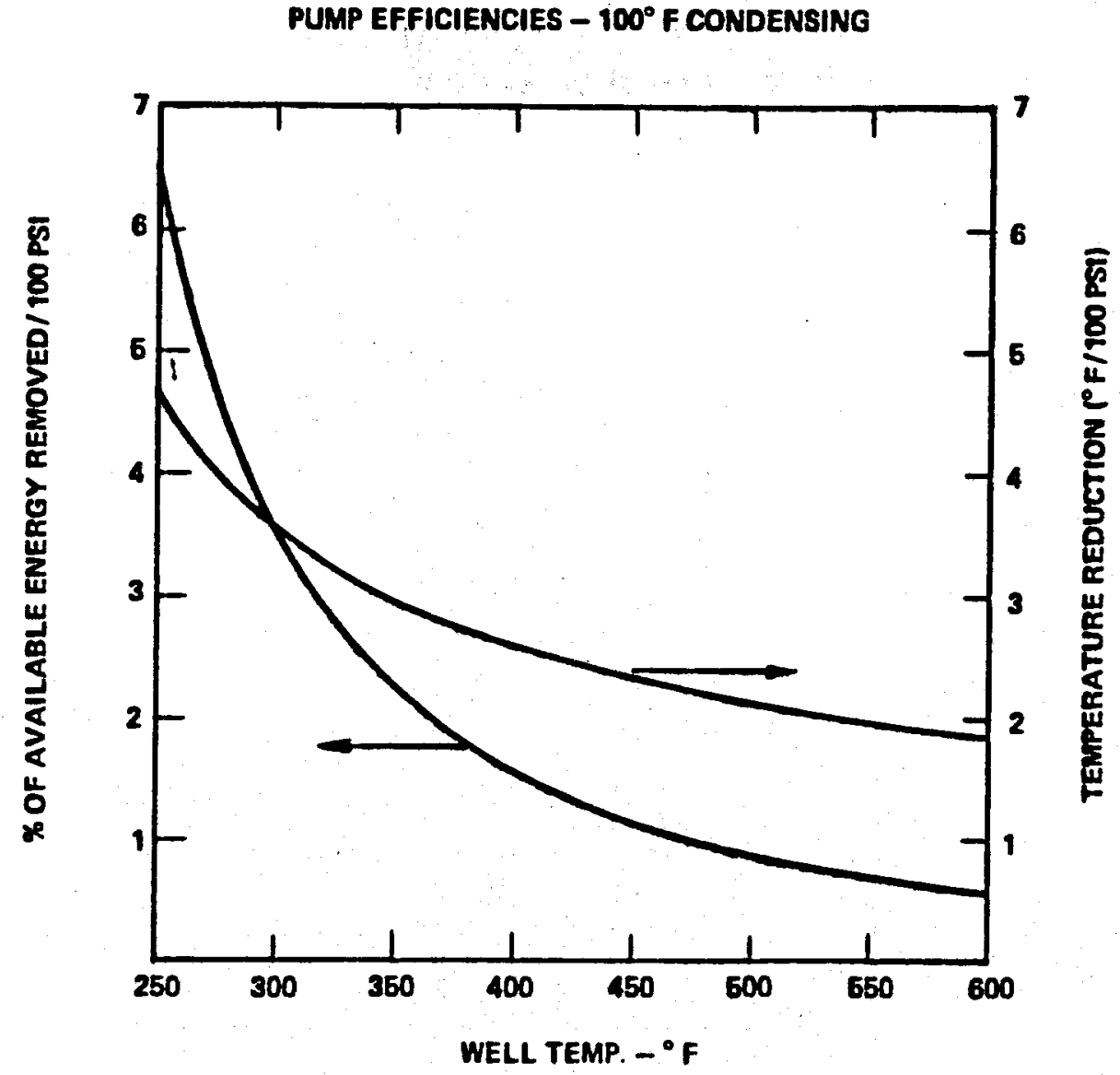

FIG. 11 Brine loss vs. temperature. 


\section{ABSTRACT}

A totally new concept for pumping geothermal wells has been designed and tested in a well. The pump work required is extracted from the thermal energy of the brine by a downhole boiler. The resulting steam drives a turbopump delivering pressurized brine to the surface. The exhaust steam is ducted to the surface where it is condensed and returned to the downhole boiler.

The TPU (turbine pump unit) utilizes a single stage mixed flow impeller that achieves pumping efficiencies over 80 percent, driven by a two-stage steam turbine. The shaft is supported by water-lubricated bearings that have been tested at temperatures over $400^{\circ} \mathrm{F}$. The field test program was conducted from June 1976 to early December 1976 at Heber, California. The pumping tests were successful, and it was demonstrated that the steam powered concept is feasible. 